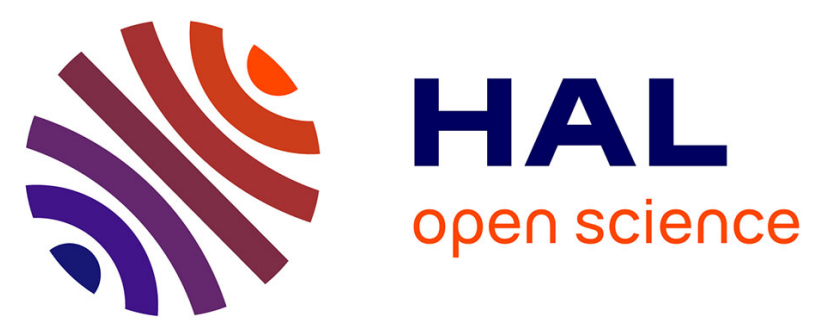

\title{
The role of the intra-daily SST variability in the Indian monsoon variability and monsoon-ENSO-IOD relationships in a global coupled model
}

Pascal Terray, Kakitha Kamala, Sébastien Masson, Gurvan Madec, A. K. Sahai, Jing-Jia Luo, Toshio Yamagata

\section{To cite this version:}

Pascal Terray, Kakitha Kamala, Sébastien Masson, Gurvan Madec, A. K. Sahai, et al.. The role of the intra-daily SST variability in the Indian monsoon variability and monsoon-ENSO-IOD relationships in a global coupled model. Climate Dynamics, 2012, 39, pp.729-754. 10.1007/s00382-011-1240-9 . hal-01322976

\section{HAL Id: hal-01322976 \\ https://hal.science/hal-01322976}

Submitted on 29 May 2016

HAL is a multi-disciplinary open access archive for the deposit and dissemination of scientific research documents, whether they are published or not. The documents may come from teaching and research institutions in France or abroad, or from public or private research centers.
L'archive ouverte pluridisciplinaire HAL, est destinée au dépôt et à la diffusion de documents scientifiques de niveau recherche, publiés ou non, émanant des établissements d'enseignement et de recherche français ou étrangers, des laboratoires publics ou privés. 
1

4

5

6

7

8

9

10

11

12

13

14

15

16

17

18

19

20

21
The role of the intra-daily SST variability

in the Indian Monsoon variability and monsoon-ENSO-IOD relationships

in a global coupled model

Pascal Terray ${ }^{1}$, Kakitha Kamala ${ }^{1}$, Sébastien Masson ${ }^{1}$, Gurvan Madec ${ }^{1}$,

A. K. Sahai ${ }^{2}$, J.-J. Luo ${ }^{3}$ and Toshio Yamagata ${ }^{3}$

${ }^{1}$ LOCEAN/IPSL, CNRS/IRD/UPMC/MNHN, Paris, France

${ }^{2}$ Indian Institute of Tropical Meteorology, Pune, India

${ }^{3}$ RIGC, Yokohama, Japan

October 2011

Corresponding author address: Pascal Terray, LOCEAN-IPSL, Université Pierre et Marie Curie, BP100 - 4 place Jussieu, 75252 Paris cedex 05, France.

Tel : +3314427 7078

E-mail : terray@locean-ipsl.upmc.fr 
The impact of diurnal SST coupling and vertical oceanic resolution on the simulation of the Indian Summer Monsoon (ISM) and its relationships with El Niño-Southern Oscillation (ENSO) and Indian Ocean Dipole (IOD) events are studied through the analysis of four integrations of a high resolution Coupled General Circulation Model (CGCM), but with different configurations. The only differences between the four integrations are the frequency of coupling between the ocean and atmosphere for the Sea Surface Temperature (SST) parameter (2 vs 24 hours coupling) and/or the vertical oceanic resolution (31 vs 301 levels) in the CGCM.

Although the summer mean tropical climate is reasonably well captured with all the configurations of the CGCM and is not significantly modified by changing the frequency of SST coupling from once to twelve per day, the ISM-ENSO teleconnections are rather poorly simulated in the two simulations in which SST is exchanged only once per day, independently of the vertical oceanic resolution used in the CGCM.

Surprisingly, when 2 hours SST coupling is implemented in the CGCM, the ISM-ENSO teleconnection is better simulated, particularly, the complex lead-lag relationships between the two phenomena, in which a weak ISM occurs during the developing phase of an El Niño event in the Pacific, are closely resembling the observed ones. Evidence is presented to show that these improvements are related to changes in the characteristics of the model's El Niño which has a more realistic evolution in its developing and decaying phases, a stronger amplitude and a shift to lower frequencies when a 2-hourly SST coupling strategy is implemented without any significant changes in the basic state of the CGCM. As a consequence of these improvements in ENSO variability, the lead relationships between Indo-Pacific SSTs and ISM rainfall resemble the observed patterns more closely, the ISM-ENSO teleconnection is strengthened during boreal summer and ISM rainfall power spectrum is in better agreement with observations. On the other hand, the ISM-IOD teleconnection is sensitive to both SST coupling frequency and the vertical oceanic resolution, but increasing the vertical oceanic resolution is degrading the ISM-IOD teleconnection in the CGCM.

These results highlight the need of a proper assessment of both temporal scale interactions and coupling strategies in order to improve current CGCMs. These results, which must be confirmed with other CGCMs, have also important implications for dynamical seasonal prediction systems or climate change projections of the monsoon.

Keywords: Indian summer monsoon; El Niño-Southern Oscillation; long-range predictability; oceanatmosphere interactions; coupled climate model. 


\section{Introduction}

\section{(n)}

During the months of June through September, the rainfall associated with the Indian Summer Monsoon (ISM) provides the main source of fresh water for millions of people over the Indian subcontinent. Predicting ISM onset and amplitude, both on the seasonal and interannual time scales, is thus not only a challenging scientific issue, but also a key societal need for South Asian countries. As such, the relative role of remote and local Sea Surface Temperature (SST) forcing in shaping ISM rainfall anomalies was investigated by many observational and modeling studies (see Webster et al., 1998; Wang, 2006 for reviews). One main conclusion from these previous works is that a primary key to cause ISM variability at the interannual time scale arise from teleconnection with the tropical Pacific Ocean and is related to the El-Niño Southern Oscillation (ENSO) phenomenon in the Pacific. While ENSO is still regarded as one of the main factors of ISM variability, the ISM-ENSO relationship has weakened during recent decades or more exactly has changed in nature for reasons which are still a matter of debate (Krishna Kumar et al., 1999, 2006; Gershunov et al., 2001; Ashok et al., 2001, 2004; Kinter et al., 2002; Annamalai et al., 2007; Kucharski et al., 2007, 2008; Xavier et al., 2007; Boschat et al., 2011a, 2011b).

Connections between tropical Indian Ocean variability, especially its dominant mode of variability, the Indian Ocean Dipole (IOD), tropical Atlantic and ISM have also been noticed by many recent studies (Meehl and Arblaster, 2002; Loschnigg et al., 2003, Li et al., 2006; Meehl et al., 2003; Ashok et al., 2001, 2004; Gadgil et al., 2005; Kucharski et al., 2007, 2008; Krishnan and Swapna, 2009). Several authors (Ashok et al., 2001, 2004; Abram et al., 2008) have suggested that the frequent occurrence of IOD events is the cause for the recent weakening of the ISM-ENSO relationship. However, a general consensus on the influence exerted by IOD or Atlantic Ocean on ISM rainfall variability has not been established so far from the observations or atmospheric forced simulations. Because of the dynamically interactive nature of the tropical ocean-atmosphere system and the near-global patterns of the teleconnections associated with the Asian monsoon, global Coupled General Circulation Models (CGCM) are instrumental in clarifying the basic mechanisms and feedbacks involved in ISM variability and ISM-ENSO-IOD interactions (Lau and Nath, 2004; Fischer et al., 2005; Behera et al., 2006; Wu and Kirtman, 2003, 2005, 2007; Terray et al., 2007; Bracco et al., 2007; Krishnan et al., 2010). Thus, improving our understanding of ISM variability will require the use of state-of-the-art CGCMs that attempt to represent all the processes that may 
be important and that realistically simulate IOD, ISM and ENSO phenomena, a challenging task for current CGCMs (Spencer et al., 2005; Joseph and Nigam, 2006; Annamalai et al., 2007; Bracco et al., 2007; Cai et al., 2009). Based on all these concerns, we need to develop accurate global CGCMs to gain more insight into the dynamics and predictability of ISM at both the intraseasonal, interannual and decadal time scales (Wang et al., 2005; Krishna Kumar et al., 2005; Wu et al., 2006; Wu and Kirtman, 2007).

However, the inherent limitations and flaws of current state-of-the-art CGCMs mean that they cannot be exclusively relied upon for seasonal forecasting or climate change sensitivity studies (Turner et al., 2005; Annamalai et al., 2007; Manganello and Huang, 2009; Cai et al., 2009). As an illustration, skill scores of dynamical seasonal prediction systems for ISM rainfall are very limited and still inferior to simple statistical models, even in the European DEMETER project where multi-model ensemble was created from seven different CCGMs (Palmer et al., 2004). In particular, recovering the complex ISM-ENSO teleconnections, which is of paramount importance for the seasonal forecasting of ISM rainfall, remains a very difficult task for recent CGCMs, as exemplified by Figure 1, which shows the lead-lag relationships between ISM rainfall and Niño-3.4 SSTs in observations and as simulated by several CCGMs participating in the third Coupled Model Intercomparison Project (CMIP3; Meehl et al., 2007). Most of the CMIP3 CGCMs are able to recover the negative correlation between the two phenomena during the monsoon season (from June to September), but the most striking feature is that almost all of the CMIP3 coupled models fail to recover the observed lead-lag relationships between Niño-3.4 SSTs and ISM, including the spring predictability barrier, which is manifested as the transition from positive to negative correlations prior to the ISM onset (Webster et al., 1998). Starting six months before ISM, the correlation between Niño-3.4 SSTs and ISM rainfall is already negative in nearly all CGCMs (Fig. 1). The amplitude of this negative correlation increases until the early ISM (June and July) and fades away very rapidly during the late ISM and the following month in the coupled simulations contrary to that observed. The physical factors, which are responsible of this failure of most current CGCMs, must be investigated carefully if we want to improve the skill of seasonal dynamical predictions or climate change projections for the ISM (Gadgil et al., 2005). Furthermore, the realistic simulation of the relationships between ISM, ENSO and IOD, which are indeed responsible for the main modes of interannual variability over India and the tropical Indian Ocean, represents a unique benchmark for evaluating current state-ofthe-art CGCMs (Saji et al., 2006; Joseph and Nigam, 2006; Annamalai et al., 2007; Cai et al., 2009). 
The purpose of this paper is to investigate how accurately the relationships between ISM, ENSO and IOD can be simulated by different configurations of the same CGCM with a special focus on the impact of upper oceanic structures with small vertical and temporal scales that can influence the development of large scale coupled phenomena such as ISM, IOD and ENSO through scale interactions and ocean-atmosphere coupling (Meehl et al., 2001). To do so, we analyze model outputs from four long integrations of the same CGCM, but with different configurations differing only by the frequency of SST coupling and the vertical oceanic resolution in the CGCM. A companion paper is specifically assessing how ENSO structure, periodicity and feedbacks are modified in the different configurations of the same CGCM (Masson et al., 2011).

The paper is organized as follows: in Section 2, we will describe the CGCM, the experimental design for the different configurations of the CGCM, the datasets and the statistical tools used. Section 3 will look at the mean boreal summer climate as simulated by the different configurations of the CGCM, noting any significant differences between them. The changes in ENSO and IOD variability are documented in Section 4. The ISM interannual variability and the ISM-ENSO-IOD relationships as simulated in the different experiments are analyzed in Section 5. Conclusions follow in Section 6.

\section{Model, experimental set up, datasets and statistical tools}

(a) The SINTEX-F2 high-resolution coupled model

The CGCM used in this study belongs to the family of SINTEX models (Guilyardi et al., 2003; Gualdi et al., 2003; Luo et al., 2003). It is an upgraded version of SINTEX-F1 CGCM (Luo et al., 2003; Luo et al. 2005). A new version has been developed (SINTEX-F2 hereafter). Its oceanic component is NEMO (http://www.nemo-ocean.eu; Madec, 2008; Madec et al., 1998) including LIM2 (Timmermann et al., 2005) for the sea-ice model. We use the configuration known as "ORCA05" which is a tri-polar global grid with a resolution of $0.5^{\circ}$ by $0.5^{\circ} \cos$ (latitude). Vertical resolution (31 or 301 levels depending on the configurations, see below) and mixing are similar to Molines et al. (2006). The atmospheric component consists of ECHAM5.3 (Roeckner et al., 2003, 2004) with a T106 horizontal resolution and 31 hybrid sigma-pressure levels. A mass flux scheme (Tiedtke, 1989) is applied for cumulus convection with modifications for penetrative convection according to Nordeng (1994). The coupling information, without any flux correction, is exchanged every 
two hours (24 hours for the SST parameter in the $24 \mathrm{~h} 31$ and $24 \mathrm{~h} 301$ configurations described below) by means of the OASIS 3 coupler (Valcke, 2006). See Masson et al. (2011) for more details.

\section{(b) Experimental set up}

Several previous studies have highlighted the potential role of the diurnal cycle on the mean state, intraseasonal and interannual variabilities of the Indo-Pacific climate through nonlinear scale interactions (Slingo et al., 2003; Danabasoglu et al., 2006; Bernie et al., 2007, 2008; Kawai and Wada, 2007; Ham et al., 2010). Motivated by these evidences, four long integrations of the updated SINTEX-F2 CGCM have been realized using different modeling strategies with a special focus on the impact of diurnal SST coupling and vertical oceanic resolution on ENSO, IOD and ISM. Table 1 summarizes the numerical experiments performed and their main characteristics. As seen in Table 1, all the configurations share the same atmospheric component at T106L31 resolution and differ only by the SST coupling frequency ( 2 hours vs 24 hours) and/or the vertical oceanic resolution in the high-resolution CGCM (31 vs 301 levels). Thus, it is important to keep in mind that the coupling frequency for all other parameters than the SST remains to be 2 hours (see Table 1). No flux correction was applied, and the CGCM does not exhibit significant climate drift in the four long-term simulations used here (not shown). In all the following analyses, the first 10 years of the simulations have been excluded in order to minimize the biases due to the spin-up of the CGCM.

The pathways by which the diurnal cycle may impact longer time scales may be classified in two categories (i) the atmospheric contribution represented by the role of the solar cycle in the air-sea coupling (Danabasoglu et al., 2006; Ham et al., 2010), and (ii) the oceanic contribution, which corresponds to the response of the coupled system to the SST diurnal cycle and high frequency variability (Slingo et al., 2003; Bernie et al., 2007, 2008). Our main focus here is to detail the response of the interannual variability of the coupled system to the SST diurnal and high frequency variability (e.g. oceanic contribution) since this question has not been investigated in the previous studies (Slingo et al., 2003; Bernie et al., 2007, 2008). Hence, the four experiments summarized in Table 1 were specifically designed to discriminate the impact of the SST diurnal and high frequency variability from the solar cycle response of the climate system. In this respect, it is worth noting that the experimental set up used here is slightly different from those reported in Danabasoglu et al. (2006) or Ham et al. 
192 (2010) in which twin coupled experiments using 1-day vs diurnal air-sea coupling frequency

193 for all the parameters (and not only the SST) are compared. With diurnal coupling frequency

194 for all the air-sea fluxes it is not possible to differentiate the relative role of the SST high

195 frequency variability from the solar cycle response.

(c) Datasets and statistical tools

Various datasets have been used to evaluate the model's performance and to provide a comprehensive description of ISM variability and its links with ENSO and IOD in the different configurations.

Monthly-mean winds are from the National Centers for Environmental Prediction/National Center for Atmospheric Research reanalysis (NCEP/NCAR, Kalnay et al. 1996). The period from 1979 to 2008 has been used to compute the wind climatology. Since precipitation is regarded as one of the least reliable fields from reanalyses, we use the 1979-2008 monthly mean data from the Climate Prediction Center (CPC) Merged Analysis of Precipitation for the observed rainfall (CMAP, Xie and Arkin 1997). However, to study ISM variability and its teleconnections with ENSO and IOD on longer periods comparable to the length of the four integrations of the coupled model, the classical All-India-Rainfall (AIR) dataset, based on rain-gauge data, has also been considered (Parthasarathy et al., 1994). The SST dataset selected for the study is the Hadley Centre Sea Ice and sea surface temperature dataset (HadISST1.1) developed by Rayner et al. (2003). The surface heat fluxes analyzed here are derived from products of the objectively analyzed air-sea fluxes (OAFlux) for the Global

214 Oceans project (Yu et al., 2008) and are obtained from the Woods Hole Oceanographic 215 Institute through ftp://ftp.whoi.edu/pub/science/oaflux/data. Finally, the Simple Ocean Data 216 Assimilation (SODA) version 2.0.2 (Carton et al. 2005) is used for diagnosing the thermocline depth in the eastern Indian Ocean in Section 3. SODA 2.0.2 covers the period from 1958 to 2001.

The statistical tools used here include mainly spectral analysis based on a Fast Fourier Transform algorithm (Welsch, 1967) and a large battery of statistical tests to detect statistical significant differences in power density between two frequencies or two ranges of frequencies in different power spectra. For the sake of brevity, details about these statistical tests are not given here and the interested reader is referred to Masson et al. (2011). Standard correlation analysis has also been used to assess the ISM-ENSO-IOD relationships and the space-time evolution of Indo-Pacific SSTs associated with ENSO in Section 5. The statistical 
significance levels for the correlation coefficients have been estimated using the phasescrambling bootstrap test proposed by Ebisuzaki (1997) with 999 samples. This statistical test takes directly into account the autocorrelation characteristics of the time series for assessing the confidence level of the correlations.

\section{The coupled GCM boreal summer mean climate}

The overall performance of SINTEX-F2 has already been examined in Masson et al. (2011) and is thus not repeated here. Instead, we will mainly focus in this section on salient features of the simulated tropical climate that will be relevant to interpret the results reported in the next sections and, more particularly, on the significant differences, if any, between the basic state of the monsoon and the tropical Indian Ocean in the different configurations.

(a) Boreal summer mean state

The observed boreal summer (i.e., during June to September - JJAS) mean climatologies and differences with the four configurations for SST, precipitation and $850 \mathrm{hPa}$ wind are shown in Figures 2, 3 and 4, respectively.

SST biases have a longitudinal distribution with a warm bias in the tropics and a cold bias at mid-latitudes (Fig. 2). Note that contrary to many coupled models (Reichler and Kim, 2008), SINTEX-F2 does show only a weak "cold tongue" bias in the equatorial Pacific, especially if the vertical oceanic resolution is increased (see Figs. 2d, e). However, the tropical warm bias remains too strong and is more pronounced to the north of the equator and in the upwelling regions of the three oceanic basins during boreal summer. Poor representation of coastal regions and upwelling processes in coarse ocean model and a lack of proper simulation of air-sea interactions are plausible causes for these large SST biases in the western Indian, eastern Pacific and Atlantic oceans. Note, however, that increasing the vertical oceanic resolution (e.g. the $2 \mathrm{~h} 301$ and 24h301) does not reduce the warm bias in the upwelling regions (see Figs. 2d, e).

Over the Indian Ocean, the CGCM shows an overall overestimation of the SST climatology in the western Indian Ocean, excepted in a narrow band along the Somali and 
(cold) bias of the western (eastern) Indian Ocean leads also to an erroneous weak or even reversed equatorial SST gradient over the Indian Ocean (see Fig. 5). Furthermore, this bias is slightly enhanced with increased oceanic resolution.

The coupled simulation of Indo-Pacific rainfall climatology has been proven to be a rather difficult test for current CGCMs (Wang, 2006). However, in all the configurations, SINTEXF2 reproduces a reasonable precipitation pattern during boreal summer (Fig. 3). As an illustration, the CGCM simulates the maximum rainfall with more intensity to the north of the equator and the large-scale spatial features associated with the Inter Tropical Convergence Zone (ITCZ) band across the tropical Pacific, Indian and Atlantic oceans. For comparison, we have also computed the differences between CMAP and Global Precipitation Climatology Project (GPCP) analyses for the same base period (Fig. 3d). The rainfall amounts over the ocean are systematically lower (about 15\% lower) in the GPCP dataset (as already discussed in Annamalai et al. (2007), these differences may be due to the fact that the GPCP data were not tied as closely to atoll gauge estimates as CMAP data). Interestingly, in many regions, the model's biases are of the same order of magnitude than the differences between GPCP and CMAP datasets. However, as seen in Figure 3, there exists a tendency to a slight northward shift of the ITCZ in all versions of the CGCM during boreal summer, even though this systematic error is largely reduced if the GPCP dataset is used in the comparison (not shown). In the western Pacific, 2h301 and 24h301 develop less precipitation than 2h31 and 24h31, respectively, a feature consistent with the reduced "cold tongue" bias and zonal SST gradient across the Pacific in the 2h301 and 24h301 configurations (Figs. 2 and 3).

Focusing now more specifically on the regional features associated with the ISM, we observe that the CGCM fails to simulate the heavy rainfall band over the south equatorial Indian Ocean, which is one of the important heat source for ISM rainfall variability (Annamalai and Liu, 2005; Annamalai and Sperber, 2005; Goswami et al., 2006; Terray et al., 2007). Furthermore, all the configurations overestimate precipitation over the Indian Ocean, north of the equator, while the Indian subcontinent is dryer than observed. These enhanced rainfall in the western and central equatorial Indian Ocean and deficient rainfall over the Western Ghats are well-known biases of the ECHAM atmospheric model (Roeckner et al., 1996) and are also found in previous versions of the SINTEX model (Terray et al., 2005b; Cherchi et al., 2007). A possible explanation for this incorrect location of the ITCZ is that SINTEX does not reproduce the correct pole-to-equator gradient in the Indian sector. Unrealistic heavy rainfall over the northeastern part of the Indian subcontinent and the 
292 precipitation parameterization or the representation of the orography and is also a common 293 bias of many current CGCMs (see Fig. 1 of Annamalai et al., 2007).

294 Over the tropical Indo-Pacific regions, the main features of the $850 \mathrm{hPa}$ wind are 295 reasonably well captured by SINTEX-F2 (Fig. 4). Consistent with the reduced "cold tongue" 296 bias, the easterly trade winds are not too strong over the equatorial central Pacific. The 297 SINTEX-F2 model is also able to capture the major features of monsoon circulation, such as 298 the strong low-level jet from the Arabian Sea into South Asia and the southeasterly trade 299 winds in the south tropical Indian Ocean. The differences between NCEP and SINTEX-F2 $300850 \mathrm{hPa}$ wind climatologies clearly show that the most important and robust systematic error 301 in the Indian region is the existence of an anomalous cyclonic cell over the equatorial western 302 and central Indian Ocean (Fig. 4). This cyclonic low-level circulation is consistent with the 303 rainfall biases discussed above. In all the configurations, the cross-equatorial component of the flow extends too far eastward rather than being confined along the African coast. Moreover, these strong winds increase evaporation over the eastern Indian Ocean, which in turn may help maintain the erroneous SST gradient between the South-East Indian Ocean (SEIO) and the western Indian Ocean (see Fig. 5f).

However, a known systematic error of the SINTEX model, which is probably the main factor responsible for the SST biases in the eastern Indian Ocean, is the tendency to have a shallow (deeper) thermocline in the eastern Indian Ocean during boreal summer and fall (winter and spring). The thermocline-surface coupling is thus amplified in the annual cycle with deeper and cooler water easily upwelled at the surface during boreal summer and fall, cooling drastically the SEIO SSTs (Figs. 2 and 5; see also Fischer et al., 2005). In other words, it is clear that the low-level wind, SST and precipitation errors in the eastern equatorial Indian Ocean are intimately linked together. A warm bias, which is constant throughout the annual cycle, is also found in the western Indian Ocean (Fig. 5a). This warm bias seems to be the main factor responsible for the erroneous SST gradient over the equatorial Indian Ocean during boreal summer (see Fig. 2). All these coupled errors are also seen when the vertical oceanic resolution is increased (e.g. $2 \mathrm{~h} 301$ and 24h301).

(b) Climatological seasonal cycle in the Indian areas

The ISM and IOD are both strongly phase-locked to the annual cycle, so to simulate both phenomena accurately the CGCM must recover certain aspects of the seasonal cycle. 
To look at the timing and extent of the monsoon in each of the configurations, Figure 6 shows the annual cycle of simulated and observed ISM rainfall indices. The ISM rainfall indices are defined as the area-averaged precipitation over all land grid-points in the domain $65^{\circ}-95^{\circ} \mathrm{E}, 8^{\circ}-35^{\circ} \mathrm{N}$ (CMAP is used for the observations). The model simulates a reasonable rainfall annual cycle in the Indian areas with a summer precipitation maximum as in observed climate. All the configurations underestimate the rainfall intensity during the monsoon season consistent with the results of Figs. 3b-f. Another robust feature is that the magnitude of simulated rainfall during the JJAS period is also more in $2 \mathrm{~h} 31$ and $24 \mathrm{~h} 31$ than in $2 \mathrm{~h} 301$ and 24h301 configurations and are in better agreement with the observational estimates. Similar results are obtained if an Indian monsoon dynamical index is used instead of a rainfall time series in the analysis (not shown) or if the rainfall indices are defined as the area-averaged over all land-ocean or ocean only grid-points (see Table 3 ).

Further information on the seasonal cycle in the Indian areas is obtained by plotting monthly SST means for the boxes used to compute the traditional IOD index as defined by Saji et al. (1999). In the observations, the zonal SST gradient over the equatorial Indian Ocean is negative throughout all the year, excepted in April during the transition between the winter and summer monsoons (Fig. 5c). All the configurations are able to recover the shape of the seasonal cycle of the Indian Ocean zonal SST gradient, but are affected by a strong positive bias, which amplifies during late boreal summer and fall. Therefore, the simulated climatological SST gradient is reversed compared to the observations. Moreover, this positive bias is stronger when the vertical oceanic resolution is increased (e.g. $2 \mathrm{~h} 301$ and 24h301). This systematic error in the zonal SST gradient is due, on one hand, to a constant warm bias in the western Indian Ocean throughout the seasonal cycle (see Fig. 5a) and, on the other hand, to a cold bias in the eastern tropical Indian Ocean related to a shallower than observed equatorial thermocline and increased evaporation during boreal summer and fall (see Fig. 5b). The impact of the reversed SST zonal gradient on the IOD variability simulated by the CGCM will be investigated in the next section.

(c) Configurations differences

The statistical significance of the differences among the boreal summer climatology in the different experiments was estimated through a permutation test with 9999 shuffles (see Terray 
et al. 2003 for more details) and one main conclusion of these computations is that none of 359 the differences between $2 \mathrm{~h} 31$ (2h301) and 24h31 (24h301) SST, rainfall and surface wind 360 climatologies are statistically significant at the $90 \%$ confidence level according to this permutation test (not shown). The comparison between the simulated climatologies has been further extended to other quantities such as ocean temperature and winds at different levels. Overall, all diagnostics confirm that the modification of the SST coupling frequency does not substantially alter the CGCM climatology.

On the other hand, the use of an increased vertical oceanic resolution does change significantly the modeled SST, rainfall and $850 \mathrm{hPa}$ wind climatologies in the Pacific, as illustrated in Figure 7 for $2 \mathrm{~h} 31$ vs $2 \mathrm{~h} 301$. Zonal SST gradient and the surface branch of the Walker circulation along the equatorial Pacific are strengthened in $2 \mathrm{~h} 31$ (24h31) compared to $2 \mathrm{~h} 301$ (24h301). Consistently, the equatorial thermocline depth deepens in the western Pacific and shoals in the eastern Pacific in $2 \mathrm{~h} 31$ when compared to $2 \mathrm{~h} 301$ (not shown). These features explain why rainfall is increased over the western Pacific and the Maritime Continent in $2 \mathrm{~h} 31$ (24h31) in comparison to $2 \mathrm{~h} 301$ (24h301) (Fig. 7b). Over the Indian sector, rainfall average over India and the surface wind shear associated with the monsoon trough (over the Indian subcontinent) are also increased in $2 \mathrm{~h} 31$ (24h31) compared to $2 \mathrm{~h} 301$ (24h301). Thus, $2 \mathrm{~h} 31$ and $24 \mathrm{~h} 31$ feature several indicators of significant differences toward a stronger monsoon in its mean summer climate, which are in agreement with the enhanced Pacific trade winds and Walker circulation. So, SINTEX-F2 exhibit some systematic differences when the vertical oceanic resolution is increased, which may impact on the simulation of the ISMENSO-IOD relationships and this will be investigated in the following section.

Surprisingly, the significant differences, which emerge between $2 \mathrm{~h} 31$ (24h31) and $2 \mathrm{~h} 301$ (24h301), also imply that, in many regions, the climatology's biases of the coupled model are not necessarily reduced when the vertical oceanic resolution is increased.

\section{ENSO and IOD variability}

Prior to analyzing the ENSO-ISM and IOD-ISM relationships, we need to discuss the statistical properties of ENSO and IOD in the different simulations. 
Standard-deviations of Niño-34 and IOD related bi-monthly (eg season of two months) SST time series estimated from the four runs and the observations are shown in Table 2. $2 \mathrm{~h} 31$ and 24h31 configurations have slightly larger Niño-3.4 SST variability than observed while 2h301 and 24h301 have slightly lower ENSO signal. This is consistent with the changes in the mean state documented in Section 3, particularly, the strengthened Walker circulation and the related modifications of SST gradient and thermocline depth in the equatorial Pacific in $2 \mathrm{~h} 31$ and $24 \mathrm{~h} 31$ configurations (e.g. when the vertical oceanic resolution is decreased). This also suggests a plausible explanation for the increased Niño-3.4 SST variability in $2 \mathrm{~h} 31$ and 24h31: the rise of the thermocline in the east found in $2 \mathrm{~h} 31$ and $24 \mathrm{~h} 31$ allows equatorial upwelling to tap into sub-thermocline waters more easily for a given wind anomaly.

The standard deviation of the IOD index is much stronger in the four configurations than in observations (see Table 2). It is also noticed that the eastern node of IOD (EIOD hereafter) has greater interannual SST variability than the western node of IOD (WIOD hereafter) in all the configurations, consistent with observations. However, the SST variability of EIOD is also largely overemphasized compared to the observations as expected from the model biases described in Section 3. The $2 \mathrm{~h} 31$ and $24 \mathrm{~h} 31$ runs also produce stronger interannual SST variability in the equatorial Indian Ocean than $2 \mathrm{~h} 301$ and 24h301, respectively (see Table 2).

Interestingly, the ENSO SST signal is also strengthened when 2-hourly SST coupling is implemented instead of 1-day SST coupling and this result seems robust since it is verified for both 31 and 301 vertical levels configurations of the CGCM (see Table 2).

\section{(b) Seasonal phase-locking}

Numerous studies have pointed out that the amplitude of ENSO and IOD cycles are strongly phase-locked with the seasonal cycle (Chang et al., 2006). A good indicator of such seasonal dependence is the monthly standard deviations of our Niño-3.4 and IOD indices (Fig. 8). We have also plotted in this figure the monthly standard deviations of various important indices for the evolution of the IOD such as the latent heat flux over EIOD and the depth of the $20^{\circ} \mathrm{C}$ isotherm in the eastern equatorial indian Ocean (Spencer et al., 2005).

The observations indicate significant phase-locking of Niño-3.4 SST variability to the annual cycle, with weakest variability in April, and strongest in December-January (Fig. 8a). These well-known results suggest that the transition periods between the opposite phases of 
the ENSO cycle occurred in northern spring. $2 \mathrm{~h} 31$ and $2 \mathrm{~h} 301$ configurations capture reasonably well the observed phase of ENSO, peaking in boreal winter. However, there is also a tendency of the CGCM to produce a second peak of ENSO variability, during the early boreal summer, which is not seen in the observations (Fig. 8a). As we will demonstrate later, this bias is particularly detrimental to the simulation of the ISM-ENSO lead-lag relationships in $24 \mathrm{~h} 31$ and $24 \mathrm{~h} 301$ configurations.

The monthly standard deviations of IOD and EIOD SST time series rise between May and October when dipole events occurred and fall afterward in both observations and the different simulations (Figs. 8b, d). However, IOD standard deviation in all months is much higher in the CGCM and is mostly driven by the EIOD SST variability. The worst results are obtained with the low vertical oceanic resolution, but also when 2-hourly SST coupling is implemented (e.g. $2 \mathrm{~h} 31$ and $2 \mathrm{~h} 301$ configurations). Most of these changes in EIOD SST variability may be related to the strength of the wind-evaporation-SST and wind-thermocline-SST feedbacks in the eastern Indian Ocean (Li et al., 2003; Spencer et al., 2005; Fischer et al., 2005).

The maximum of interannual variability of latent heat flux or thermocline depth in the eastern Indian Ocean is also anchored in the seasonal cycle; for the latent heat flux over EIOD it is in the late boreal summer (August-September) and for the thermocline depth it arrives a few months later in November (Figs. 8e-g). First, the differences between the model configurations are far smaller than the errors relative to the observations. As an illustration, the simulated latent heat flux variability is largely overemphasized in EIOD, but without any clear differences with respect to the vertical oceanic resolution or the SST coupling frequency (Fig. 8f).

Despite the large errors in the climatological thermocline depth (see Figs. 5d, e), the seasonal cycle of thermocline depth variability in the equatorial eastern Indian Ocean (and off Sumatra) is reproduced quite well in $2 \mathrm{~h} 31$ and $2 \mathrm{~h} 301$ configurations (e.g. when 2-hourly SST coupling is used) with a maximum occuring in October-November, while 24h31 and 24h301 configurations have a tendancy toward a much weaker thermocline variability, especially over the equatorial eastern Indian Ocean (Figs. 8e, f). This may explain why $2 \mathrm{~h} 31$ and $2 \mathrm{~h} 301$ have a higher EIOD SST variability than $24 \mathrm{~h} 31$ and 24h301, respectively, during boreal fall through the Bjerknes-type positive feedback (Fig. 8d). The differences in SST variability over the eastern Indian Ocean between the twin experiments with increased oceanic resolution (e.g 2h31-2h301 and 24h31-24h301) may be also related to changes in thermocline variability over the eastern Indian Ocean, especially off Sumatra (Fig. 8f). 
All these features are consistent with the results of Fischer et al. (2005) who show that the

460

461

462

463

464

465

466

467

468

469

470

471

472

473

474

475

476

477

478

479

480

481

482

483

484

485

486

487

488

489

490

491

492

wind-thermocline-SST positive feedback is an important dynamical mechanism at work in IOD growth in the SINTEX model. However, since the thermocline standard-deviation in the eastern equatorial Indian Ocean and off Sumatra is underestimated in the model, but the SST and latent heat flux standard-deviations are both overestimated, the wind-evaporation-SST feedback is probably also playing a key role in the simulated EIOD SST variability (Figs. 8dg).

(c) Frequency

Figure 9 shows the power spectra of Niño-3.4 SST and IOD time series from the model experiments and the observations. Focusing first on the Niño-3.4 SST time series, observations show a quite broad frequency peak between 3 and 5 yr. The $2 \mathrm{~h} 31$ and $2 \mathrm{~h} 301$ spectra are also significantly and strongly peaked at time scales around 4-5 years, while there is a broader distribution of power across a range of frequencies both in $24 \mathrm{~h} 31$ and $24 \mathrm{~h} 301$. Interestingly, the power spectra for $24 \mathrm{~h} 31$ and $24 \mathrm{~h} 301$ are near, or outside, the $99 \%$ confidence interval of the observed Niño-3.4 SSTs power spectrum for frequencies corresponding to the interannual time scale. Furthermore, $24 \mathrm{~h} 31$ and $24 \mathrm{~h} 301$ configurations also miss the observed ratio between the energies associated with the annual cycle and the interannual time scale which are thought to be important for a proper simulation of observed ENSO variability (not shown; Guilyardi, 2006). In this respect, $2 \mathrm{~h} 31$ and $2 \mathrm{~h} 301$ spectra have a highly realistic shape and dominant frequency, suggesting that the SST coupling frequency plays an important role in making the ENSO signal in SINTEX-F2. On the other hand, increasing the vertical oceanic resolution has only modest effects on spectral signature of the simulated Niño-3.4 SSTs compared to the modifications induced by the 2-hourly SST coupling.

Looking now to the IOD peridodicity, observations suggests two main modes of variability, e.g. the 4-7 years and biennial time scales. Consistent with the higher IOD standard-deviations in $2 \mathrm{~h} 31$ and $24 \mathrm{~h} 31$ (see Fig. $8 \mathrm{~b}$ ), the $2 \mathrm{~h} 31$ and $24 \mathrm{~h} 31$ spectra are above the upper 99\% confidence limit estimated from the observations for frequencies in the interannual range; however both are also able to reproduce the overall shape of the observed spectrum. However, the diurnal SST coupling frequency has an impact in the simulated IOD spectrum if we look at the high oceanic vertical resolution runs: the power between the two 
preferred bands of IOD variability has been reduced whilst it is increased in each band for 2h301 compared to $24 \mathrm{~h} 301$ (see Fig. 9d).

To further demonstrate the statistically significant effect of the diurnal SST coupling on ENSO spectral characteristics, the log-ratios of power spectra for all the monthly SST time series in the Indo-Pacific regions as simulated in the $2 \mathrm{~h} 31-24 \mathrm{~h} 31$ and $2 \mathrm{~h} 301-24 \mathrm{~h} 301$ experiments have been computed. These log-ratios have been squared and summed over the range of frequencies corresponding to the interannual time scales (periods between 14 and 72 months) and the statistical significance of these sums has been tested against a Chi2 distribution (Fig. 10). More details on this Chi2 statistic and how to detect statistically significant differences between two power spectra are given in Diggle (1990). Consistent with our interpretation of the Niño-34 SST spectra, the power spectra of SST time series as simulated by $2 \mathrm{~h} 31$ and $2 \mathrm{~h} 301$ are significantly different from those derived from $24 \mathrm{~h} 31$ and 24h301, respectively, over large portions of the eastern and central Pacific and also in many regions which are known to be largely influenced by ENSO through remote teleconnections (e.g. the North and South Pacific, the South Indian Ocean, Alexander et al., 2002), confirming that all the differences suggested above are robust and may affect remote regions through atmospheric or oceanic pathways.

In summary, the amplitude of ENSO and IOD signals is decreased when the vertical oceanic resolution is increased (e.g. in $2 \mathrm{~h} 301$ and 24h301), probably through the changes of the mean state documented in Section 3. The strength, frequency, and phase locking to the annual cycle of El Niño are more realistic in the $2 \mathrm{~h} 31$ and $2 \mathrm{~h} 301$ configurations (e.g. with 2hourly SST coupling) than in the $24 \mathrm{~h} 31$ and $24 \mathrm{~h} 301$ configurations (e.g. with 1-day SST coupling). Moreover, the seasonal phase-locking of eastern Indian Ocean SST or z20 variability is also improved with 2-hourly SST coupling, independently of the vertical oceanic resolution used in the runs. We will now examine the possible impacts of these changes on ISM and the ISM-ENSO-IOD relationships.

\section{ISM variability and ISM-ENSO-IOD relationships}

Numerous studies have pointed out the important role that ENSO and IOD play in regulating ISM interannual variability and investigated the physical processes at the base of the ISM-ENSO and ISM-IOD relationships using climate models (Ju and Slingo, 1995; 
Ashok et al., 2004; Lau and Nath, 2004; Turner et al., 2005 ; Saji et al., 2006; Cherchi et al., 2007; Terray et al., 2007; Bracco et al., 2007; Annamalai et al., 2007; Cai et al., 2009; Krishnan et al., 2010). Yet, the difficulties associated with the coupled modeling of the observed signal have received relatively less attention in the literature $\mathrm{CWu}$ and Kirtman, 2005; Spencer et al., 2005; Turner et al., 2005; Terray et al., 2005b; Bracco et al., 2007). A key issue is then to quantify to what extent the significant differences between the simulated mean state when the oceanic resolution is increased (i.e. $2 \mathrm{~h} 301$ and $24 \mathrm{~h} 301$ configurations) or the significant changes in ENSO characteristics when 2-hourly SST coupling is implemented (i.e. $2 \mathrm{~h} 31$ and $2 \mathrm{~h} 301$ configurations) may improve the coupled simulation of ISM variability and ISM-ENSO relationships in SINTEX (Terray et al., 2005b; Cherchi et al., 2007).

(a) ISM interannual variability

As a first measure of ISM variability in the different configurations, we define ISM rainfall indices as the area-average of June to September (JJAS) rainfall anomalies over land, ocean or land-ocean in the region $8^{\circ}-35^{\circ} \mathrm{N}$ and $65^{\circ}-95^{\circ} \mathrm{E}$. The mean and standard-deviation of the various ISM rainfall time series are compared with the observations in Table $3.2 \mathrm{~h} 31$ configuration is displaying both the higher mean rainfall and stronger variability. However, no obvious systematic changes on rainfall variability are apparent when contrasting the configurations with a modification of the vertical oceanic resolution or SST coupling frequency. Overall, the variability of area-averaged ISM rainfall indices in the configurations compares well with observations despite of the significant systematic errors in the mean state described above.

To elucidate the temporal time scales involved in ISM rainfall variability, Figure 11 shows the power spectra of ISM rainfall (over land) and normalized Niño-34 SST time series during boreal summer (JJAS average) in observations and the different configurations. Interestingly, the observed ISM rainfall time series is not basically biennial as it is assumed by many studies (Yasunari, 1990; Meehl and Arblaster, 2002; Meehl et al., 2003), but rather exhibits a quasi-triennial oscillation as many monsoon indicators (Bhalme and Jadhav, 1984). Focusing now on the model's experiments, the results highlight that the dominant time scales of the ISM rainfall indices have varied considerably and significantly between the $2 \mathrm{~h} 31$ (2h301) and 24h31 (24h301) configurations. The ISM rainfall spectrum in $2 \mathrm{~h} 31$ and $2 \mathrm{~h} 301$ configurations is strongly peaked at timescales between 2 and 6 years as the ENSO indices during boreal summer. On the other hand, the ISM rainfall power spectrum in $24 \mathrm{~h} 31$ or $24 \mathrm{~h} 301$ 
configurations shows much decreased power across this range of frequencies and exhibits more energy at very long periods. Moreover, the ISM rainfall power spectra of $2 \mathrm{~h} 31$ and 2h301 are in reasonable and better agreement with the one estimated from the observations. The log spectral ratios of ISM rainfall time series in the twin experiments $2 \mathrm{~h} 31-24 \mathrm{~h} 31$ and 2h301-24h301 confirm the significant impact of 2-hourly SST coupling on the periodicity and regularity of ISM rainfall indices (Figs. 11b, d). Furthermore, the corresponding results for summer Niño-34 SSTs suggest that the improvements in ISM rainfall spectra simulated by the $2 \mathrm{~h} 31$ and $2 \mathrm{~h} 301$ configurations are linked to the fact that both versions of SINTEX-F2 perform better in their representation of ENSO and its spectral signature when compared with the $24 \mathrm{~h} 31$ and $24 \mathrm{~h} 301$ configurations (Figs. 11.e-h).

\section{(b) ENSO-ISM relationships}

In order to corroborate this hypothesis, we now test the ability of SINTEX-F2 to reproduce the observed relationships between ISM and ENSO by computing the lead-lag correlations between the ISM rainfall (land-average over JJAS) and Niño-3.4 SST time series for all the configurations and observations (AIR index is used) in a three years window from the beginning of year -1 to the end of year +1 , the year 0 referring to the year of the ISM season (Fig. 12a).

The strong and significant negative correlation between ISM rainfall and SSTs over eastern and central Pacific during boreal summer of year 0 implies that warmer (cooler) SSTs over these regions will suppress (enhance) monsoon rainfall over India, a well-known relationship (e.g. Webster et al., 1998; Wang et al., 2001). All the configurations of SINTEXF2 are able to reproduce this negative correlation between ISM rainfall and SSTs over eastern and central Pacific during boreal summer (Fig. 12a). Consistent with the increased standard deviation of Niño-3.4 SSTs (see Table 3) and the more energetic ENSO during boreal summer when diurnal SST coupling is implemented (see Figs. 11.e-h), the magnitude of the synchronous ISM-ENSO correlations is better simulated in the $2 \mathrm{~h} 31$ and $2 \mathrm{~h} 301$ configurations than in $24 \mathrm{~h} 31$ and $24 \mathrm{~h} 301$ experiments, respectively. Moreover, in the case of $24 \mathrm{~h} 31$ and $24 \mathrm{~h} 301$ configurations, the maximum negative correlation is just before the ISM onset in May-June and the timing of the teleconnection is thus incorrect.

As can be clearly verified from Fig. 12a, the negative correlation between Niño-3.4 SSTs and ISM rainfall occur only after boreal spring and the highest negative correlations are noted during the late ISM and the following months. Surprisingly, the correspondence between the 
model and the observations, as far as the ISM-Niño-3.4 SSTs lead-lag relationship is concerned, is overall, very good and significantly improved only when 2-hourly SST coupling is implemented (i.e. $2 \mathrm{~h} 31$ and $2 \mathrm{~h} 301$ configurations). Both in $2 \mathrm{~h} 31$ and $2 \mathrm{~h} 301$, the maximum negative correlations for zero or slightly positive lags (i.e. for the ISM rainfall leading the Niño-3.4 time series) are much better captured. This result suggests that the model's ENSO in its development stage remotely influences the ISM dynamics and leads to a substantial reduction of ISM rainfall as in observations. Furthermore, the $2 \mathrm{~h} 31$ configuration is also able to recover the seasonal modulation of the monsoon-ENSO relationship with the rapid change of sign of the correlations from positive to negative from year -1 to year 0 as observed. On the other hand, both the $24 \mathrm{~h} 31$ and $24 \mathrm{~h} 301$ configurations share the same deficiencies as the other CMIP3 coupled models exemplified in Fig.1, fail to reproduce the "spring predictability barrier' of ENSO (Webster and Yang, 1992) and show significant negative correlations with the Niño-3.4 SSTs before rather than synchronous and after the ISM. This common spurious ENSO influence on ISM variability may be plausibly attributed to an incorrect phase-locking of the model's ENSO to the annual cycle as we will demonstrate below (i.e. anomalous persistence of the model's ENSO events during spring or too early onset of the events before boreal spring).

$$
\text { We verified the independence of the preceding results on the observed dataset used and }
$$
choice of the ISM rainfall index by duplicating the correlation analyses of Fig. 12a, but with the CMAP dataset and the ISM rainfall indices computed as land, ocean and land-averages both from the observations and the different configurations of SINTEX-F2 (not shown). The main results are analogous to what was previously described in the sense that the $2 \mathrm{~h} 31$ and $2 \mathrm{~h} 301$ configurations are more realistically simulating the ISM rainfall variability and its relationship with ENSO, including the asymmetry in the lead-lag correlations and the spring predictability barrier, while the two other configurations with 1-day SST coupling do not capture the overall shape of the observed seasonal modulation of the ISM-ENSO relationship and, especially, the spring barrier.

The property to capture the seasonal evolution of the correlations between monthly Niño-34 SSTs and ISM rainfall is plausibly related to the ability of the $2 \mathrm{~h} 31$ and $2 \mathrm{~h} 301$ configurations to simulate correctly the space-time evolution of the SST anomalies and associated diabatic heating anomalies during El Niño events (Turner et al., 2005; Annamalai et al., 2007). Thus, we now focus on the SST patterns associated with Niño-3.4 SST time 
series (Figures 13, 14 and 15) For the sake of brevity we show these diagnostics from only two of the four model's configurations, but a similar correlation analysis has been undertaken for the $2 \mathrm{~h} 301$ and $24 \mathrm{~h} 301$ configurations and we will also note any differences between these runs and the twin experiments $2 \mathrm{~h} 31$ and $24 \mathrm{~h} 31$.

The correspondence between $2 \mathrm{~h} 31(2 \mathrm{~h} 301)$ and the observations is striking during the development stage of El Niño events. First, the observed correlation patterns before the El Niño onset suggests the importance of extratropical latitudes, with possible precursory SST signals stemming from the North Pacific and South Indian regions during February-March (Terray et al., 2005a; Terray and Dominak, 2005; Terray et al., 2007; Vimont et al., 2003, 2009; Alexander et al., 2010). Interestingly, $2 \mathrm{~h} 31$ is able to recover more precisely than $24 \mathrm{~h} 31$, the SST precursory pattern found in the North Pacific region, which takes the form of a warm C-shaped 'footprint' during AM both in observations and $2 \mathrm{~h} 31$, consistent with Vimont's "seasonal footprinting mechanism" (Vimont et al., 2003).

A clear ENSO signal is depicted with an eastward propagation of warm anomalies from the west equatorial Pacific to the central and eastern Pacific from April-May to AugustSeptember in both observations and the simulations. This eastward propagating SST signal is characteristic of the observed ENSO evolution only after the so-called 1976/77 climate shift (Wang, 1995; Trenberth and Stepaniak, 2001; Terray et Dominak, 2005; Guilyardi, 2006), but it is dominating the correlation patterns when the computations are undertaken on the full 1950-2005 period. During the peak phase of ENSO, the tongue of positive correlations extends too far west in the simulations, a bias also shared by many current CGCMs (AchutaRao and Sperber, 2002, 2006). Moreover, this tongue of positive correlations is too meridionally confined and the negative correlations forming the two branches of the traditional horseshoe pattern are also split and much less intense in $24 \mathrm{~h} 31$ (24h301) than in the observations or $2 \mathrm{~h} 31(2 \mathrm{~h} 301)$.

Model performance in the Indian Ocean is far from the success of the Pacific Ocean. As in the period after the 1976/77 climate shift, El Niño (La Niña) onset is preceded by a basinwide Indian Ocean cooling (warming) in the simulations (Kug and Kang, 2006; Izumo et al., 2008; Boschat et al., 2011a). However, the precursory SST subtropical dipole pattern in the south Indian Ocean clearly visible during February-March in the observations (Terray and Dominak, 2005; Terray, 2011; Yoo et al., 2010) is missing in our simulations. Next, the 
659 observed positive correlations over the western Indian Ocean, increasing from June-July to 660 October-November (related to the weaker ISM circulation observed during summer of El 661 Niño developing year), are strongly polluted by the negative correlations extending from the 662 eastern equatorial Indian Ocean associated with a too strong IOD signal in the simulations. 663 But, once again, one can observe that this bias is much stronger in 24h31 (24h301) than $2 \mathrm{~h} 31$ 664 (2h301). Consistent with the existence of a significant IOD-ENSO relationship in SINTEX 665 (Gualdi et al., 2003; Fischer et al., 2005), positive correlations are simulated in the western 666 Indian Ocean and negative correlations in the eastern Indian Ocean during boreal fall by all 667 the configurations. However, these regional signals are much stronger than observed and 668 occurred too early, during boreal summer, in all the configurations, but especially in the $66924 \mathrm{~h} 31$ and $24 \mathrm{~h} 301$ configurations. Finally, all the configurations reproduce the basin-wide warming of the tropical Indian Ocean, which is observed when El Niño is mature, but this warming is too weak in $24 \mathrm{~h} 31(24 \mathrm{~h} 301)$. All these results highlight the positive impact of the SST coupling frequency on the precursors and temporal evolution of ENSO at the Indo-

673 Pacific basin scale.

(c) IOD-ISM relationships

As in previous versions of the SINTEX model, all the integrations display a mode of variability internal to the Indian Ocean with a dynamic comparable to the observed IOD (Fig. 8; see also Gualdi et al., 2003, Fischer et al., 2005; Behera et al., 2006). Maximum correlation between ISM rainfall and monthly IOD occurs in September-November with an amplitude of -0.3 (Fig. 12b). Interestingly, this season is also the period in which the ENSO-IOD relationship is significant in the observations (Fischer et al., 2005; Behera et al., 2006). As is clearly seen in Fig. $12 \mathrm{~b}$, the $2 \mathrm{~h} 301$ and $24 \mathrm{~h} 301$ configurations with increased vertical oceanic resolution have problem in representing the teleconnections between ISM rainfall and IOD during boreal summer of year $0.24 \mathrm{~h} 31$ configuration represents correctly some of the features associated with the observed ISM-IOD relationship, but other aspects are less well captured such as the tight phase-locking to the late boreal summer and fall season of the correlations and spurious (significant) negative correlations before or near the ISM onset are simulated. This is plausibly related to the too early IOD onset in $24 \mathrm{~h} 31$ as discussed above. The correlations are only realistically reproduced with the $2 \mathrm{~h} 31$ configuration which uses a reduced vertical oceanic resolution, but 2-hourly SST coupling. Overall, the vertical oceanic resolution in the CGCM has a stronger (negative) impact than the SST coupling 
frequency as far as the ISM-IOD relationships are concerned. Further work is needed to understand the physical processes which are responsible of these important modifications in the interannual variability of SINTEX-F2 in the Indian Ocean when changing the vertical oceanic resolution.

\section{Conclusions}

698

There are numerous factors that may explain the current failure of CMIP3 coupled models in simulating the observed ISM-ENSO relationship including 1) the models' ability to simulate the mean Indo-Pacific climate, 2) the models' ability to simulate ENSO and 3) the models' ability to simulate a realistic ENSO-ISM teleconnection (Annamalai et al., 2007).

Most CGCMs develop significant systematic errors in the mean state climate, particularly in the monsoon circulation and precipitation, and there is currently little confidence in seasonal forecasts or climate change projections due to the inaccuracies in CGCMs. Eliminations of these biases are therefore highly desirable. Flux corrections methods have been suggested as a practical method for improving the quality of seasonal and interannual variability in CGCMs (Turner et al., 2005; Bracco et al., 2007; Manganello and Huang, 2009). As striking examples, the studies of Turner et al. (2005), Bracco et al. (2007) or Manganello and Huang (2009) have demonstrated that improvement in representing the mean state of the tropical Pacific through the use of flux adjustments gave rise to a more realistic ENSO, which in turn improved the monsoon-ENSO relationship in coupled simulations. However, the results from flux-corrected experiments may be model-dependent and are very difficult to interpret due to the inconsistency of the climate model introduced by the flux corrections (Spencer et al., 2007; Manganello and Huang, 2009).

In this study, as an alternative to flux corrections, the impacts of oceanic diurnal cycle on the development of large-scale coupled phenomena such as ISM, IOD and ENSO are investigated through the comparison of four different experiments using the same state-of-theart high resolution CGCM. In the first experiment (2h31), diurnal coupling is applied in the CGCM by using 2-hourly coupling steps for all air-sea fluxes. A twin experiment (24h31) 
using exactly the same CGCM, but with 1-day coupling frequency for the SST, has been conducted in order to investigate whether diurnal SST high frequency variations may have an effect on the simulated Indo-Pacific mean-state and variability. The interpretation of the results is supported by a second ensemble with increased vertical oceanic resolution (e.g. 2h301 and 24h301 with 301 vertical levels in the ocean model). According to recent studies (Danabasoglu et al., 2006; Bernie et al., 2008), the first two experiments (2h31 and 24h31) with 31 vertical levels may not have a sufficient vertical resolution in the upper ocean to allow a proper diurnal variability of the depth of the mixed layer, while the last two experiments are able to capture this diurnal cycle of the mixed layer and may, consequently have a more significant impact on the mean state and dynamics of the system through both the diurnal rectification effect and other induced air-sea feedbacks (Ham et al., 2010). Despite of this, the significant differences and improvements concerning the interannual variability of the monsoon-ENSO system when comparing $2 \mathrm{~h} 31$ to $24 \mathrm{~h} 31$, on one hand, and $2 \mathrm{~h} 301$ to 24h301 experiments, on the other hand, are very similar in many aspects.

As a first result, we found that increasing the vertical oceanic resolution in the CGCM has a significant impact on the mean state, especially in the tropical Pacific, but that 2-hourly SST coupling does not produce significant modulations of the background mean-state and seasonal cycle in the tropics. However, when we moved to interannual variability, our simulations point out to a reduction of coupled model biases when diurnal SST coupling is implemented, independently of the vertical oceanic resolution used in the CGCM.

In agreement with our companion study (Masson et al., 2011), we found that ENSO variability is very sensitive to diurnal SST coupling. In $2 \mathrm{~h} 31$ and $2 \mathrm{~h} 301$ experiments, Niño-34 SSTs have a larger standard deviation, a power spectrum with a sharper peak corresponding to a 4-5 years oscillation and a more realistic evolution of tropical Pacific SST and associated precipitation anomalies. Focusing on Indian Ocean variability, we found that the phase locking to the annual cycle of eastern Indian Ocean SST and thermocline depth is also improved as are the power spectra of ISM rainfall indices when 2-hourly SST coupling is implemented. In other words, both $2 \mathrm{~h} 31$ and $2 \mathrm{~h} 301$ performed better in their representations of ENSO and ISM variability when compared, respectively, with $24 \mathrm{~h} 31$ and $24 \mathrm{~h} 301$ 
The different nature of ENSO in the model's configurations may obviously have a global impact through remote teleconnections associated with the redistribution of latent heat sources and sinks in the equatorial Pacific (Annamalai et al., 2007). The current work confirms this hypothesis by demonstrating that the interannual variability of the whole ENSO-ISM system is very sensitive to diurnal SST coupling. With 2-hourly SST coupling, the simulation of the lead-lag relationships between ENSO and ISM is dramatically improved and the CGCM is able to capture much better the spring predictability barrier, which is of paramount importance for dynamical seasonal prediction of the monsoon. Related to the stronger ISM-ENSO coupling, the spectrum of ISM rainfall variability is also shifted to ENSO-related frequencies. This suggests that ISM in $2 \mathrm{~h} 31$ and $2 \mathrm{~h} 301$ configurations can respond much more realistically to east Pacific SSTs once some of the systematic errors in ENSO's evolution have been removed. On the other hand, the ISM-IOD teleconnection is sensible to both diurnal SST coupling and the vertical oceanic resolution, but increasing the vertical oceanic resolution is degrading the ISM-IOD teleconnection in the CGCM. In other words, we suggest that the factors that are responsible for the more realistic simulation of the ISM-ENSO-IOD relationships in our experiments with 2-hourly SST coupling can be traced back to a large extent to significant changes in ENSO characteristics, such as its amplitude, periodicity and evolution.

There have been already several studies devoted to the impact of the diurnal cycle on the mean state, intraseasonal and interannual variability of the tropical system as simulated by state-of-the-art CGCMs (Danabasoglu et al., 2006; Bernie et al., 2009; Ham et al., 2010). According to these recent studies, diurnal air-sea coupling improve the performance of the CGCMs by changing the climatology of the coupled model and producing a warmer mean state which help to reduce the "cold tongue" bias in the equatorial Pacific by a mechanism involving the diurnal variability of the mixed layer (Danabasoglu et al., 2006; Bernie et al., 2009). These rectifications of the mean state may then modify both the intraseasonal and interannual variabilities of the simulated system (Bernie et al., 2009; Ham et al., 2010).

However, if the diurnal oceanic cycle and the diurnal rectification mechanism of the mean state has some role to play in our results, the robustness and similarity of the differences between $2 \mathrm{~h} 31-24 \mathrm{~h} 31$ and $2 \mathrm{~h} 301-24 \mathrm{~h} 301$ configurations show that the diurnal oceanic cycle forms only part of the explanation of the substantial changes in the nature of ENSO and timing of the monsoon-ENSO teleconnections when 2-hourly SST coupling is implemented. 
teleconnection patterns are not related to changes in the mean state of the coupled model in 791 our experiments, leaving open the question of other amplification mechanisms due 792 specifically to a more accurate air-sea coupling strategy. These differences between our 793 results and previous studies are obviously related to the fact that, in our experiments, all airsea fluxes other than SST are communicated using coupling steps of 2 hours, while other studies have contrasted 1-day to 2-hourly coupling experiments for all the air-sea fluxes. This leads to the hypothesis that other mechanisms must be at play for explaining our results, such as a better simulation of temporal scale interactions when 2-hourly SST coupling is activated. The implication of all these results, yet to be verified by a detailed analysis, is that large-scale air-sea coupling and temporal scale interactions are prime mechanisms for the rectification of the interannual variability of the coupled system in our coupled experiments instead of a change of the mean state. Thus, our results emphasize the need for a better understanding of the impact of the synoptic and intraseasonal time scales and their nonlinear scale interactions with the interannual time scale as observed and simulated by CGCMs (Meehl et al., 2001). The detailed analysis of these scale interactions in the tropical Indo-Pacific region in the framework of our coupled model will be the subject of a forthcoming study. In any case, our results highlight that air-sea coupling has to be represented as accurately as possible to simulate the interannual variability of the ENSO-monsoon system and to correct present model's deficiencies.

If we take into account that most of the CMIP3 coupled models fail to recover the complex ISM-ENSO lead-lag relationships and produced similar results to the SINTEX-F2 model in 811 its $24 \mathrm{~h} 31$ configuration, our results are intriguing. A plausible explanation for this general 812 failure is that most of the CMIP3 CGCMs still did not have the correct phase of ENSO with 813 respect to the annual cycle (Terray, 2006). The diversity in the simulation of ENSO variability 814 in the CMIP3 coupled models is still extremely high (Guilyardi, 2006), particularly with 815 respect to the phase-locking of ENSO on the annual cycle, and this shortcoming may 816 adversely affect the ability of the coupled models to simulate the monsoon-ENSO 817 teleconnection as seen in Fig. 1. However, it is also instructive to mention that a large 818 majority of the CMIP3 coupled models exchange atmospheric and oceanic parameters just 819 once a day. In such models, a poor representation of the diurnal air-sea coupling and related 820 scale interactions could also lead to errors than can be rectified into the interannual variability 821 of the system through non-linearities, even without any significant changes in the climatology 822 of the coupled model, as suggested by our results. Interestingly, three of four of the models 
identified by Annamalai et al. (2007) that can successfully simulate the monsoon-ENSO teleconnection also use 2-hourly coupling (see Fig. 1).

In conclusion, our study argues that important progress in simulating the interannual variability of the tropical system can be achieved by modifications of the coupling strategies currently used in CGCMs, without using any flux correction methods. Our model diagnostics indicate that a proper simulation of the scale interactions embedded in the dynamics of the climate system may also be a prerequisite to capture a realistic ISM-ENSO teleconnection, in addition to a correct simulation of the basic state as suggested by others (Turner et al., 2005; Annamalai et al., 2007). This emphasizes the need for a more detailed investigation of the impact of coupling strategies on the simulation of Indo-Pacific interannual variability in current CGCMs.

At the end, we want to emphasize that we do not argue that diurnal SST coupling will be equally important in other state-of-the-art CGCMs and the results presented here may be model-dependent. However, we do believe that coupling strategy is a relatively overlooked area and may be more thoroughly diagnose in current CGCMs if further progress in the simulation of the variability of the coupled climate system is to be achieved.

Acknowledgments: Financial support from the Indo-French CEFIPRA project $\left(\mathrm{N}^{\circ} 3907 / 1\right)$ and the European Community project ENSEMBLES (Project no. GOCE-CT-2003-505539) is acknowledged. All the SINTEX-F2 experiments were carried out on the Earth Simulator (JAMSTEC) in the frame of the France-Japan collaboration. Our sensibility experiments with 301 levels in the ocean have to be double thanks to the outstanding computational performances offered by this unique supercomputer. S. Masson and G. Madec were supported by ANR (INLOES project). Many thanks to R. Benshila, C. Talandier, A. Caubel, E. Maisonnave, M.A. Foujols, C. Levy, Y.Meursedoif, F. Pinsard, C. Deltel, S. Denvil and P. Brochard who have come to the ESC to implement, optimize and run the simulations. Their visit at the ESC was greatly facilitated by the kind help of K. Takahashi, A. Kurita, R. Itakura, A. Toya and M.-E. Demory. The NCEP-NCAR reanalysis, CMAP and HadISST1.1 data were provided by the NOAA-CIRES Climate Diagnostics Center from the Web site (http://www.cdc.noaa.gov). Finally, we acknowledge the outstanding work undertaken by the many international modeling groups who provided their numerous model experiments for the Program for Climate Model Diagnosis and Intercomparison (PCMDI). For more details on model data or documentation, readers are referred to the PCMDI Web site (http://wwwpcmdi.llnl.gov). 


\section{References}

858

859

Abram NJ, Gagan MK, Cole JE, Hantoro WS, Mudelsee M (2008) Recent intensification of

860

861

862 tropical climate variability in the Indian Ocean. Nat. Geosci. 1, 849-853.

AchutaRao K, Sperber KR (2002) Simulation of the El Niño Southern Oscillation: Results from the coupled model intercomparison project. Climate Dyn, 19, 191-209.

864

865

AchutaRao KM, Sperber KR (2006) ENSO simulation in coupled ocean-atmosphere models:

866

867

868

869 Are the current models better? Climate Dyn., 27, 1-15.

Alexander MA, Bladé I, Newman M, Lanzante JR, Lau N-C, Scott JD (2002) The atmospheric bridge: The influence of ENSO teleconnections on air-sea interaction over the global oceans.

870

871

872 J. Climate, 15, 2205-2231.

873

874

875

876

877

878

879

880

881

882

883

884

885

886

887

888

889

890

891

892

893

894

895

896

897

898

899

900

901

902

903

Alexander MA, Vimont DJ, Chang P, Scott JD (2010) The impact of extratropical atmospheric variability on ENSO: testing the Seasonal Footprinting Mechanism using coupled model experiments. J. Climate, 23, 2885-2901.

Annamalai H, Liu P (2005) Response of the Asian summer monsoon to changes in El Niño properties. Quart. J. Roy. Meteor. Soc., 131, 805-831.

Annamalai H, Sperber KR (2005) Regional heat sources and the active and break phases of boreal summer intraseasonal (30-50 day) variability. J. Atmos. Sci., 62, 2726-2748.

Annamalai H, Hamilton K, Sperber KR (2007) The South Asian summer monsoon and its relationship with ENSO in the IPCC AR4 simulations. J. Climate, 20, 1071-1092.

Ashok K, Guan Z, Yamagata T (2001) Influence of the Indian Ocean Dipole on the relationship between the Indian monsoon rainfall and ENSO. Geophys. Res. Lett., 28, 4499-4502.

Ashok K, Guan Z, Saji NH, Yamagata T (2004) Individual and combined influences of ENSO and the Indian Ocean Dipole on the Indian Summer Monsoon. J. Climate, 17, 3141-3154.

Behera SK, Luo JJ, Masson S, Rao SA, Sakuma H (2006) A CGCM study on the interaction between IOD and ENSO. J. Climate, 19, 1688-1705.

Bernie DJ, Guilyardi E, Madec G, Slingo JM, Woolnough SJ (2007). Impact of resolving the diurnal cycle in an ocean-atmosphere GCM. Part 1: a diurnally forced OGCM. Climate Dyn., 29, 575-590.

Bernie DJ, Guilyardi E, Madec G, Slingo JM, Woolnough SJ, Cole J (2008) Impact of resolving the diurnal cycle in an ocean--atmosphere GCM. Part 2: A diurnally coupled CGCM. Climate Dyn., 31, 909-925.

Bhalme HN, Jadhav SK (1984) The Southern Oscillation and its relation to the monsoon rainfall. Int. J. of Climatology, 4, 509-520. DOI: 10.1002/joc.3370040506. 
904

905

906

907

908

909

910

911

912

913

914

915

916

917

918

919

920

921

922

923

924

925

926

927

928

929

930

931

932

933

934

935

936

937

938

939

940

941

942

943

944

945

946

947

948

949

Boschat G, Terray P, Masson S (2011a) Interannual relationships between Indian Summer Monsoon and Indo-Pacific coupled modes of variability during recent decades. Clim. Dyn., 37:1019-1043, doi:10.1007/s00382-010-0887-y.

Boschat G, Terray P, Masson S (2011b) Robustness of SST teleconnections and precursory patterns associated with the Indian Summer Monsoon. Clim. Dyn., online, doi:10.1007/s00382-011-1100-7.

Bracco A, Kucharski F, Molteni F, Hazeleger W, Severijns C (2007) A recipe for simulating the interannual variability of the Asian summer monsoon and its relation with ENSO. Clim. Dyn., DOI: 10.1007/s000382-006-0190-0.

Cai W, Sullivan A, Cowan T (2009) Rainfall Teleconnections with Indo-Pacific variability in the WCRP CMIP3 Models. J. Climate, 22, 5046-5071.

Carton, JA, Giese BS, Grodsky SA (2005) Sea level rise and the warming of the oceans in the SODA ocean reanalysis. J. Geophys. Res., 110, C09006, doi:10.1029/2004JC002817.

Chang C-P, Harr P, Ju J (2001) Possible Roles of Atlantic Circulations on the Weakening Indian Monsoon Rainfall-ENSO Relationship. J. Climate, 14, 2376-2380

Chang C-P and Coauthors (2006) Climate fluctuations of tropical coupled systems - The role of ocean dynamics. J. Climate, 19, 5122-5174.

Cherchi A, Gualdi S, Behera S, Luo JJ, Masson S, Yamagata T, Navarra A (2007) The influence of tropical Indian Ocean SST on the Indian summer monsoon. J. Climate, 20, 3083-3105.

Danabasoglu G, Large WG, Tribbia JJ, Gent PR, Briegleb BP, McWilliams JC (2006) Diurnal coupling in the tropical oceans of CCSM3. J. Climate, 19, 2347-365.

Diggle PJ (1990) Time series : a biostatistical introduction. Chapter 4, Clarendon Press, Oxford.

Ebisuzaki W (1997) A method to estimate the statistical significance of a correlation when the data are serially correlated. J. Climate, 10, 2147-2153.

Fischer AS, Terray P, Delecluse P, Gualdi S, Guilyardi E (2005) Two Independent Triggers for the Indian Ocean Dipole/Zonal Mode in a Coupled GCM. J. Climate, 18, 3428-3449.

Gadgil S, Rajeevan M, Nanjundiah R (2005) Monsoon prediction - why yet another failure? Curr. Sci., 84, 1713-1719.

Gershunov A, Schneider N, Barnett T (2001) Low-frequency modulation of the ENSO-Indian monsoon rainfall relationship: signal or noise? J. Climate, 14, 2486-2492. 
950

951

952

953

954

955

956

957

958

959

960

961

962

963

964

965

966

967

968

969

970

971

972

973

974

975

976

977

978

979

980

981

982

983

984

985

986

987

988

989

990

991

992

993

994

995

996

997

998

Goswami BN, Wu G, Yasunari T (2006) Annual cycle, Intraseasonal Oscillations and Roadblock to seasonal predictability of the Asian summer monsoon. J. Climate, 19, 50785099.

Gualdi, S, Guilyardi E, Navarra A, Masina S, Delecluse P (2003) The interannual variability in the tropical Indian Ocean as simulated by a CGCM. Clim. Dyn., 20, 567-582.

Guilyardi E (2006) El Niño-mean state--seasonal cycle interactions in a multi-model ensemble. Clim. Dyn., 26, 329-348.

Guilyardi E, Delecluse P, Gualdi S, Navarra, A (2003) Mechanisms for ENSO phase change in a coupled GCM. J. Climate, 16, 1141-158.

Guilyardi E, Wittenberg, A, Fedorov A, Collins M, Wang C (2009) Understanding El Niño in ocean-atmosphere general circulation models. Bull. Amer. Meteor. Soc., 90, 325-340.

Ham YG, Kug JS, Kang IS, Jin FF, Timmermann A (2010) Impact of diurnal atmosphere--ocean coupling on tropical climate simulations using a coupled GCM. Clim. Dyn., 34, 905-917.

Izumo T, de Boyer Montégut C, Luo J-J, Behera SK, Masson S, Yamagata T (2008) The role of the western Arabian Sea upwelling in Indian monsoon rainfall variability, J. Climate, 21, 5603-5623.

Joseph R, Nigam S (2006) ENSO evolution and teleconnection in IPCC's twentieth-century climate simulations: Realistic representation? J. Climate, 19, 4360-4377.

Ju J, Slingo JM (1995) The Asian summer monsoon and ENSO. Quart. J. Roy. Meteor. Soc., 121, 1133-1168.

Kalnay E, Kanamitsu M, Kistler R, Collins W, Deaven D, Gandin L, Iredell M, Saha S, White G, Woollen J, Zhu Y, Chelliah M, Ebisuzaki W, Higgins W, Janowiak J, Mo KC, Ropelewski C, Wang J, Leetmaa A, Reynolds R, Jenne R, Joseph D (1996) The NCEP/NCAR 40-year reanalysis project. Bull. Amer. Met. Soc., 77, 437-471.

Kawai Y, Wada A (2007) Diurnal sea surface temperature variation and its impact on the atmosphere and ocean: a review. Journal of Oceanography, 63, 721-744.

Kinter JL, Miyakoda K, Yang S (2002) Recent change in the connection from the Asian Monsoon to ENSO. J. Climate, 15, 1203-1215.

Krishna Kumar K, Rajagopalan B, Cane M (1999) On the Weakening Relationship Between the Indian Monsoon and ENSO, Science, 284, 2156-2159.

Krishna Kumar K, Hoerling M, Rajagopalan B (2005) Advancing dynamical prediction of Indian monsoon rainfall, Geophys. Res. Lett., 32, 1-4.

Krishna Kumar, K. et al. (2006) Unravelling the Mystery of Indian Monsoon Failure During El Niño. Science 314, 115; DOI: 10.1126/science.1131152. 
Krishnamurthy, V., et B.N. Goswami, 2000: Indian monsoon-ENSO relationship on inter decadal time scales. J. Climate, 13, 579-595.

Krishnan R, Swapna P (2009) Significance influence of the boreal summer monsoon flow on the Indian Ocean response during dipole events. J. Climate, 22, 5611-5634.

Krishnan R, Sundaram S, Swapna P, Kumar V, Ayantika DC, Mujumdar M (2010) The crucial role of ocean-atmosphere coupling on the Indian monsoon anomalous response during dipole events. Clim. Dyn., DOI: 10.1007/s00382-010-0830-2

Kucharski F, Bracco A, Yoo JH, Molteni F (2007) Low-frequency variability of the Indian Monsoon-ENSO relation and the Tropical Atlantic; The 'weakening' of the 1980s and 1990s. J. Climate, 20, 4255-4266.

Kucharski F, Bracco A, Yoo JH, Molteni F (2008) Atlantic forced component of the Indian monsoon interannual variability. Geophys. Res. Lett., 35, $L 04706$. doi:10.1029/2007GL033037.

Kug JS, Kang I-S (2006) Interactive feedback between ENSO and the Indian Ocean. J. Climate, $19,1784-1801$.

Lau NC, Nath MJ, (2004) Coupled GCM Simulation of Atmosphere-Ocean Variability Associated with Zonally Asymmetric SST Changes in the Tropical Indian Ocean. J. Climate, 17, 245-265

Li T, Wang B, Chang CP, Zhang YS (2003) A theory for the Indian Ocean Dipole-Zonal Mode. J. Atmos. Sci., 60, 2119-2135.

Li T, Liu P, Fu X,Wang B, Meehl GA (2006) Spatial-temporal structure of tropical biennial oscillation. J. Climate, 19, 3070-3087.

Lindzen RS, Nigam S (1987) On the role of sea surface temperature gradients in forcing lowlevel winds and convergence in the Tropics. J. Atmos. Sci., 44, 2418-2436.

Loschnigg J, Meehl GA, Arblaster JM, Compo GP, Webster PJ (2003) The Asian monsoon, the tropospheric biennial oscillation, and the Indian Ocean dipole in the NCAR CSM. J. Climate, 16, 1617-1642.

Luo JJ, Masson S, Behera S, Delecluse P, Gualdi S, Navarra A, Yamagata T (2003) South Pacific origin of the decadal ENSO-like variation as simulated by a coupled GCM. Geophys. Res. Lett., 30, 2250-2254.

Luo JJ, Masson S, Roeckner E, Madec G, Yamagata T (2005) Reducing climatology bias in an ocean--atmosphere CGCM with improved coupling physics. J. Climate, 18, 2344-360.

Madec G (2008) "NEMO ocean engine". Note du Pole de modélisation, Institut Pierre-Simon Laplace (IPSL), France, No 27 ISSN No 1288-1619. 
Madec G, Delecluse P, Imbard M, Lévy C (1998) OPA 8.1 Ocean General Circulation Model reference manual. Note du Pole de modélisation, Institut Pierre-Simon Laplace (IPSL), France, $\mathrm{N}^{\circ} 11,91 \mathrm{pp}$.

Manganello JV, Huang B (2009) The influence of systematic errors in the Southeast Pacific on ENSO variability and prediction in a coupled GCM. Clim. Dyn., 32, 1015-1034, DOI 10.1007/s00382-008-0407-5.

Masson S, Terray P, Madec G, Luo JJ, Yamagata T, Takahashi K (2011) Impact of intra-daily SST variability on ENSO characteristics in a coupled model. Submitted to Climate Dynamics.

Meehl GA, Lukas R, Kiladis GN, Wheeler M, Matthews A, Weickmann KM (2001) A 1061 conceptual framework for time and space scale interactions in the climate system. Clim. Dyn., 17, 753-775.

Meehl GA, Arblaster J (2002) The tropospheric biennial oscillation and the Asian-Australian monsoon rainfall. J. Climate, 15, 722-744.

Meehl GA, Arblaster JM, Loschnigg J (2003) Coupled Ocean-Atmosphere Dynamical Processes in the Tropical Indian and Pacific Oceans and the TBO. J. Climate, 16, 2138-2158.

Meehl, G. A. et al. (2007) The WCRP CMIP3 multi-model dataset: a new era in climate change research. Bull. Am. Met. Soc., 88: 1383-1394.

Molines JM, Barnier B, Penduff T, Brodeau L, Treguier AM, Theetten S, Madec G (2006), Definition of the global $1 / 2^{\circ}$ experiment with CORE interannual forcing, ORCA05-G50. LEGI report, November 2006.

LEGI-DRA-1-11-2006, http://www.ifremer.fr/lpo/drakkar/drakkar/configs/ORCA05/orca05 G50.pdf.

1076

1077

1078

1079

1080

1081

1082

1083

1084

1085

Nordeng TE (1994) Extended versions of the convective parameterization scheme at ECMWF and their impact on the mean and transient activity of the model in the tropics, Tech. Memo. 206, Eur. Cent. for Medium-Range Weather Forecasts, Reading, UK.

Palmer TN, et Coauthors (2004) Development of an European multi-model ensemble system for seasonal to interannual prediction (DEMETER). Bull. Am. Met. Soc., 85, 853-872.

Parthasarathy B, Munot AA, Kothawale DR (1994) All-India monthly and seasonal rainfall series: 1871-1993. Theor. Appl. Climatol. 49, 217-224.

Rayner NA, Parker DE, Horton EB, Folland CK, Alexander LV, Rowell DP, Kent EC, Kaplan A (2003) Global analyses of sea surface temperature, sea ice, and night marine air temperature since the late nineteenth century. J. Geophys. Res., 108(D14)4407. doi: 10.1029/2002JD002670.

Reichler T, and Kim J (2008). How well do coupled models simulate today's climate? Bull. Am. Met. Soc., 89, 303-311. 
1095

1096

1097

1098

1099

1100

1101

1102

1103

1104

1105

1106

1107

1108

1109

1110

1111

1112

1113

1114

1115

1116

1117

1118

1119

1120

1121

1122

1123

1124

1125

1126

1127

1128

1129

1130

1131

1132

1133

1134

1135

1136

1137

1138

1139

1140

1141

1142

Roeckner E, et Coauthors (1996) The atmospheric general circulation model ECHAM-4: model description and simulation of present-day climate. Max-Planck-Institut für Meteorologie, report n²18, 94pp.

Roeckner E, Bäuml G, Bonaventura L, Brokopf R, Esch M, Giorgetta M, Hagemann S, Kirchner I, Kornblueh L, Manzini E, Rhodin A, Schlese U, Schulzweida U, Tompkins A (2003) The atmospheric general circulation model ECHAM 5. PART I: Model description. MPIReport 349.

Roeckner E, Brokopf R, Esch M, Giorgetta M, Hagemann S, Kornblueh L, Manzini E, Schlese U, Schulzweida U (2004) The atmospheric general circulation model ECHAM5 Part II: Sensitivity of simulated climate to horizontal and vertical resolution. Max-Planck-Institute for Meteorology, MPI-Report 354.

Saji NH, Goswami BN, Vinayachandran PN, Yamagata TA (1999) Dipole Mode in the Tropical Indian Ocean. Nature, 401, 360-363.

Saji NH, Xie S-P, Yamagata T (2006) Tropical Indian Ocean variability in the IPCC twentiethcentury climate simulations. J. Climate, 19, 4397-4417. DOI: 10.1175/JCLI3847.1.

Slingo J, Inness P, Neale R, Woolnough S, Yang G (2003) Scale interactions on diurnal to seasonal timescales and their relevance to model systematic errors. Annals of Geophysics, 46, 139-155.

Spencer H, Sutton RT, Slingo JM, Roberts M, Black E (2005) Indian Ocean Climate and Dipole Variability in Hadley Centre Coupled GCMs. J. Climate, 18, 2286-2307.

Spencer H, Sutton RT, Slingo JM (2007) El Niño in a Coupled Climate Model: Sensitivity to Changes in Mean State Induced by Heat Flux and Wind Stress Corrections. J. Climate, 20, 2273-2273.

Terray P, Delecluse P, Labattu S, Terray L (2003) Sea Surface Temperature Associations with the Late Indian Summer Monsoon. Clim. Dyn., 21, 593-618.

Terray P, Dominiak S (2005) Indian Ocean Sea Surface Temperature and El Niño-Southern Oscillation: a new perspective. J. Climate, 18, 1351-1368.

Terray P, Dominiak S, Delecluse P (2005a) Role of the southern Indian Ocean in the transitions of the monsoon-ENSO system during recent decades. Clim. Dyn., 24, 169-195, DOI: $10.1007 /$ s00382-004-0480-3.

Terray P, Guilyardi E, Fischer AS, Delecluse P (2005b) Dynamics of the Indian Monsoon and ENSO Relationships in the SINTEX global Coupled Model. Clim. Dyn., 24, 145-168.

Terray P (2006) Assessment of the representation of monsoon and its teleconnection with the ocean variability from IPCC scenarios with the European models. European ENSEMBLES project (Project no. GOCE-CT-2003-505539). Deliverable D.5.17, 20 pp. 
Terray P, Chauvin F, Douville H (2007) Impact of southeast Indian Ocean Sea Surface Temperature anomalies on monsoon-ENSO-dipole variability in a coupled ocean-atmosphere model. Clim. Dyn., 28, 553-580. doi:10.1007/s00382-006-0192-y

Terray P (2011) Southern Hemisphere extra-tropical forcing: a new paradigm for El NiñoSouthern Oscillation. Clim. Dyn., 36:2171-2199, doi:10.1007/s00382-010-0825-z.

Tiedtke M (1989). A comprehensive mass flux scheme for cumulus parameterization in largescale models. Mon. Weather Rev., 117, 1779-1800.

1158

1159

1160

1161

1162

1163

1164

1165

1166

1167

1168

1169

1170

1171

1172

1173

1174

1175

1176

1177

1178

1179

1180

1181

1182

1183

1184

1185

1186

1187

1188

1189

Timmermann R, Goosse H, Madec G, Fichefet T, Ethe C, Duliere C (2005) On the representation of high latitude processes in the ORCA-LIM global coupled sea-ice-ocean model. Ocean Modell., 8, 175-201.

Trenberth KE, Stepaniak DP (2001) Indices of El Niño evolution. J. Climate, 14, 1697-1701.

Turner AG, Inness PM, Slingo JM (2005) The role of the basic state in the ENSO-monsoon relationship and implications for predictability. Quart. J. Roy. Meteor. Soc., 131, 781-804.

Valcke S (2006) OASIS3 User Guide (prism_2-5). PRISM Support Initiative Report No 3, 64pp

Vimont DJ, Wallace JM, Battisti DS (2003) The seasonal footprinting mechanism in the Pacific: Implications for ENSO. J. Climate, 16, 2668-2675.

Vimont DJ, Alexander M, Fontaine A (2009) Midlatitude Excitation of Tropical Variability in the Pacific: The Role of Thermodynamic Coupling and Seasonality. J. Climate, 22, 518-534.

Wang B (1995) Interdecadal changes in El Niño onset in the last four decades. J. Climate, 8, 267-285.

Wang B (2006) The Asian Monsoon. Springer- Verlag/Praxis Publishing, New York, 787 pp.

Wang B, Wu R, Lau K-M (2001) Interannual Variability of the Asian Summer Monsoon: Contrasts between the Indian and the Western North Pacific-East Asian Monsoons. J. Climate, 14, 4073-4090.

Wang B, Ding Q, Fu X, Kang I-S, Jin K, Shukla J, Doblas-Reyes F (2005) Fundamental challenges in simulation and prediction of summer monsoon rainfall, Geophys. Res. Lett., 32, L15711,doi: 10.1029/2005GL022734 12.

Webster PJ, Magana VO, Palmer TN, Shukla J, Tomas RA, Yanai M, Yasunari T (1998) Monsoons: Processes, predictability and the prospects for prediction. J. Geophys. Res., 103(C7):14 451-14 510.

Webster PJ, Yang S (1992) Monsoon and ENSO: Selectively interactive systems. Quart. J. Roy. Meteor. Soc., 118, 877-926. 
Welch PD (1967) The use of Fast Fourier Transform for the estimation of power spectra: a method based on time averaging over short, modified periodograms. IEEE Transactions on Audio and Electroacoustics, 15, 70-73.

Wu R, Kirtman BP (2003) On the impacts of Indian summer monsoon on ENSO in a coupled GCM. Quart. J. Roy. Meteor. Soc., 129, 3439-3468.

Wu R, Kirtman BP (2005) Role of Indian and Pacific Ocean air-sea coupling in tropical atmospheric variability. Clim. Dyn., 25, 155-179.

Wu R, Kirtman BP (2007) Role of Indian Ocean in the biennial transition of the Indian summer monsoon. J. Climate, 20, 2147-2164.

Wu R, Kirtman BP, Pegion K (2006) Local air-sea relationship in observations and model simulations. J. Climate, 19, 4914-4932.

Wu R, Kirtman BP (2007) Regimes of local air-sea interactions and implications for performance of forced simulations. Clim. Dyn., 29, 393-410.

Xavier, P. K., Marzin, C. and Goswami, B. N. (2007) An objective definition of the Indian summer monsoon season and a new perspective on the ENSO-monsoon relationship. Quart. J. Roy. Meteor. Soc., 133: 749-764.

Xie P, Arkin PA (1997) Global precipitation: A 17-year monthly analysis based on gauge observations, satellite estimates and numerical model outputs. Bull. Amer. Meteor. Soc., 78, 2539-2558.

Yasunari T (1990) Impact of Indian monsoon on the coupled atmosphere/ocean system in the tropical Pacific. Meteor. \& Atmos. Phys., 44, 29-41.

Yoo SH, Fasullo J, Yang S, Ho CH (2010) On the relationship between Indian Ocean sea surface temperature and the transition from El Niño to La Niña. J. Geophys. Res., 115, D15114, doi:10.1029/2009JD012978.

Yu L, Jin X, Weller RA (2008) Multidecade Global Flux Datasets from the Objectively Analyzed Air-sea Fluxes (OAFlux) Project: Latent and sensible heat fluxes, ocean evaporation, and related surface meteorological variables. Woods Hole Oceanographic Institution, OAFlux Project Technical Report. OA-2008-01, 64pp. Woods Hole. Massachusetts. 
1233 Figure 1: Lead-lag correlations between the ISM rainfall and the monthly Niño-34 SSTs 1234 (SST averaged over $5^{\circ} \mathrm{S}-5^{\circ} \mathrm{N}, 170^{\circ}-120^{\circ} \mathrm{W}$ ) starting several months before the onset of the 1235 monsoon (January) and finishing several months after the withdrawal of the monsoon 1236 (December) in the twentieth century runs (20c3m) of the CMIP3 from 20 different state-ofthe-art coupled models and observational estimates. All the correlation coefficients are estimated from the 1870-2000 period both for observations and 20c3m simulations after detrending the SST time series. For each of the models one realization (the first) of the twentieth-century simulations were used to evaluate the ISM-ENSO relationship.

Figure 2: (a) SST boreal summer climatology as derived from the HadISST dataset and estimated from the 1958-2008 period (b) (c) (d) (e) differences with the SST climatologies of $2 \mathrm{~h} 31,24 \mathrm{~h} 31,2 \mathrm{~h} 301$ and $24 \mathrm{~h} 301$, respectively.

Figure 3: Same as Figure 2, but for the rainfall climatology estimated from CMAP on the 1979-2008 period. Differences between the GPCP and CMAP boreal summer rainfall climatologies are also shown in Fig. 3b.

Figure 4: Same as Figure 2, but for the $850 \mathrm{hPa}$ wind climatology estimated from NCEP reanalysis on the 1979-2008 period.

Figure 5: (a) Climatological annual cycle of SST averaged over the eastern node of IOD $\left(15^{\circ} \mathrm{S}-0^{\circ}, 85^{\circ}-110^{\circ} \mathrm{E}\right)$ computed from the HadISST dataset and the four SINTEX-F2 configurations (b) Same as (a), but for the western node of IOD $\left(15^{\circ} \mathrm{S}-10^{\circ} \mathrm{N}, 50^{\circ}-75^{\circ} \mathrm{E}\right)$ (c) Climatological annual cycle of the IOD index from observations and the four configurations (d) Climatological annual cycle of the depth of the $20^{\circ} \mathrm{C}$ isotherm averaged over the eastern equatorial Indian Ocean $\left(2^{\circ} \mathrm{S}-2^{\circ} \mathrm{N}, 90^{\circ}-100^{\circ} \mathrm{E}\right)$ computed from SODA and the four configurations (e) Same as (d), but for the depth of $20^{\circ} \mathrm{C}$ over the Sumatra region $\left(10^{\circ}-2^{\circ} \mathrm{S}\right.$, $95^{\circ}-105^{\circ} \mathrm{E}$ ) (f) Climatological annual cycle of latent heat flux averaged over the eastern node of IOD computed from OAFLUX dataset (Yu et al., 2008) and the four configurations of SINTEX-F2.

1259 Figure 6: Mean annual cycle of rainfall averaged over the Indian subcontinent (land grid points between $8-35^{\circ} \mathrm{N}$ and $65-95^{\circ} \mathrm{E}$ ) for the observations (CMAP dataset) and the coupled model simulations.

1262 Figure 7: (a) Differences between the boreal summer SST climatologies of the $2 \mathrm{~h} 31$ and $2 \mathrm{~h} 301$ configurations (b) Same as (a), but for the rainfall climatologies (c) Same as (a), but for the $850 \mathrm{hPa}$ wind climatologies. In panels (a) and (b), the differences which are significant at the $95 \%$ confidence level are underlined. In panel (c), the map only show $850 \mathrm{hPa}$ wind differences which are above the $95 \%$ confidence level. These confidence levels have been assessed using a permutation procedure with 9999 shuffles; see Terray et al. (2003) for more details.

1269 Figure 8: (a) Monthly standard deviations of the Niño-34 SST time series from HadISST dataset and the four configurations (b) Same as (a), but for the IOD index (c) Same as (a), but for western node IOD $\left(15^{\circ} \mathrm{S}-10^{\circ} \mathrm{N}, 50^{\circ}-75^{\circ} \mathrm{E}\right) \mathrm{SST}$ time series (d) Same as (a), but eastern node IOD $\left(15^{\circ} \mathrm{S}-0^{\circ}, 85^{\circ}-110^{\circ} \mathrm{E}\right) \mathrm{SST}$ time series d) Monthly standard deviations of the depth 
of the $20^{\circ} \mathrm{C}$ isotherm averaged over the eastern equatorial Indian Ocean $\left(2^{\circ} \mathrm{S}-2^{\circ} \mathrm{N}, 90^{\circ}-100^{\circ} \mathrm{E}\right)$ computed from SODA and the four configurations (e) Same as (d), but for the depth of $20^{\circ} \mathrm{C}$ over the Sumatra region $\left(10^{\circ}-2^{\circ} \mathrm{S}, 95^{\circ}-105^{\circ} \mathrm{E}\right)$ (f) Monthly standard deviations of latent heat flux averaged over the eastern node of IOD computed from OAFLUX dataset (Yu et al., 2008) and the four configurations of SINTEX-F2.

1278 Figure 9: (a) Power spectra of seasonally adjusted and detrended bi-monthly Niño-34 SST time series for observations (black line) 2h31 (red line) and 24h31 (green line) configurations (b) Same as (a) but for 2h301 (red line) and 24h301 (green line) configurations (c) Same as (a), but for the IOD index (d) Same as (b), but for the IOD index. The bottom axis of each panel is the period (unit: year), the left axis is variance (unit: ${ }^{\circ} \mathrm{C}^{2}$ ) and both axes are in logarithm scale. The power spectrum is estimated using a FFT algorithm on overlapping segments (Welch, 1967) and the 99\% confidence interval for the spectra estimated from the observations is plotted in black dashed lines in each panel.

Figure 10: (a) Sum of squared log-ratios of the power spectral densities (Chi2 statistic) of $2 \mathrm{~h} 31$ and $24 \mathrm{~h} 31$ grid-point SST time series over the Indo-Pacific region (color shading) for the periods between 14.4 and 72 months and associated 90\% confidence level for testing the hypothesis of a common spectrum for the two estimated spectra between $2 \mathrm{~h} 31$ and $24 \mathrm{~h} 31$ (b) Same as in (a), but for the $2 \mathrm{~h} 301$ and $24 \mathrm{~h} 301$ configurations.

1291 Figure 11: (a) Normalized power spectra of ISM rainfall time series for observations (black line) $2 \mathrm{~h} 31$ (red line) and $24 \mathrm{~h} 31$ (green line) configurations. The bottom axis is the period (unit: year), the left axis is variance (unit: $(\mathrm{mm} / \mathrm{day})^{2}$ ) and both axes are in logarithm scale. The power spectrum is estimated using a FFT algorithm on overlapping segments (Welch, 1967) and the $99 \%$ confidence interval for the spectra estimated from the observations is plotted in black dashed lines (b) Logarithm of the ratio of the power spectra of $2 \mathrm{~h} 31$ and $24 \mathrm{~h} 31$ and point-wise $90 \%$ confidence intervals for the logarithms of the spectral ratios for a postulated common spectrum of the ISM rainfall time series in $2 \mathrm{~h} 31$ and $24 \mathrm{~h} 31$ (c) and (d) Same as (a) and (b), respectively, but for the $2 \mathrm{~h} 301$ and $24 \mathrm{~h} 301$ configurations. (e), (f), (g) and (h) Same as (a), (b), (c) and (d), respectively, but for the boreal summer (JJAS) Niño-3.4 SST time series.

Figure 12: (a) Lead-lag correlations between ISM rainfall and monthly Niño-3.4 for observations (black line), 2h31 (blue line), 24h31 (green line), 2h301 (yellow line) and 24h301 (red line) configurations of SINTEX-F2, starting from the beginning of the previous year (e.g. year -1) to the end of the following year of the monsoon (e.g. year +1). IITM rainfall and HadISST datasets for the period 1900-2005 are used to estimate the correlation coefficients. X-axis indicates calendar month for a 36 months period starting one year before the developing year of ISM and Y-axis is the amplitude of the correlation. Thus, the coefficients corresponding to $-1,0,+1$ month lags refer, respectively, to the correlations between (JJAS) ISM rainfall in year 0 and may, june and july Niño-34 SST index, also during year 0, and so on. (b) Same as (a) but, between ISM rainfall and the monthly IOD index. Diamond symbols indicate correlations that are above the $95 \%$ significance confidence level according to a phase-scramble bootstrap test (Ebisuzaki, 1997).

1314 Figure 13: Lagged correlations between bi-monthly averaged Indo-Pacific SSTs and the 1315 December-January Niño-3.4 SST for the HadISST. The correlations are calculated beginning 
1316 in February-March, prior to the El Niño onset, and ending in December-January at the peak 1317 season of El Niño events. Correlations that are above the 95\% significance confidence level 1318 according to a phase-scramble bootstrap test (Ebisuzaki, 1997) are underlined.

1319 Figure 14: Same as Fig. 13, but for 2h31 configuration.

1320 Figure 15: Same as Fig. 13, but for 24h31 configuration. 


\section{Table captions}

1324

1325 Table 1: Summary of the numerical experiments with their main characteristics, including

1326 length, horizontal and vertical resolutions and frequency of coupling for the different air-sea 1327 fluxes.

1328

1329 Table 2: Standard-deviations (in ${ }^{\circ} \mathrm{C}$ ) of Niño-3.4, IOD, Eastern (EIOD) and Western (WIOD) 1330 nodes of IOD bi-monthly SST time series in the four runs and HadISST dataset (1958-2008).

1331 These values are computed after the removal of the long-term mean annual cycle and the 1332 contribution of timescales longer than 20 years.

1333

1334 Table 3: Comparison of means and standard-deviations (in $\mathrm{mm} / \mathrm{day}$ ) of ISM rainfall in the 1335 SINTEX runs and CMAP (period 1979-2008) for land only, land-sea and ocean only averages 1336 in the domain $8^{\circ}-35^{\circ} \mathrm{N}$ and $65^{\circ}-95^{\circ} \mathrm{E}$.

1337

1338

1339

1340

1341 
1343 Table 1

\begin{tabular}{|c|c|c|c|c|}
\hline Experience name & $\mathbf{2 h 3 1}$ & $\mathbf{2 4 h 3 1}$ & $\mathbf{2 h 3 0 1}$ & $\mathbf{2 4 h 3 0 1}$ \\
\hline Oceanic vertical resolution & $31(10 \mathrm{~m})$ & $31(10 \mathrm{~m})$ & $301(1 \mathrm{~m})$ & $301(1 \mathrm{~m})$ \\
\hline SST coupling frequency & $2 \mathrm{~h}$ & $24 \mathrm{~h}$ & $2 \mathrm{~h}$ & $24 \mathrm{~h}$ \\
\hline Other data coupling frequency & $2 \mathrm{~h}$ & $2 \mathrm{~h}$ & $2 \mathrm{~h}$ & $2 \mathrm{~h}$ \\
\hline Experience length (in years) & 110 & 110 & 75 & 75 \\
\hline
\end{tabular}

1344

1345

1346

Table 2

\begin{tabular}{|l|c|c|c|c|c|}
\hline Indices/Configs & $\mathbf{2 h 3 1}$ & $\mathbf{2 4 h 3 1}$ & $\mathbf{2 h 3 0 1}$ & $\mathbf{2 4 h 3 0 1}$ & HADiSST \\
\hline Niño-34 SST & 0.87 & 0.71 & 0.68 & 0.59 & 0.70 \\
\hline IOD & 0.51 & 0.49 & 0.44 & 0.45 & 0.26 \\
\hline EIOD & 0.50 & 0.47 & 0.45 & 0.42 & 0.23 \\
\hline WIOD & 0.26 & 0.26 & 0.23 & 0.22 & 0.21 \\
\hline
\end{tabular}

1347

1348

1349

Table3

\begin{tabular}{|l|l|l|l|l|l|l|}
\hline Configuration & \multicolumn{2}{|c|}{ Land-average } & \multicolumn{2}{c|}{ Land-Ocean-average } & \multicolumn{2}{c|}{ Ocean-average } \\
\hline & Mean & SD & Mean & SD & Mean & SD \\
\hline CMAP & 4.73 & 0.45 & 6.94 & 0.54 & 9.69 & 0.91 \\
\hline $2 \mathrm{~h} 31$ & 4.58 & 0.43 & 6.65 & 0.59 & 10.52 & 1.03 \\
\hline $24 \mathrm{~h} 31$ & 4.21 & 0.38 & 6.07 & 0.39 & 9.18 & 0.73 \\
\hline $2 \mathrm{~h} 301$ & 4.12 & 0.35 & 5.99 & 0.32 & 9.13 & 0.57 \\
\hline $24 \mathrm{~h} 301$ & 4.15 & 0.38 & 5.98 & 0.49 & 9.05 & 0.78 \\
\hline
\end{tabular}




\section{Figure 2}

HadISST - Boreal summer climatology
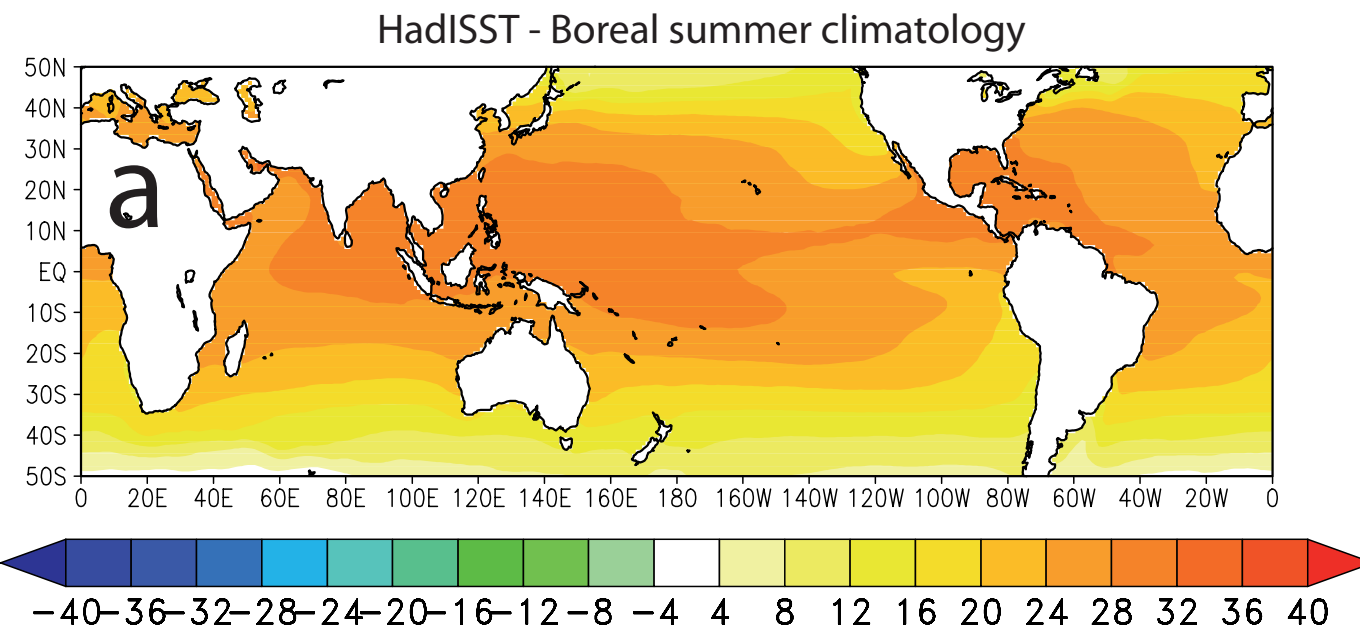

2h31 - HadISST SST $\left({ }^{\circ} \mathrm{C}\right)$

2h301 - HadISST

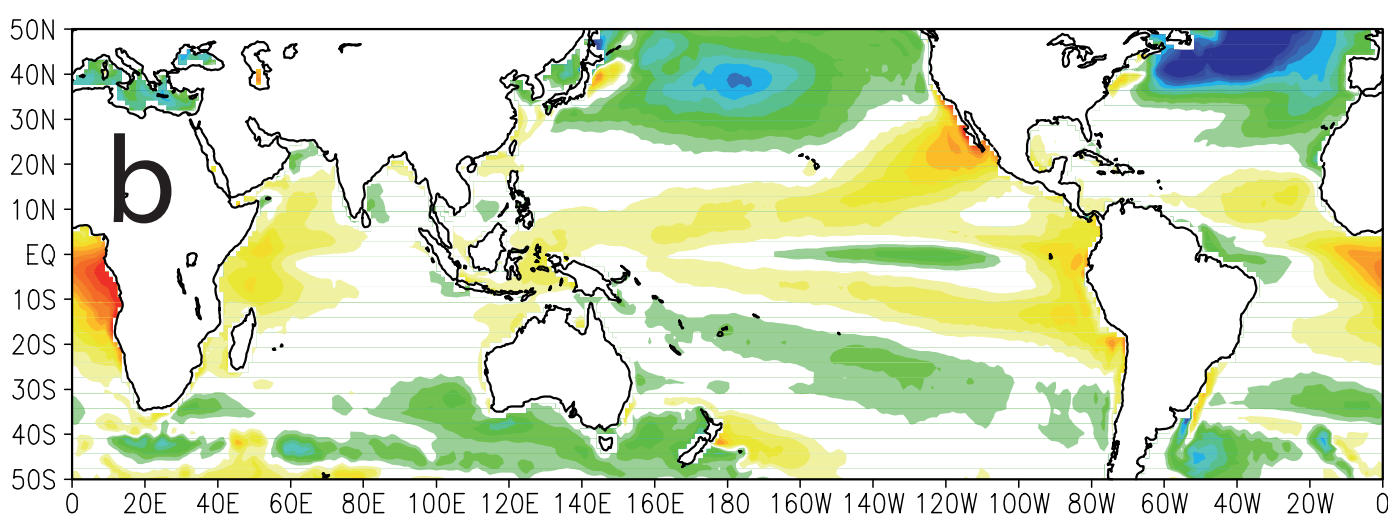

24h31 - HadISST
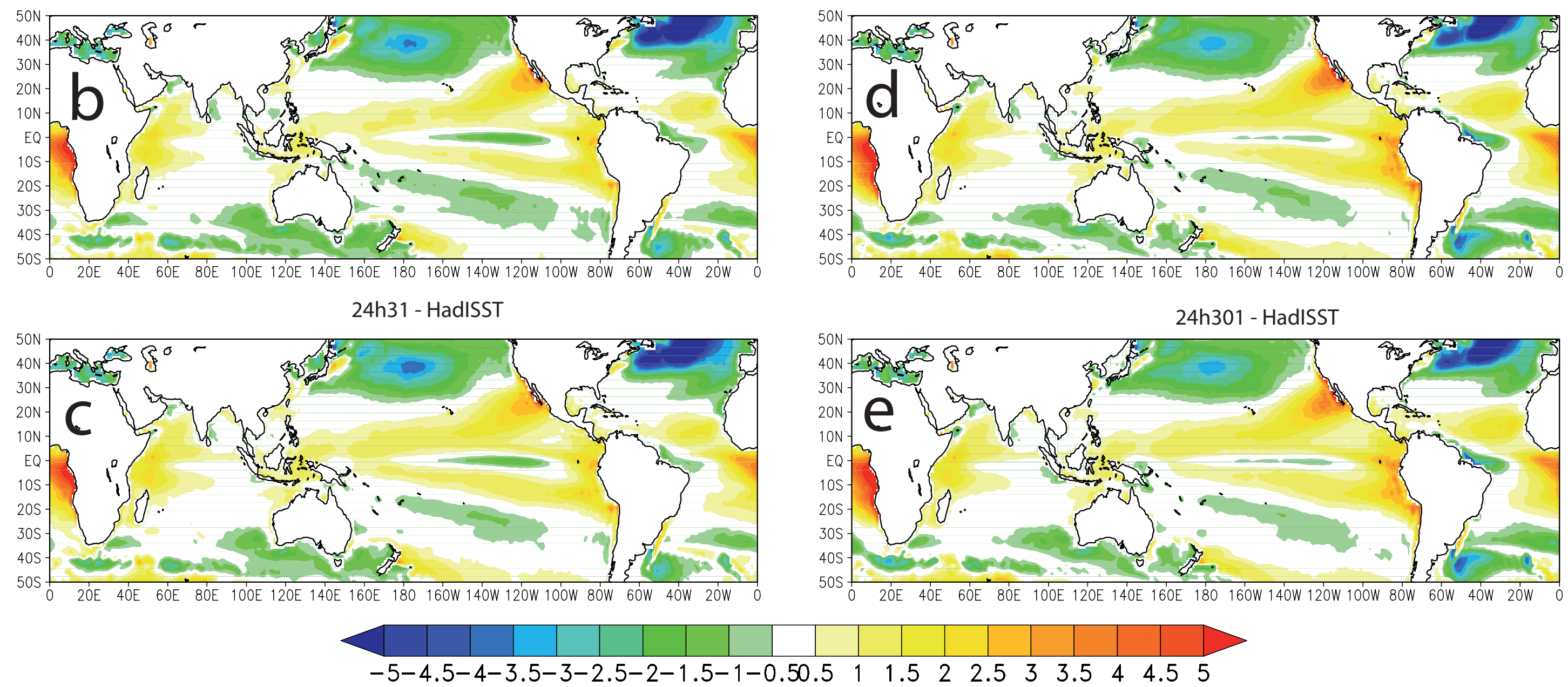

SST bias $\left({ }^{\circ} \mathrm{C}\right)$ 
Figure 3

a

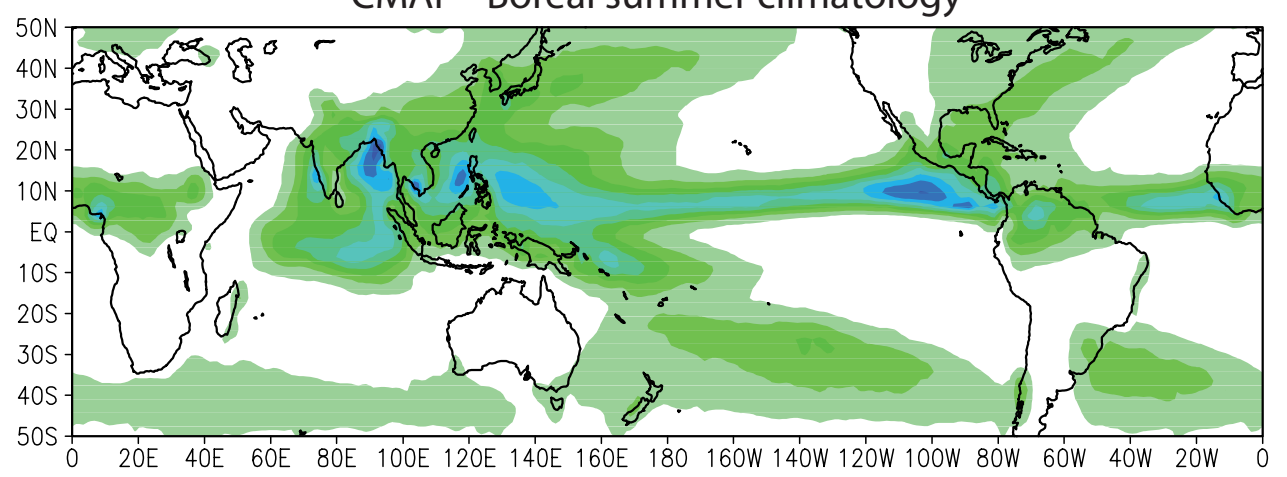

b

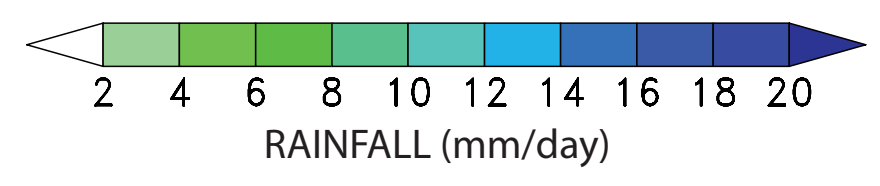

2h31 - CMAP

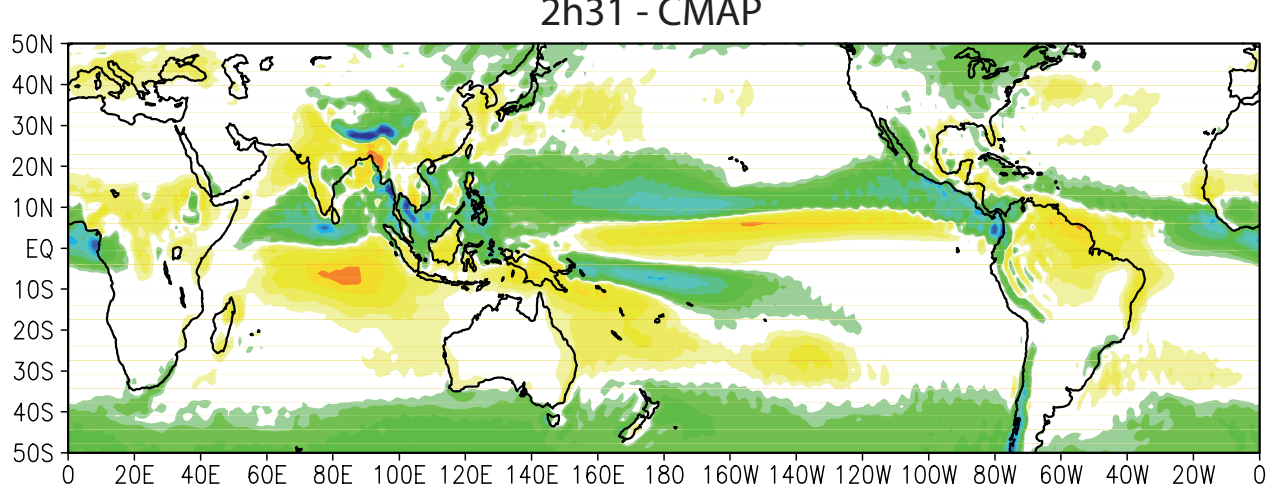

C

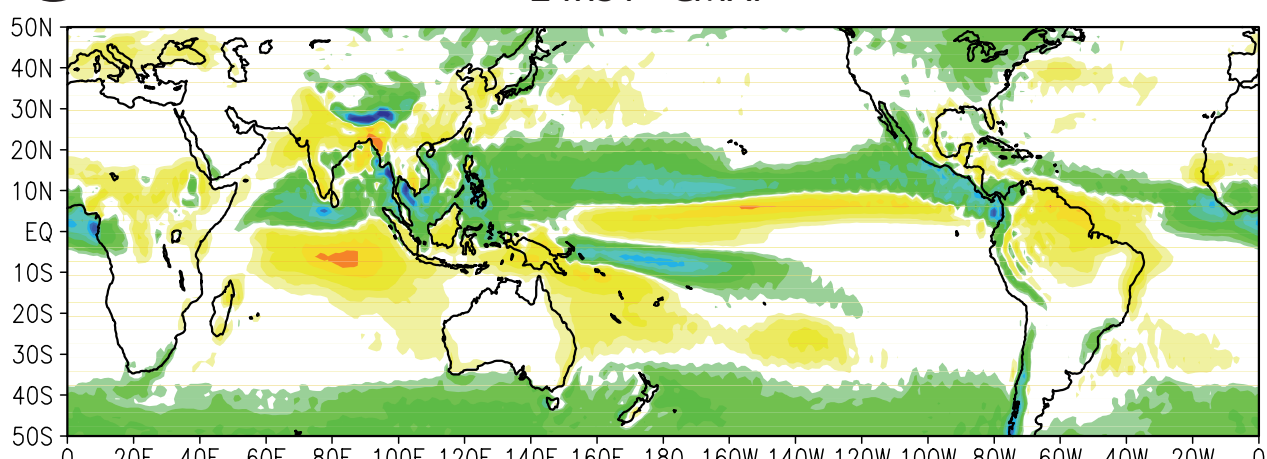

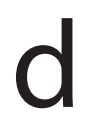
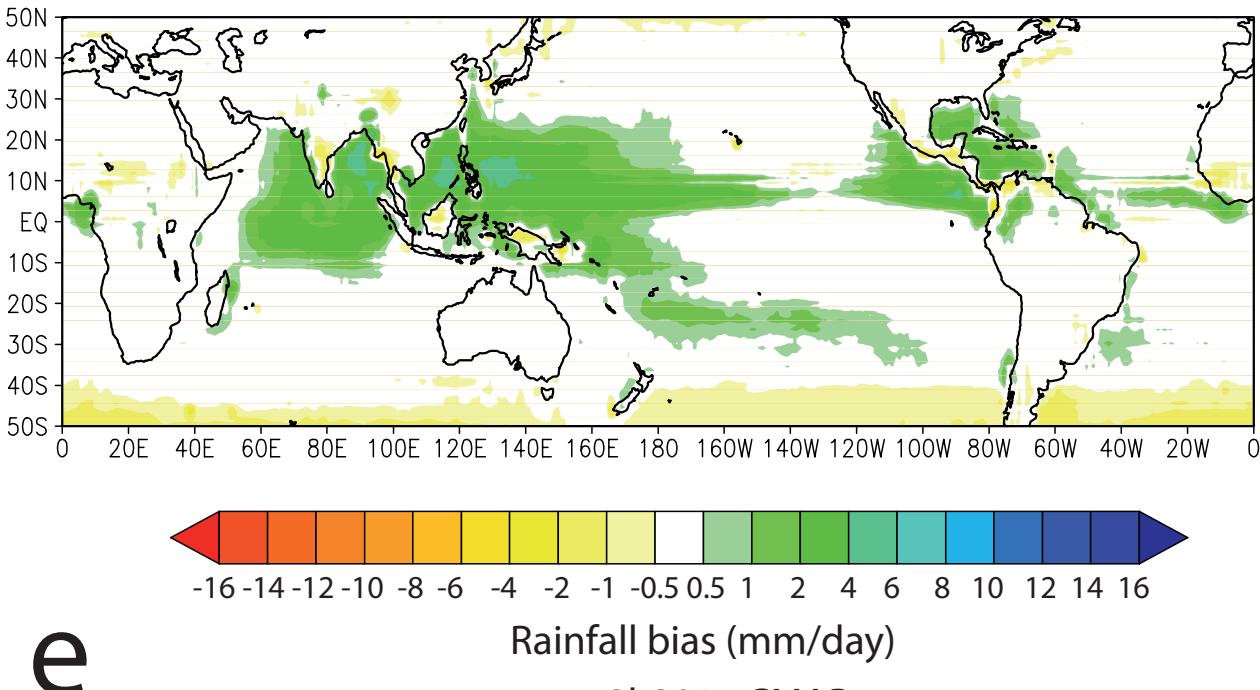
2h301 - CMAP
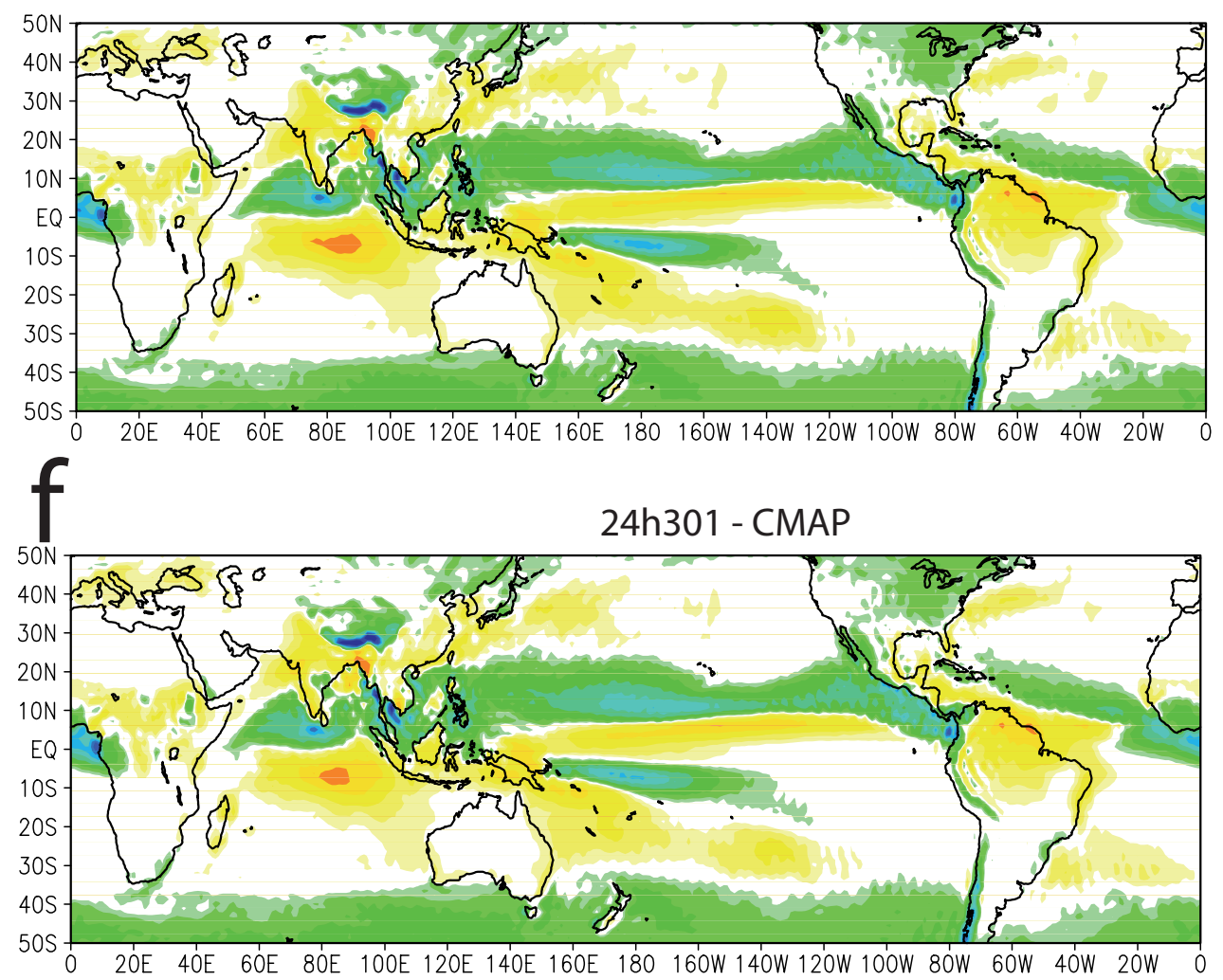

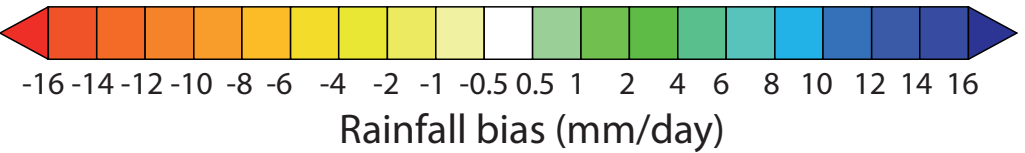

Rainfall bias ( $\mathrm{mm} /$ day) 


\section{Figure 4}

2 $850 \mathrm{hPa}$ NCEP wind - Boreal summer climatology
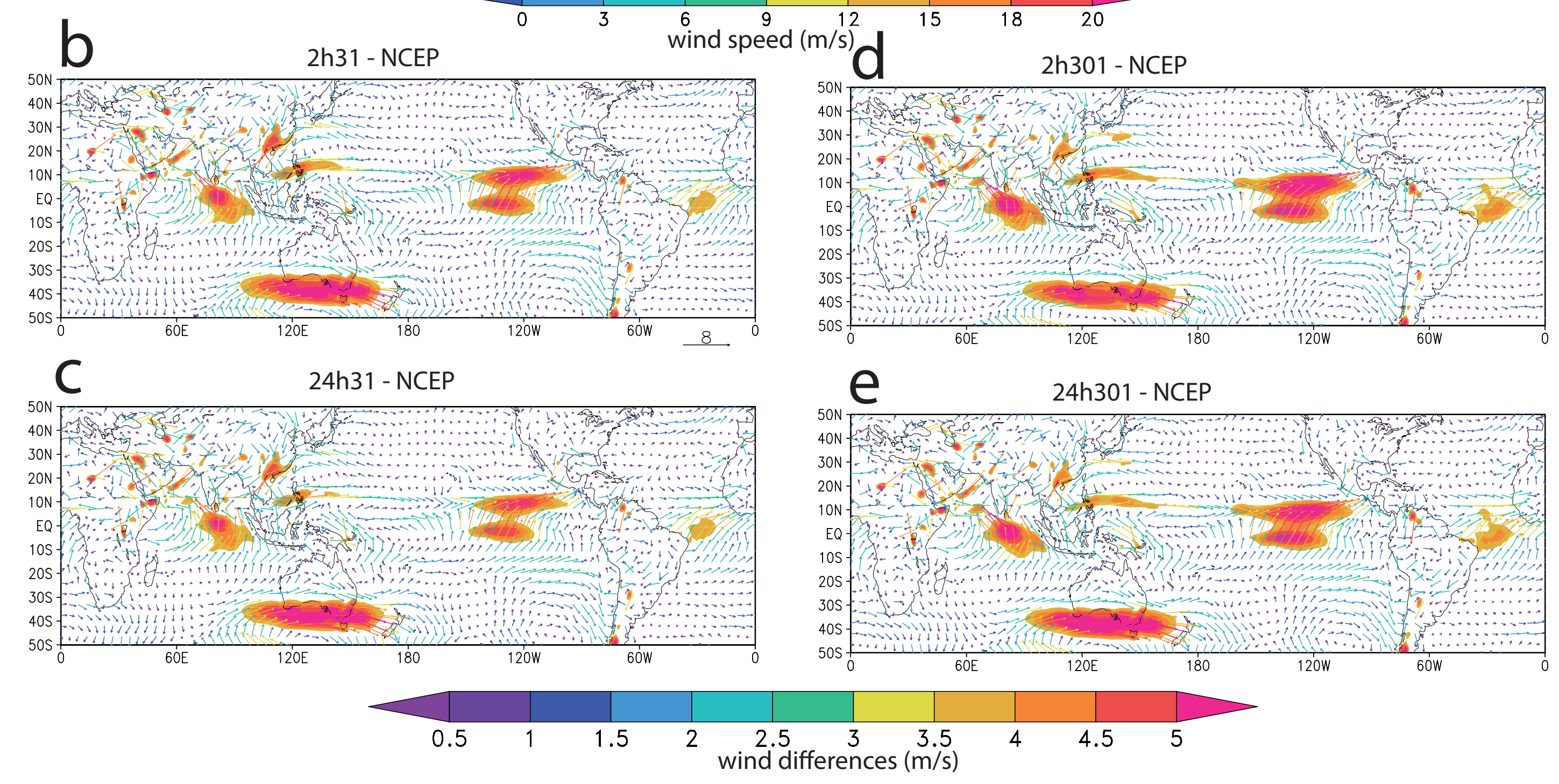
Figure 5

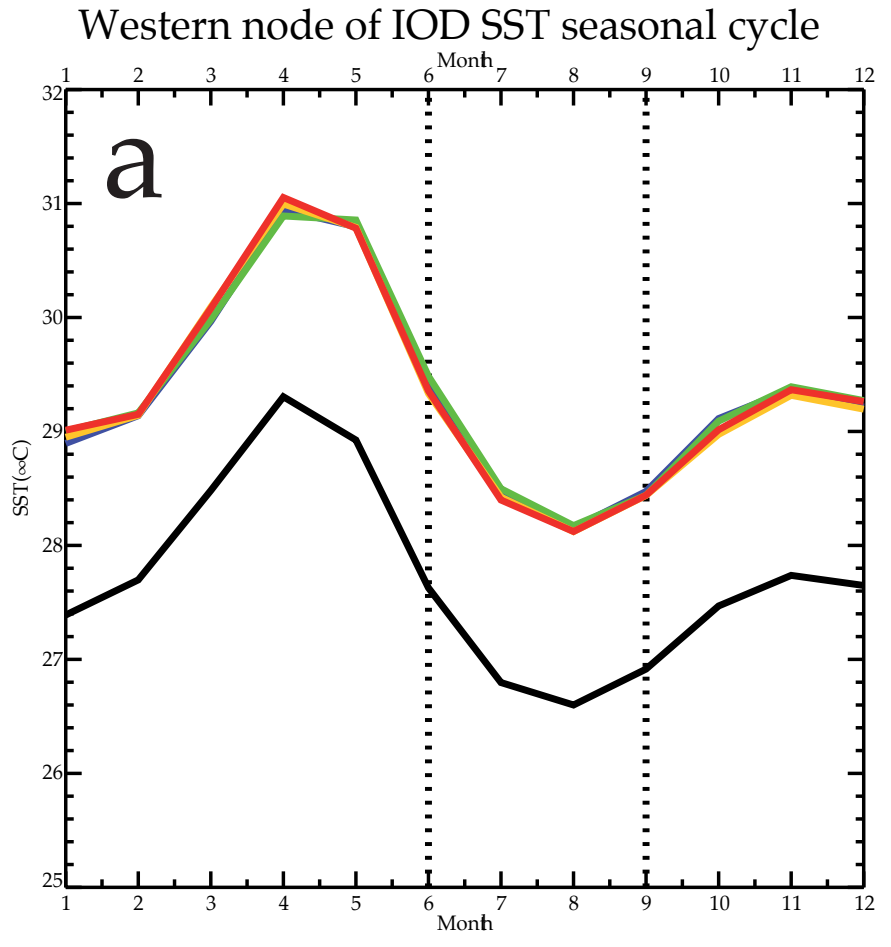

Eastern node of IOD SST seasonal cycle

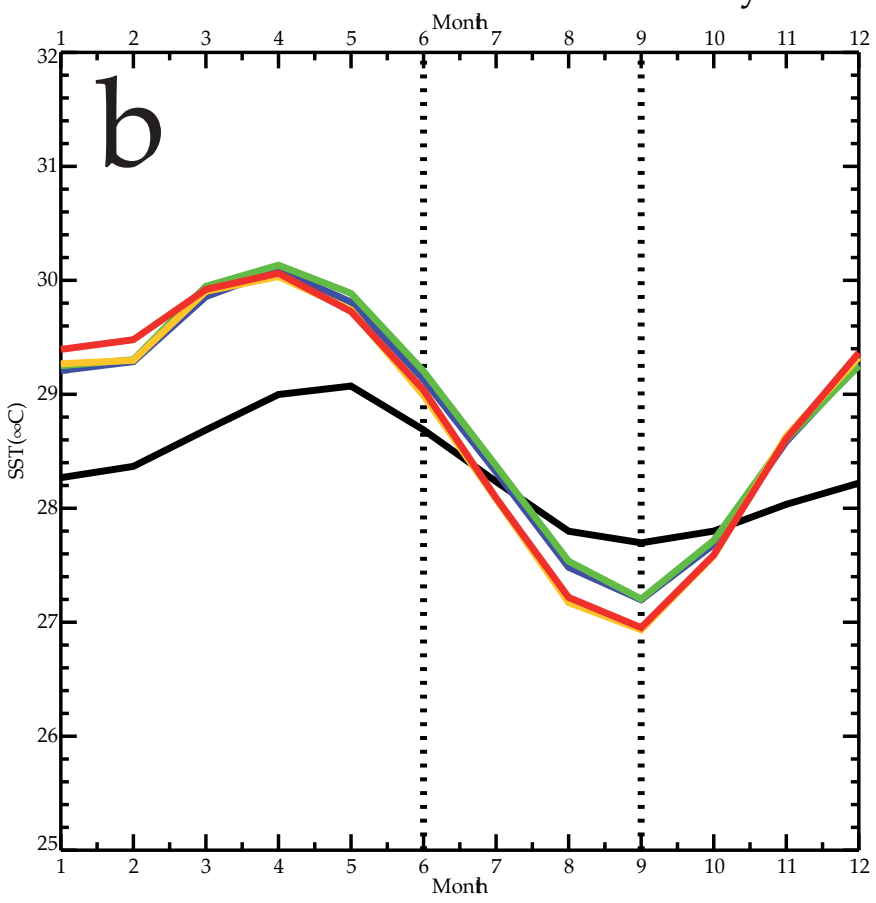

Eastern equatorial Indian Ocean Z20 seasonal cycle

Sumatra Z20 seasonal cycle
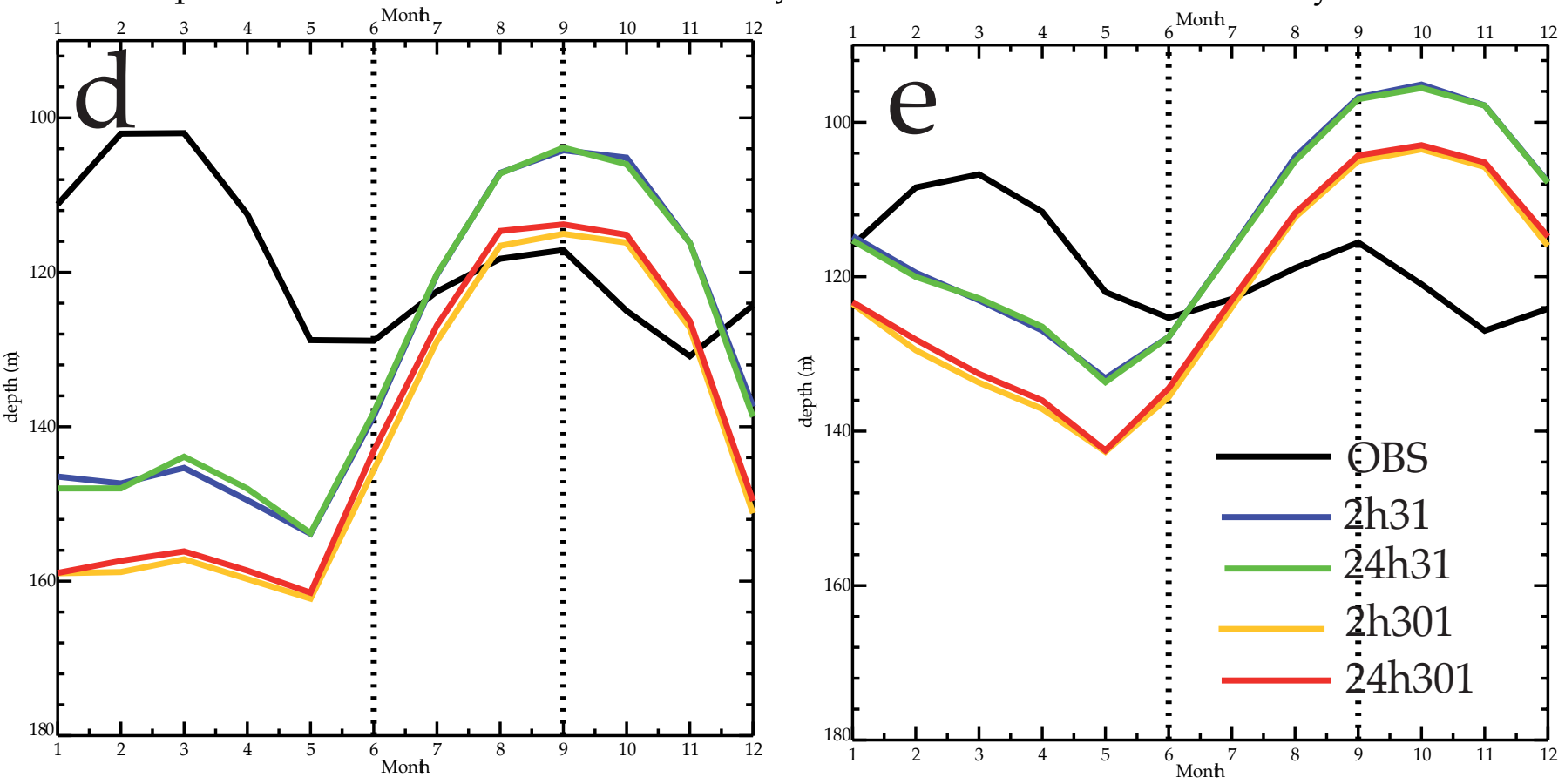

IOD SST seasonal cycle

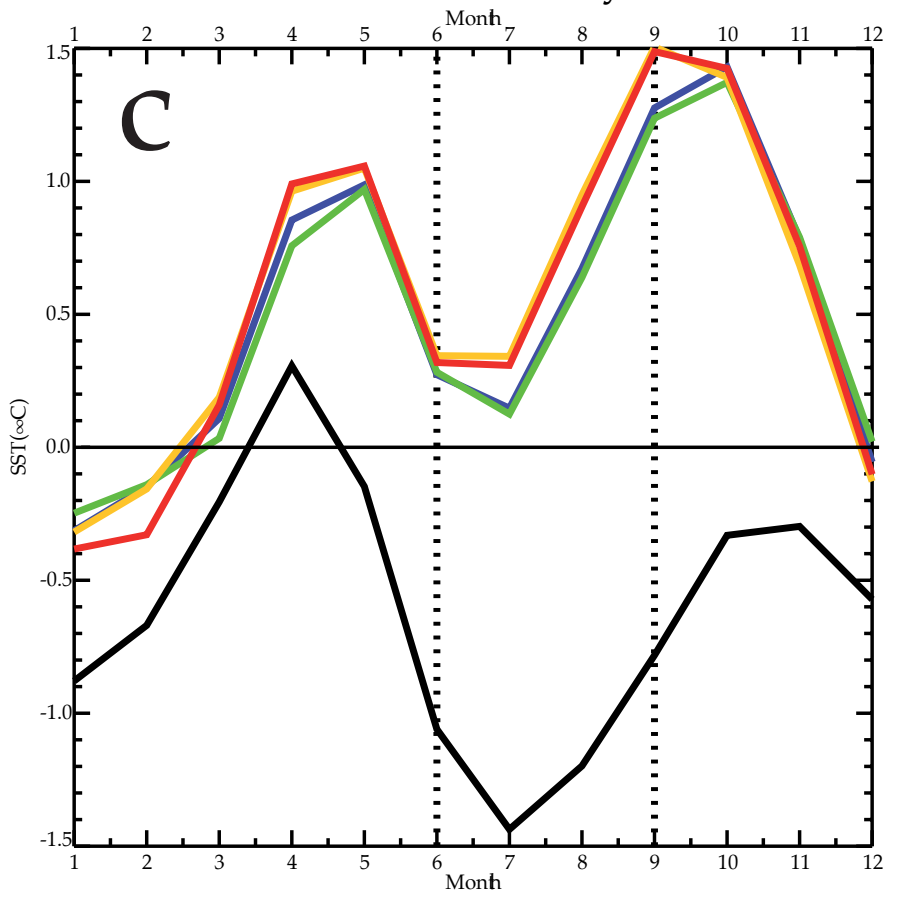

Eastern node of IOD Latent heat seasonal cycle

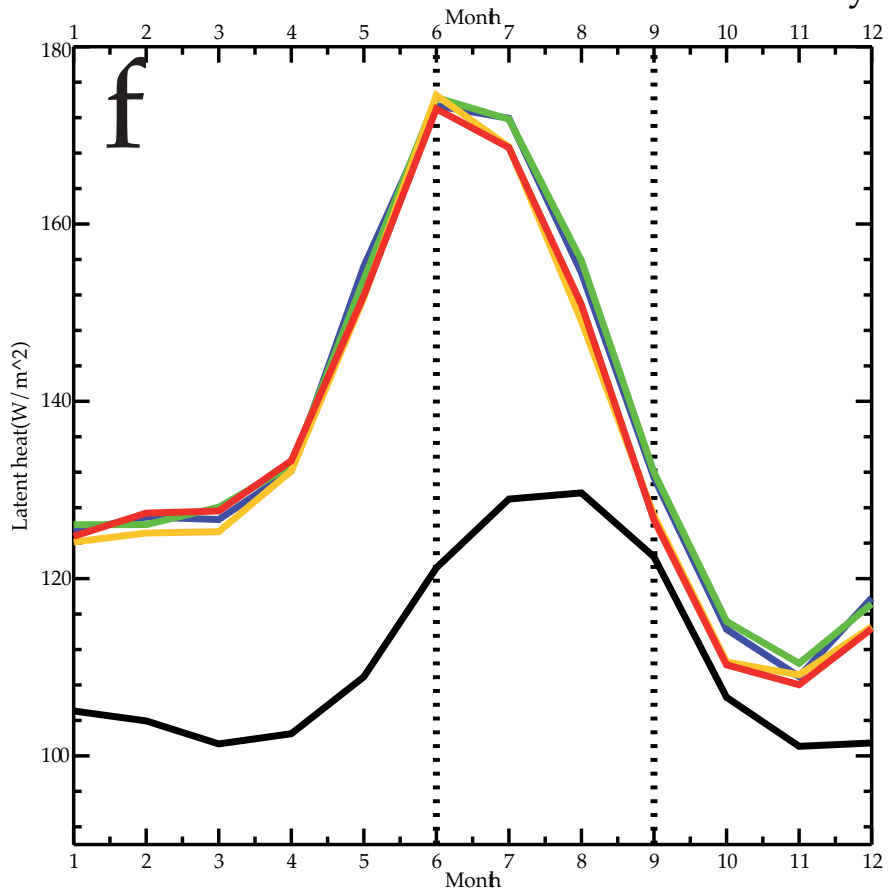


Figure 6

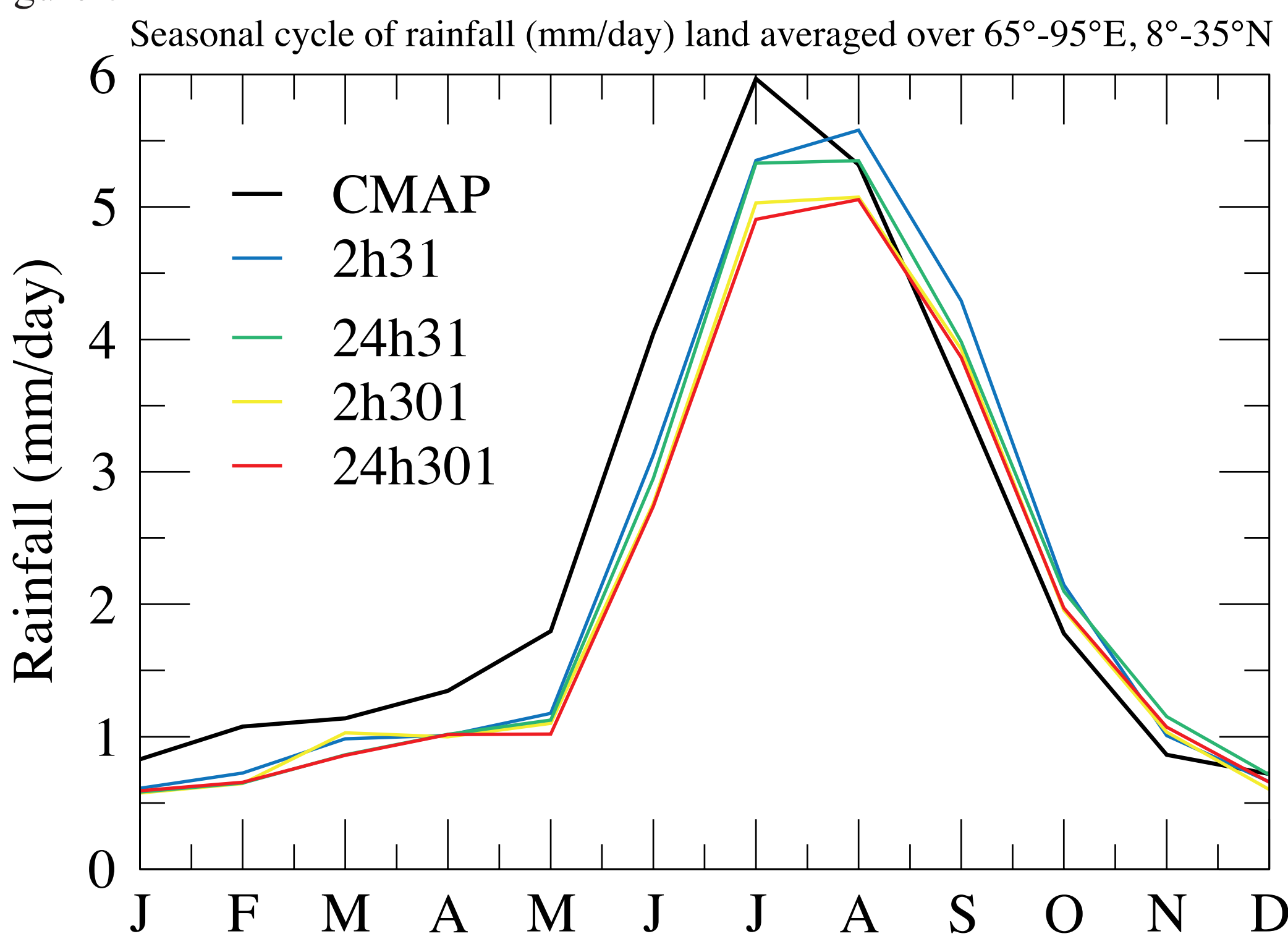


a)

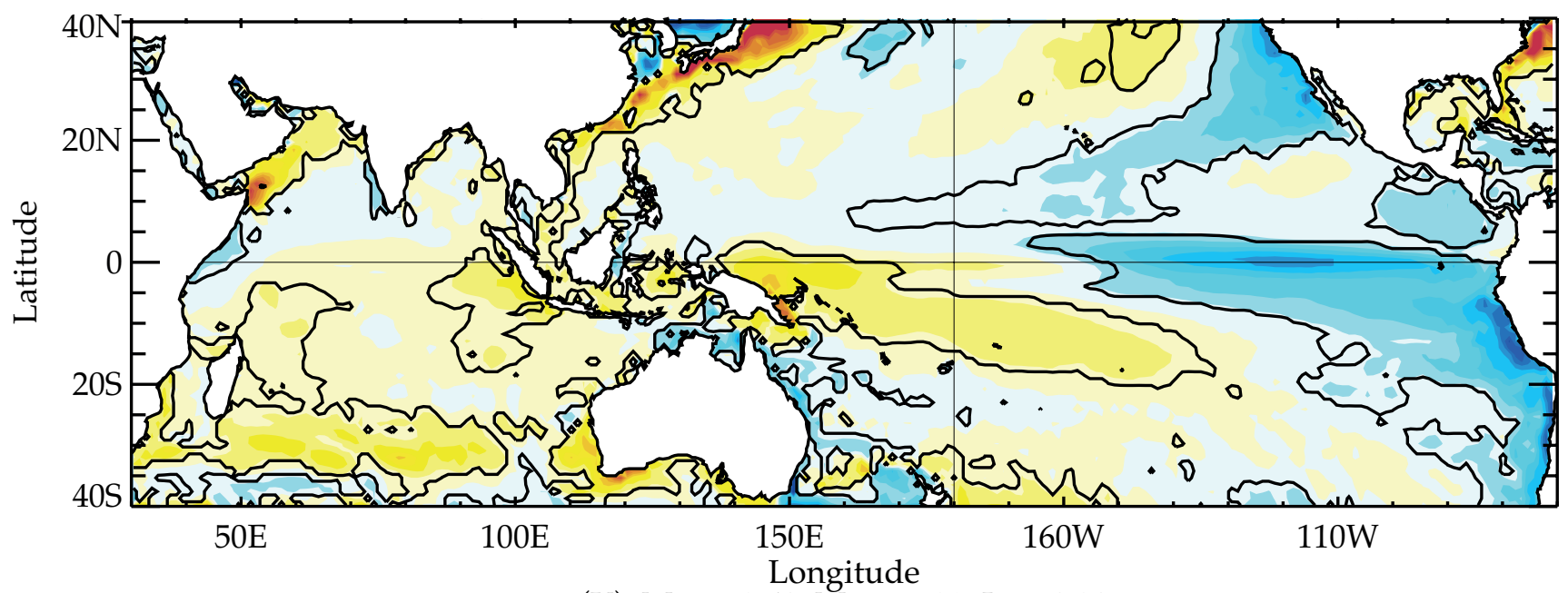

$(\mathrm{K}): \operatorname{Min}=-2.60, \operatorname{Max}=5.29, \mathrm{Int}=0.20$

$\begin{array}{lllllllllll}-2.0 & -1.6 & -1.2 & -0.8 & -0.4 & 0.0 & 0.4 & 0.8 & 1.2 & 1.6 & 2.0\end{array}$

b)

SST (K)

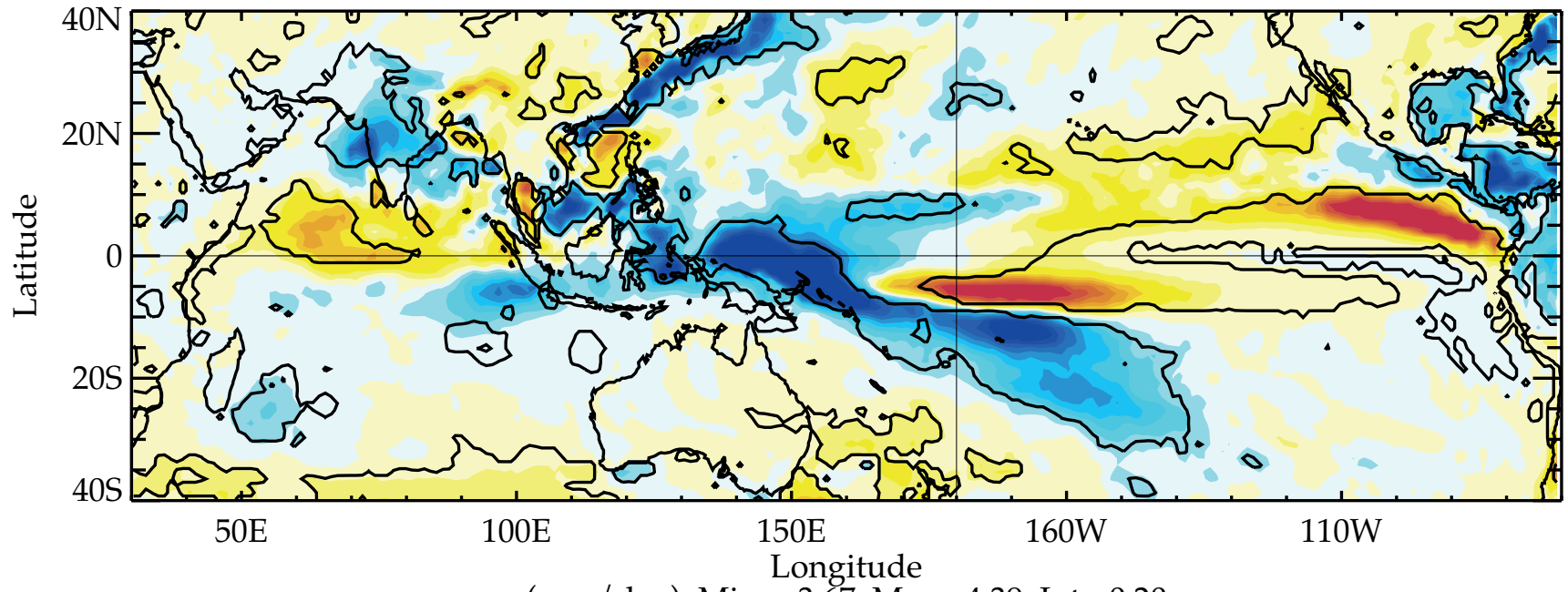

$(\mathrm{mm} /$ day $): \operatorname{Min}=-3.67, \operatorname{Max}=4.39, \mathrm{Int}=0.20$

$\begin{array}{lllllllllll}-2.0 & -1.6 & -1.2 & -0.8 & -0.4 & 0.0 & 0.4 & 0.8 & 1.2 & 1.6 & 2.0\end{array}$

C) Rainfall ( $\mathrm{mm} /$ day)

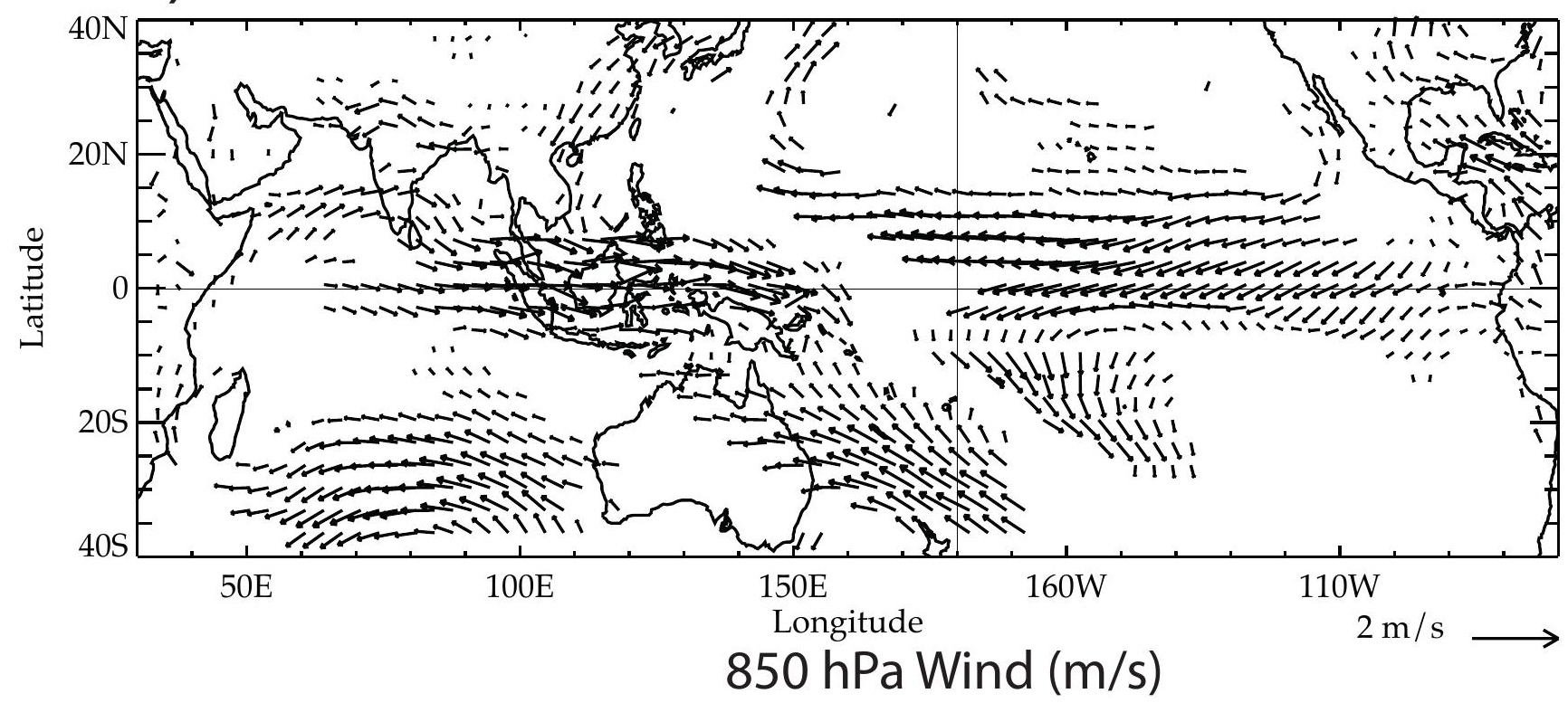



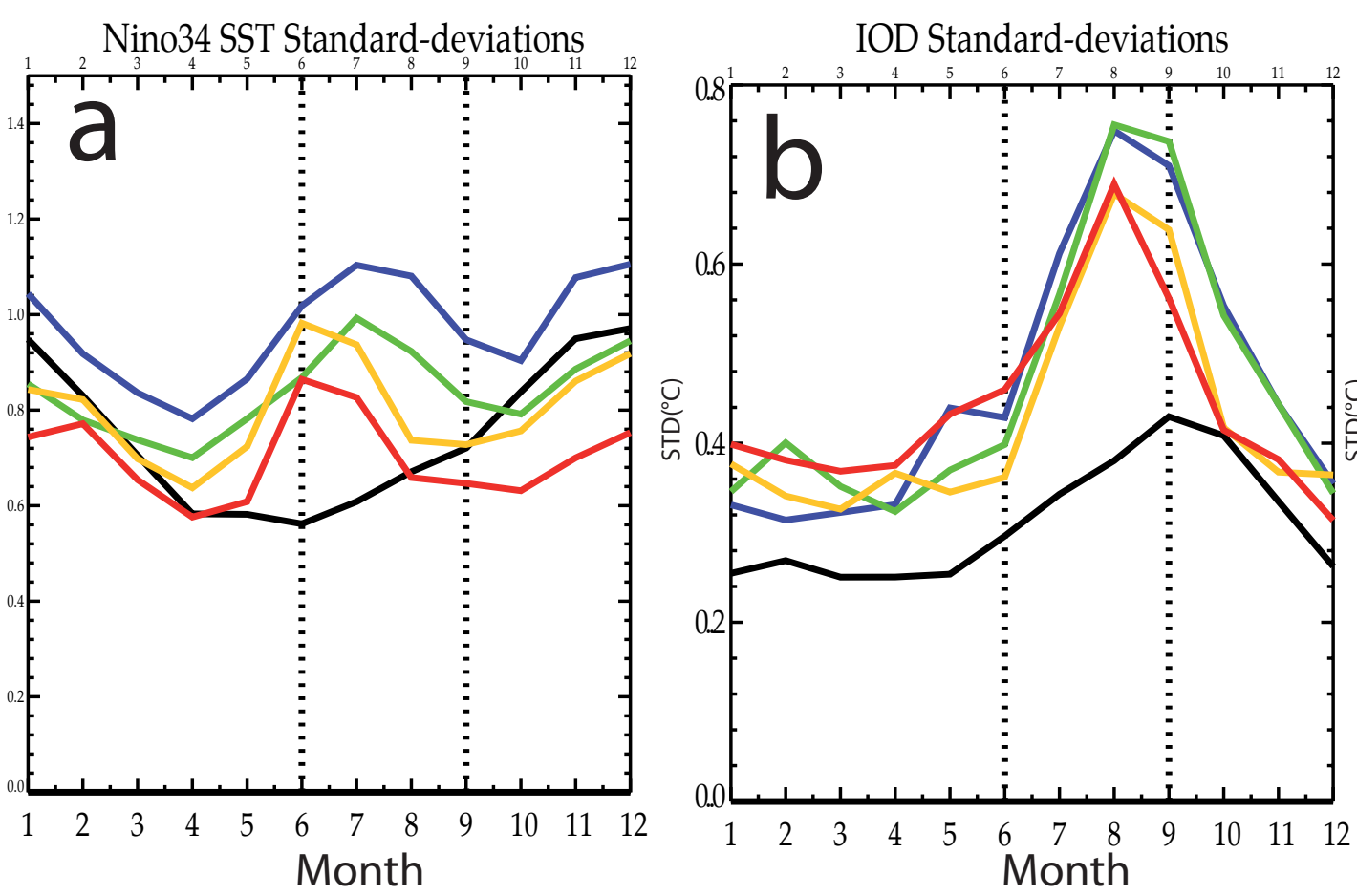

Eastern Indian Ocean Z20 Standard-deviations

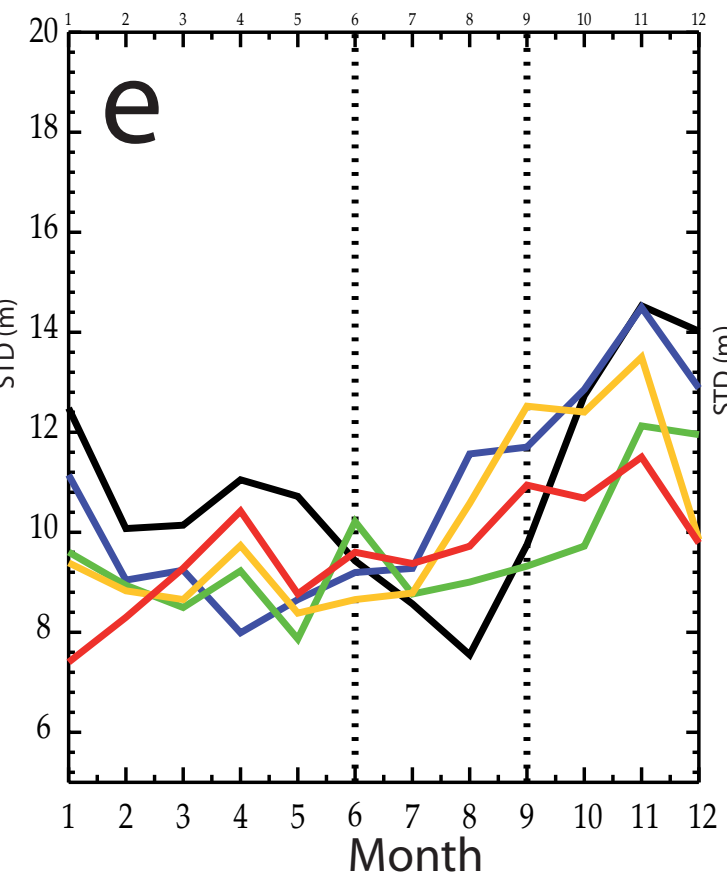

Western node of IOD Standard-deviations

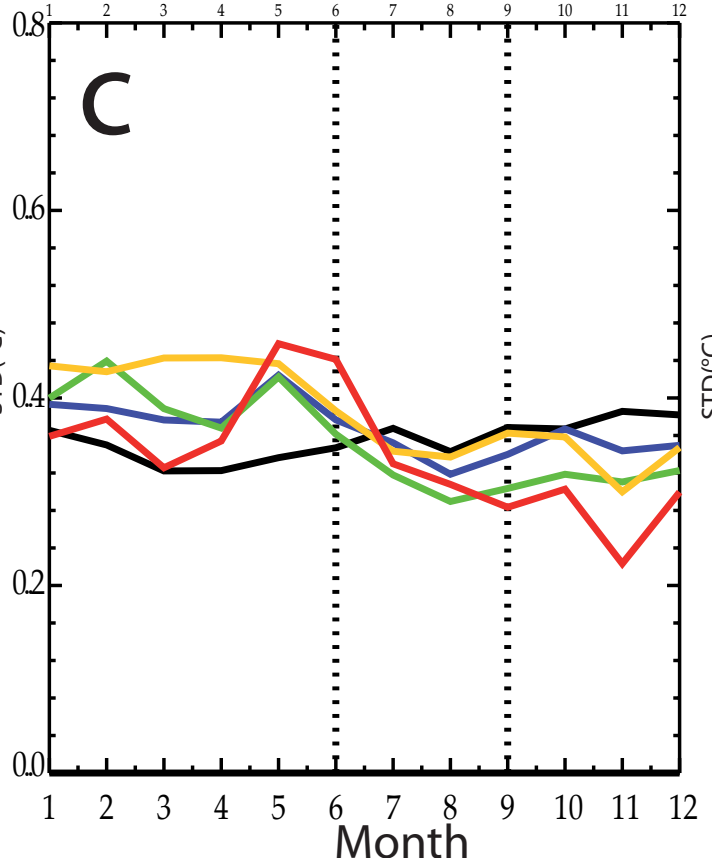

Eastern node of IOD Standard-deviations

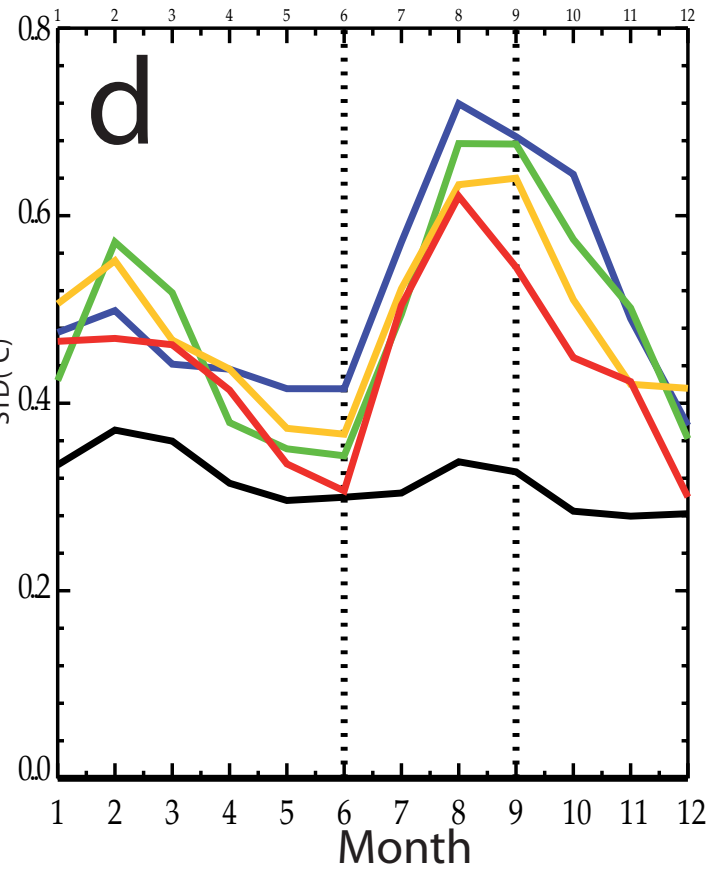

Eastern node of IOD LH Standard-deviations

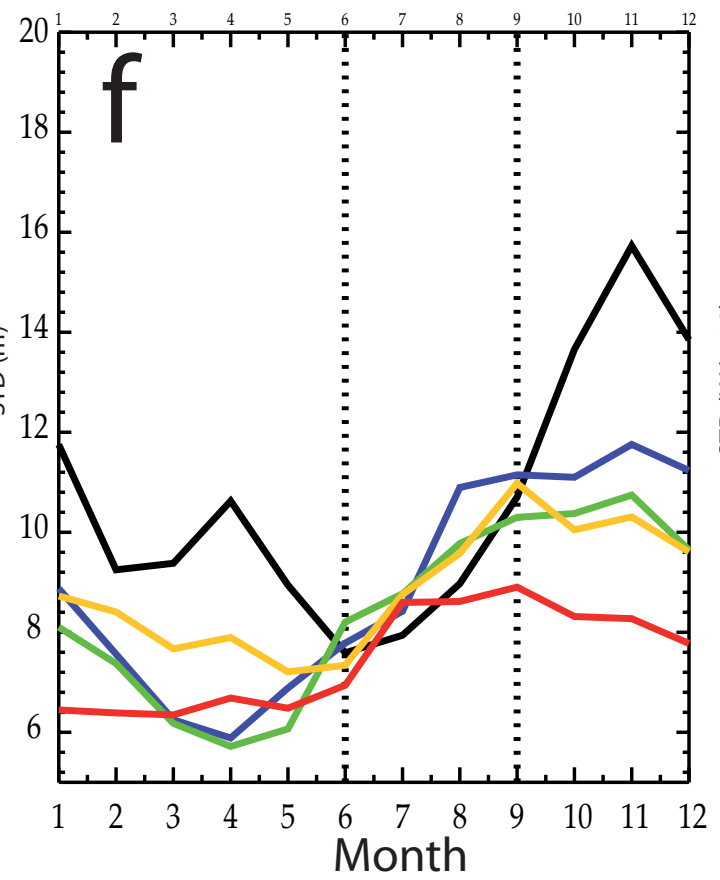

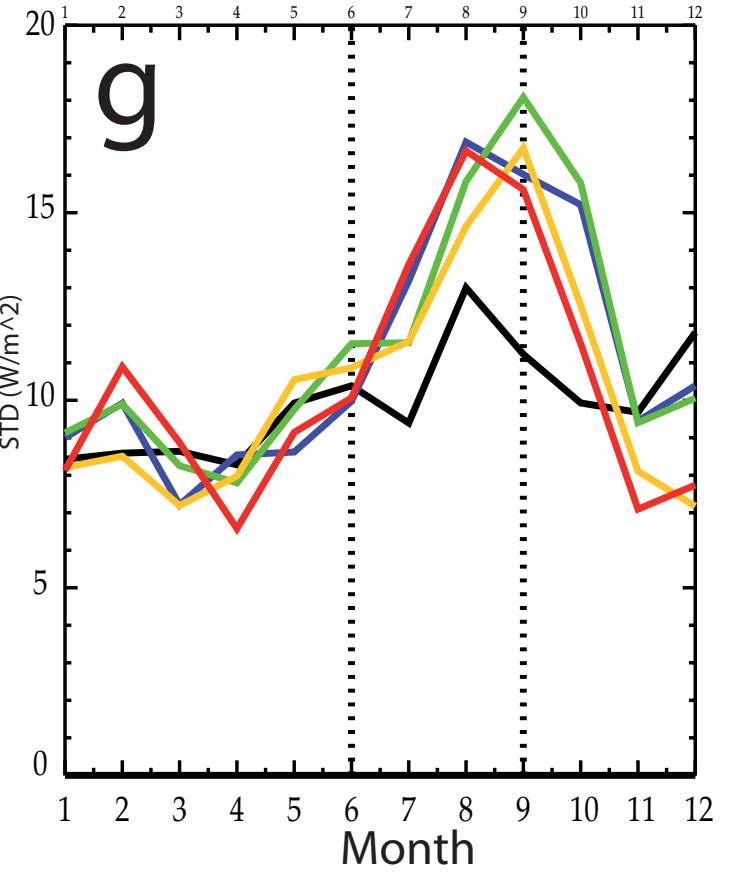



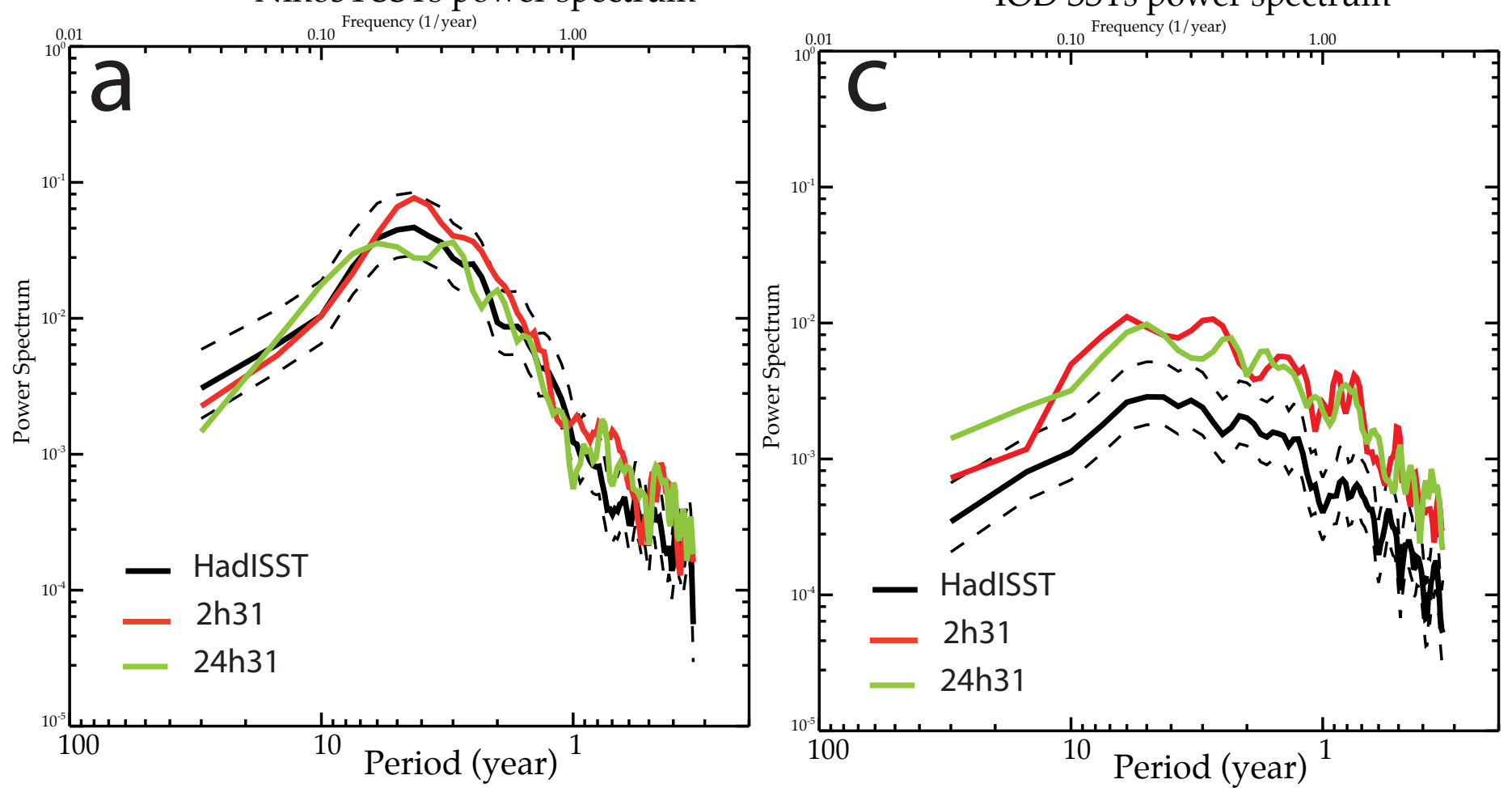

Nino34 SSTs power spectrum
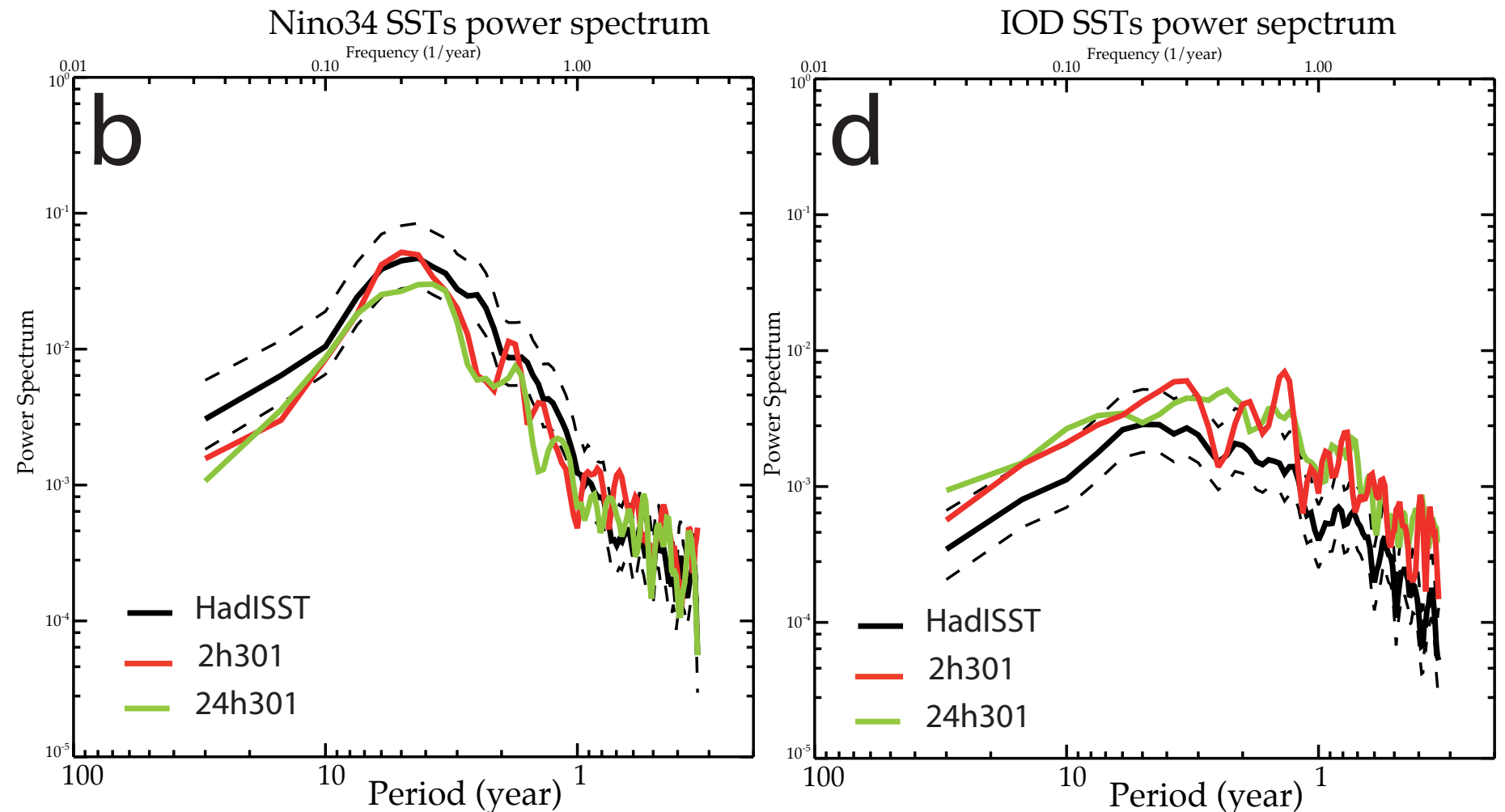
Figure 10

Spectrum difference - SST - SINTEX - 2h31 vs $24 \mathrm{~h} 31$

a

$10 \%$ probability significance level

chi2 statistic (periods : 14.4 - 72.0 months)

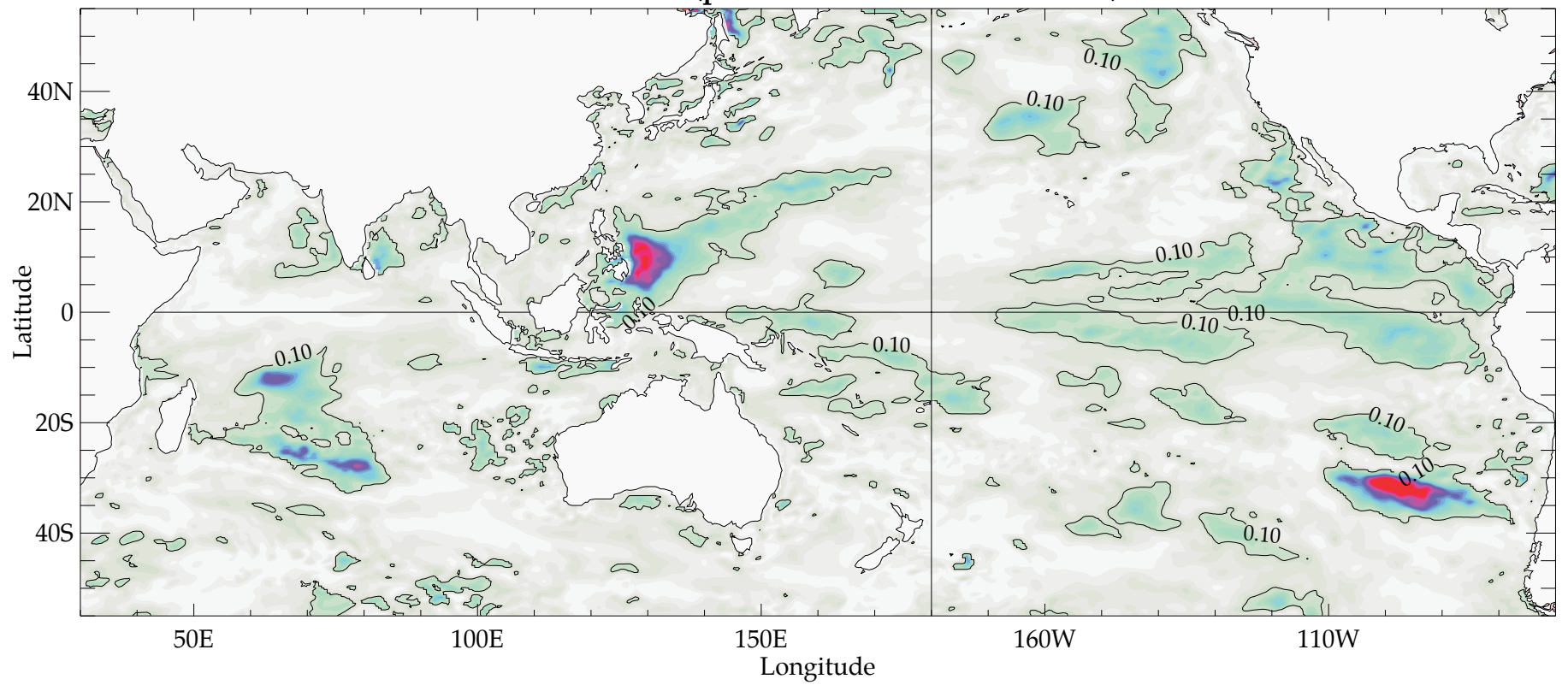

Spectrum difference - SST - SINTEX - 2h301 vs 24 h301

b

$10 \%$ probability significance level

chi2 statistic (periods : 14.4 - 72.0 months)
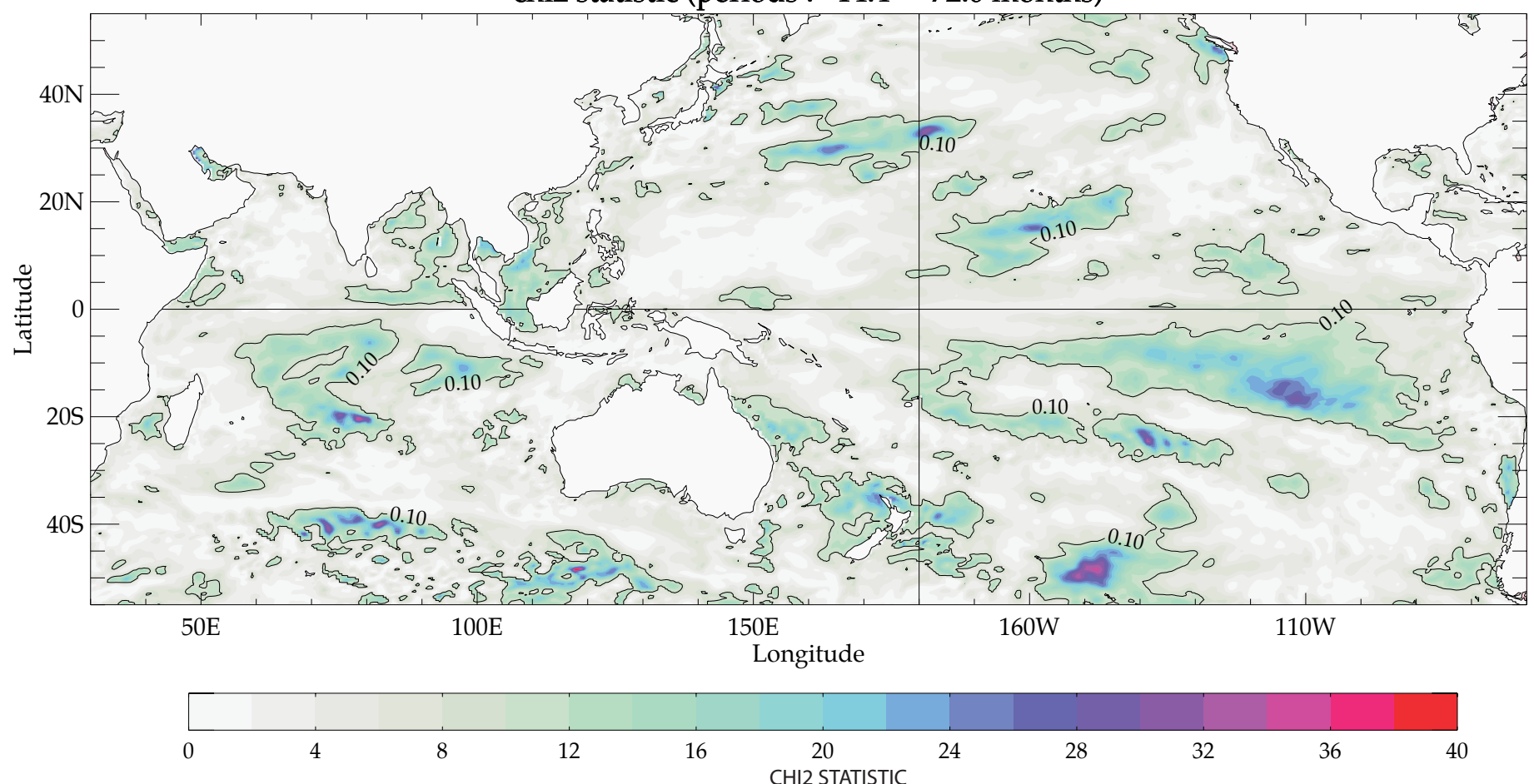
Figure 11
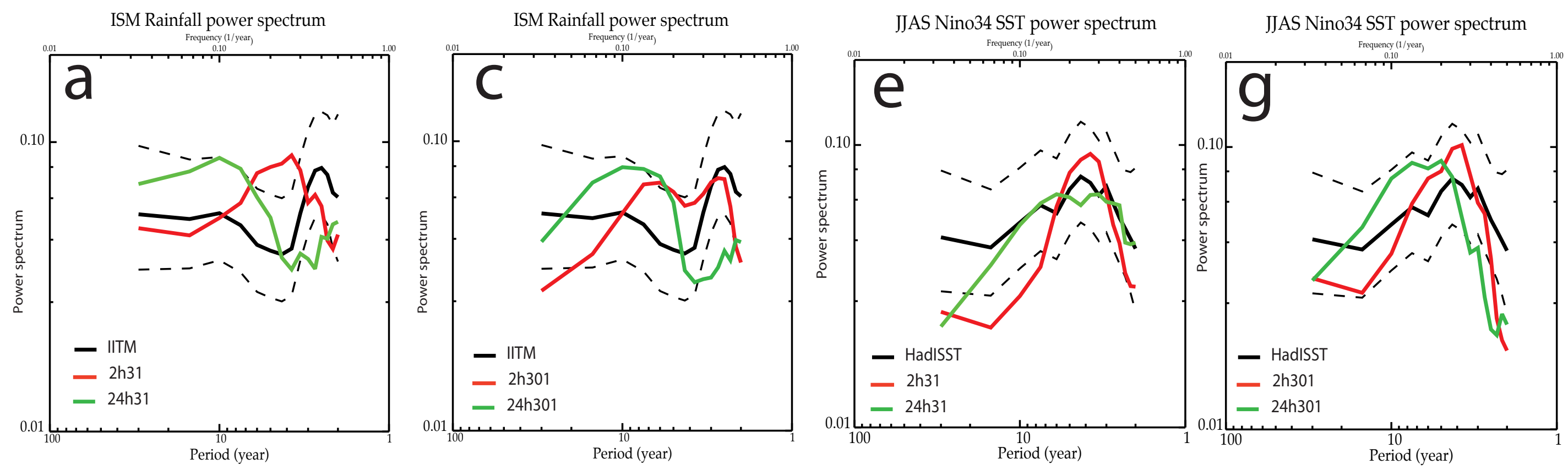

2h31/24h31 log spectral ratio ISM Rainfall

2h301/24h301 log spectral ratio ISM Rainfall

2h31/24h31 log spectral ratio JJAS Nino34 SST
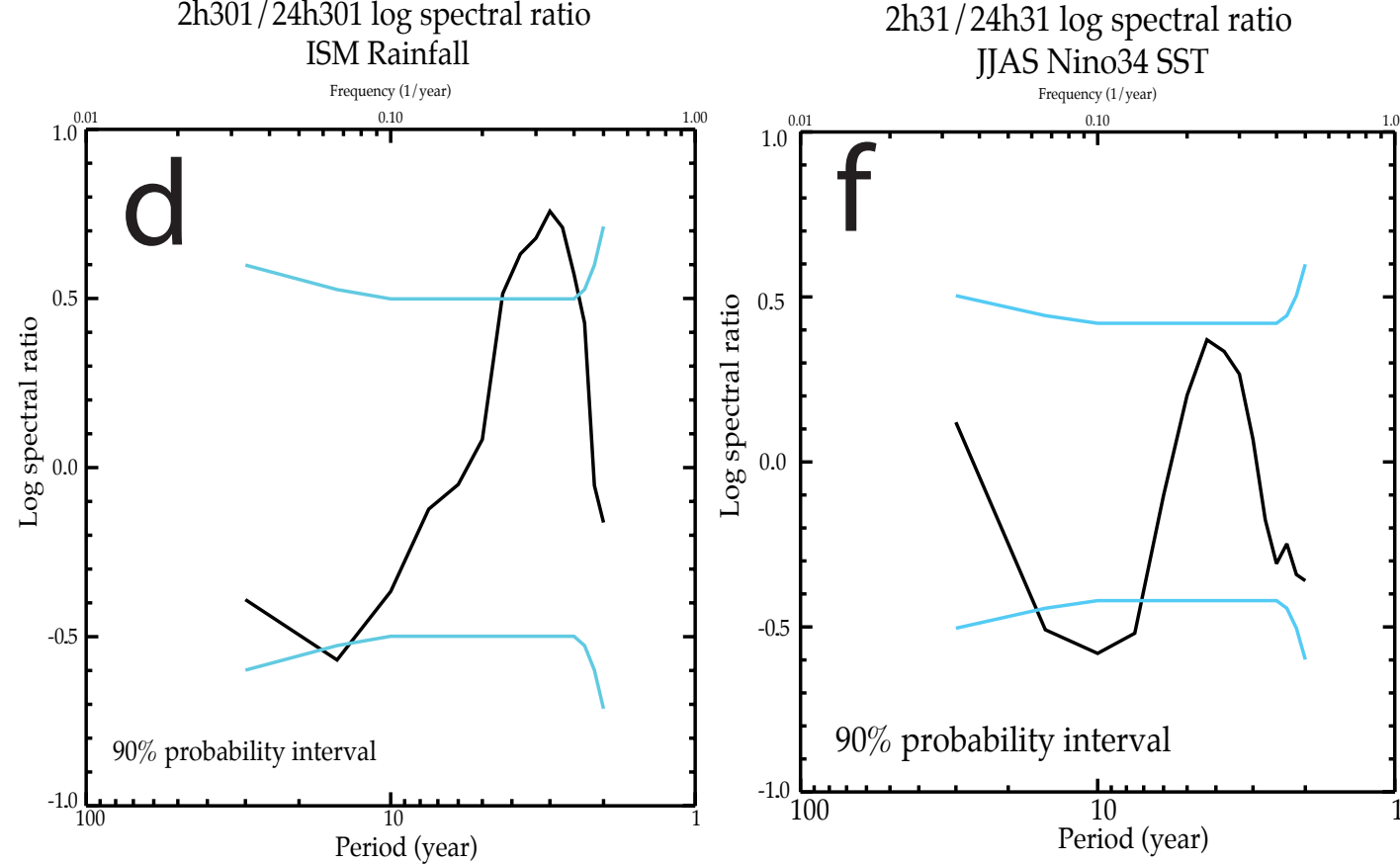

2h301/ $24 \mathrm{~h} 301 \log$ spectral ratio JJAS Nino34 SST

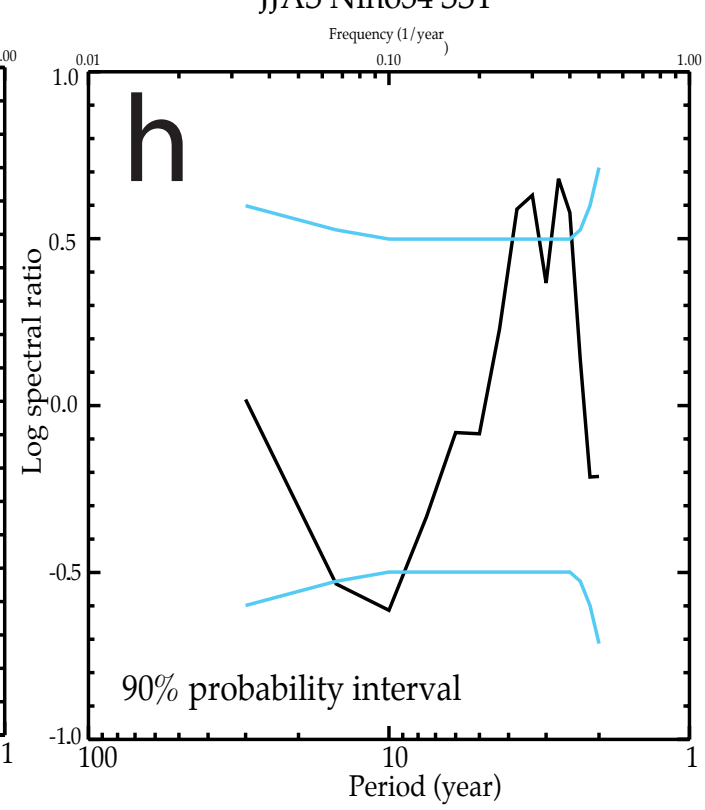


a

Lead-lag correlations for Monthly Nino34 SST index vs ISMR Lags (Months)

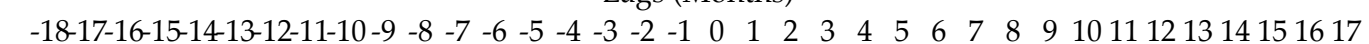
\begin{tabular}{c:c:c}
\hline year -1 & year $\mathbf{0}$ & year +1
\end{tabular}

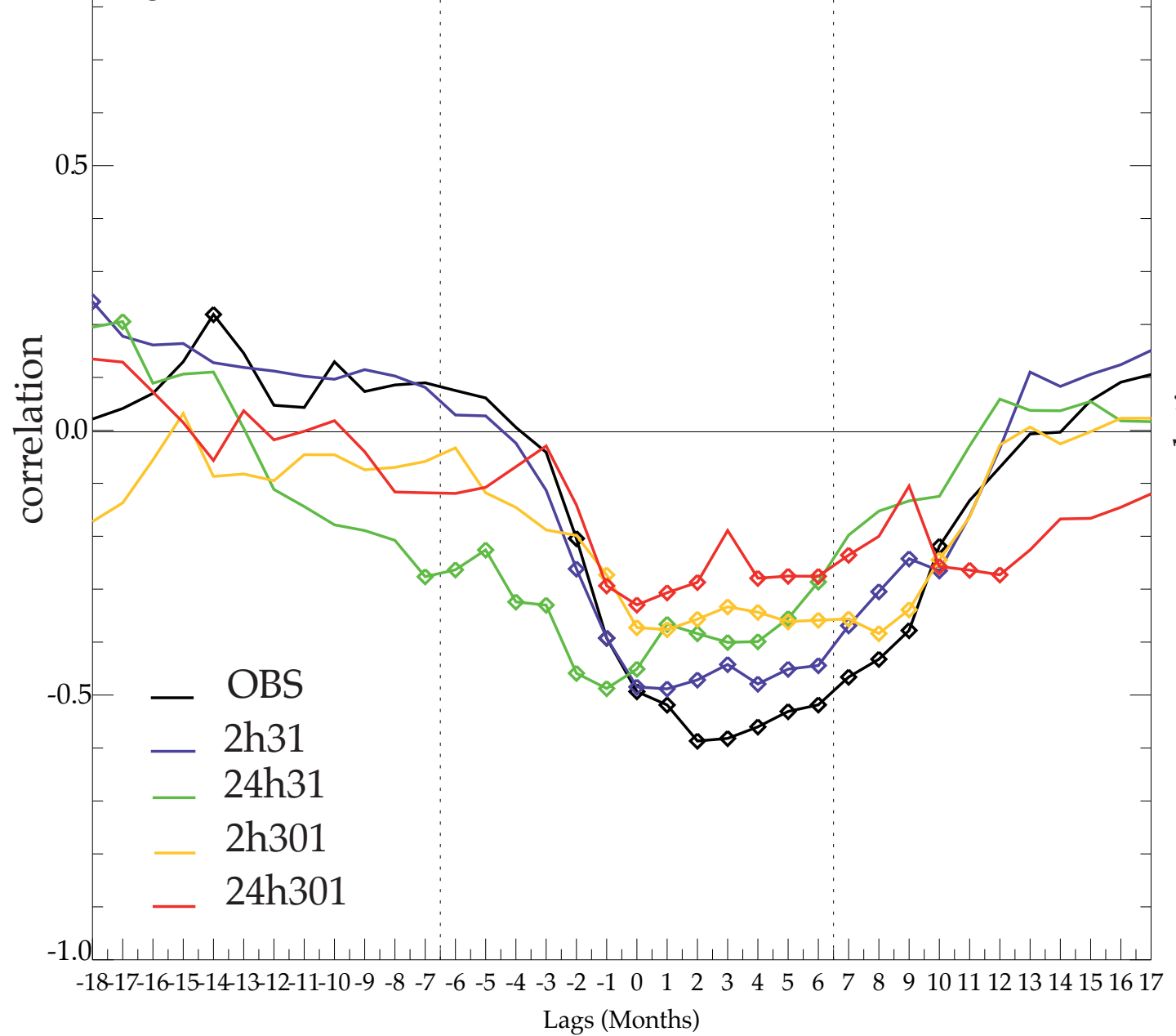

b

Lead-lag correlations for Monthly IOD index vs ISMR

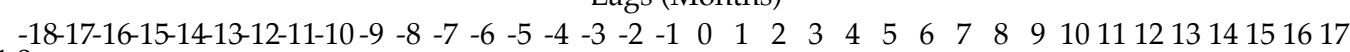

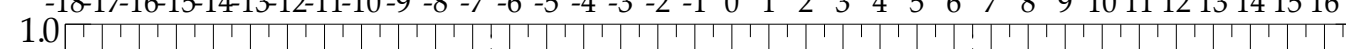

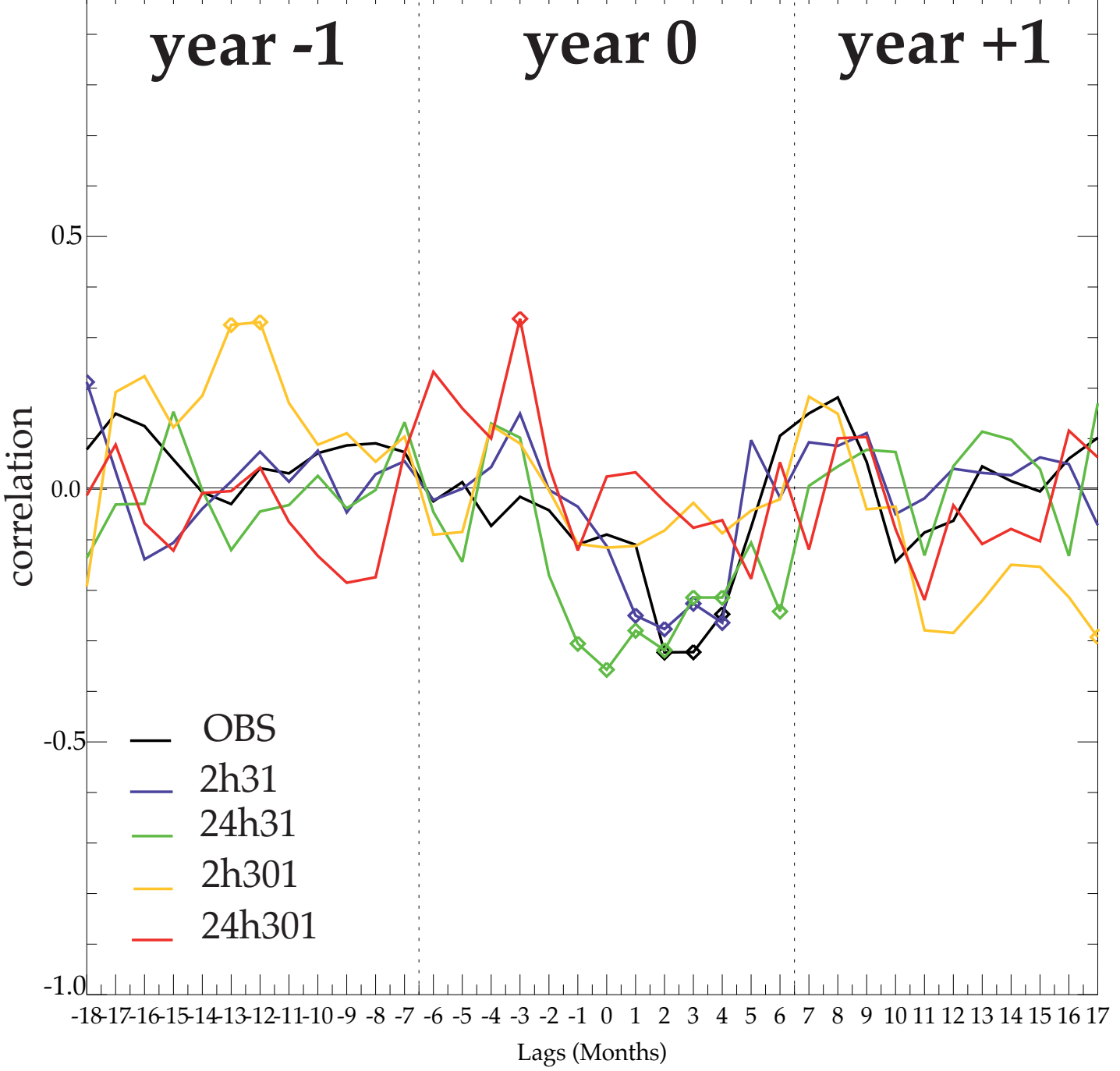


Figure 13

\section{Correlations Nino34 SST (12-1) Indo-Pacific SSTs - HadISST1 1950-2005 - Year 0}

Correlations - February-March

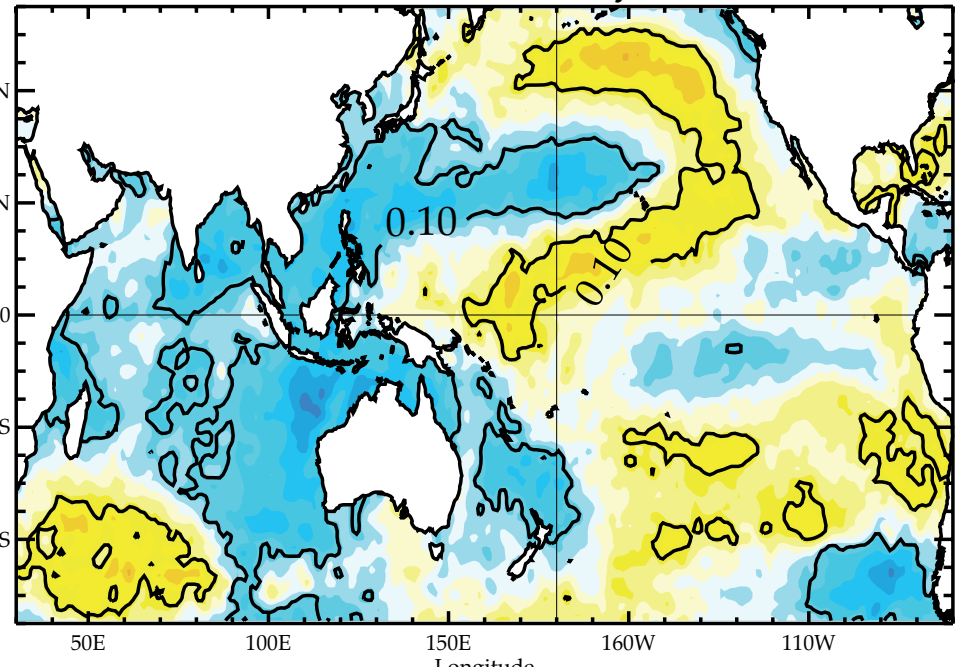

Correlations - June-July

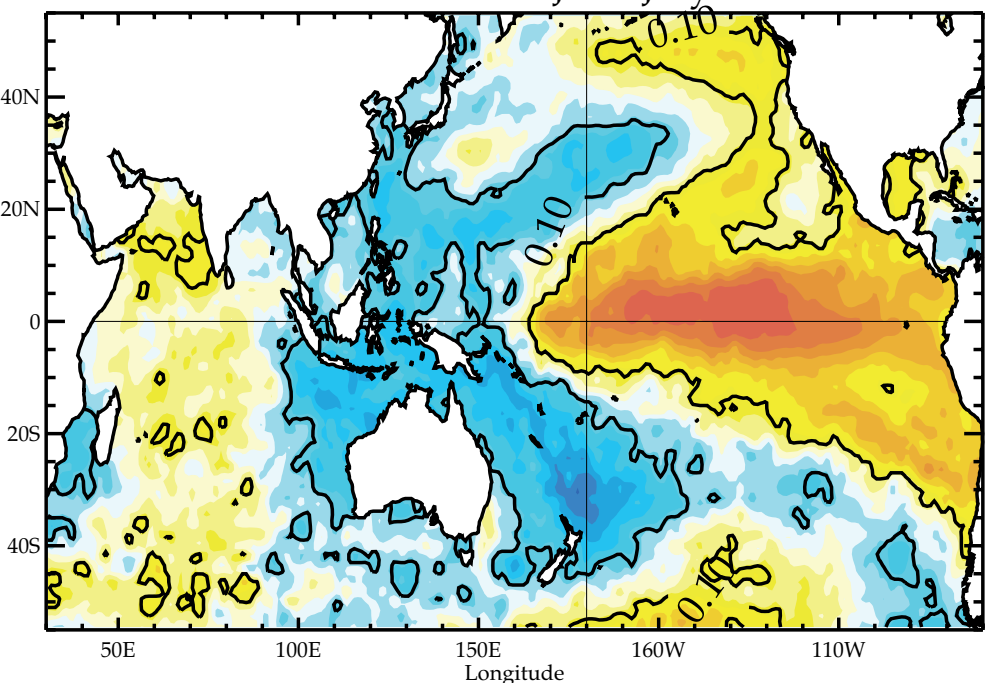

Correlations - October-November

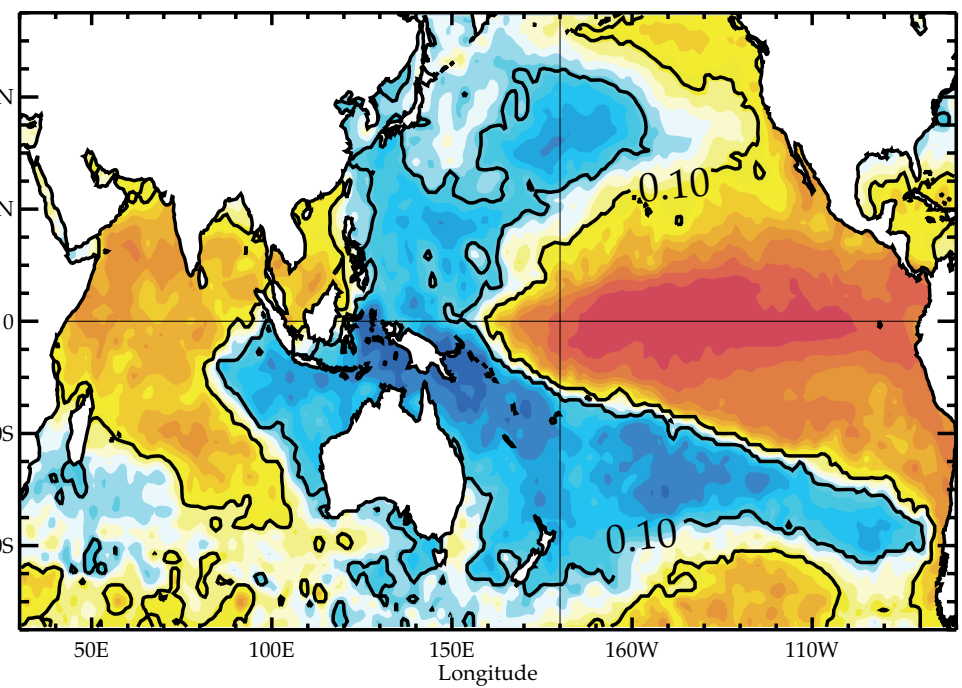

Correlations - April-May

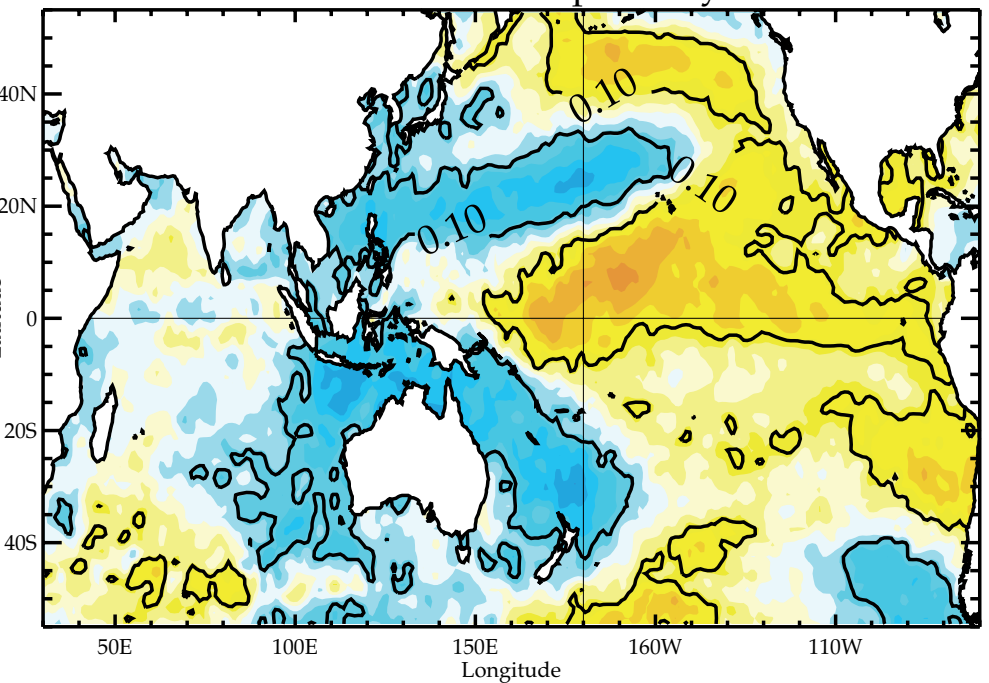

Correlations - August-September

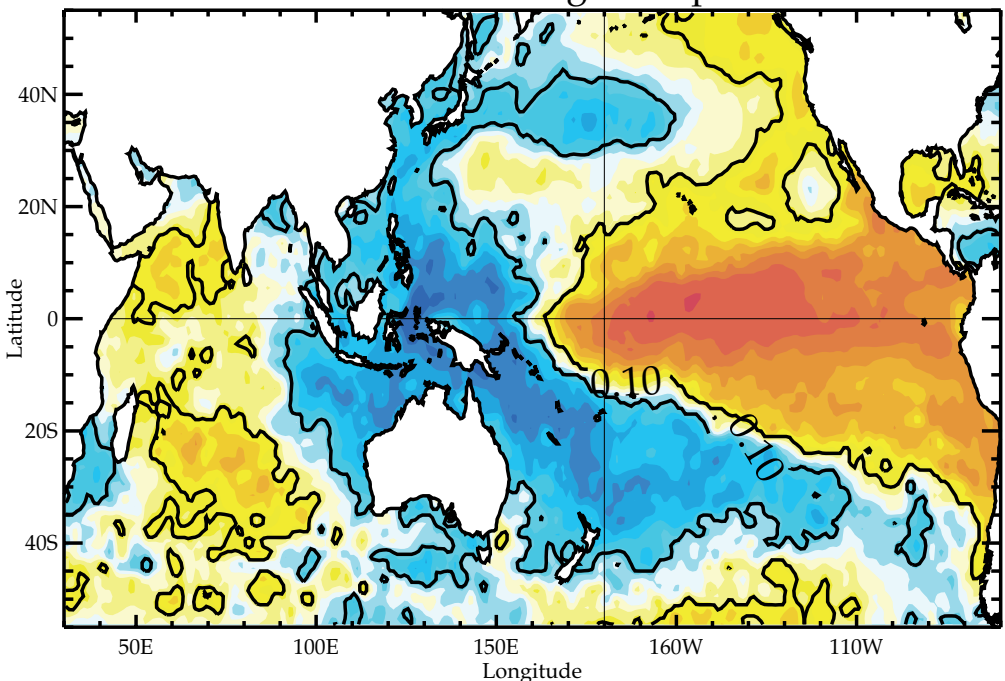

Correlations - December-January

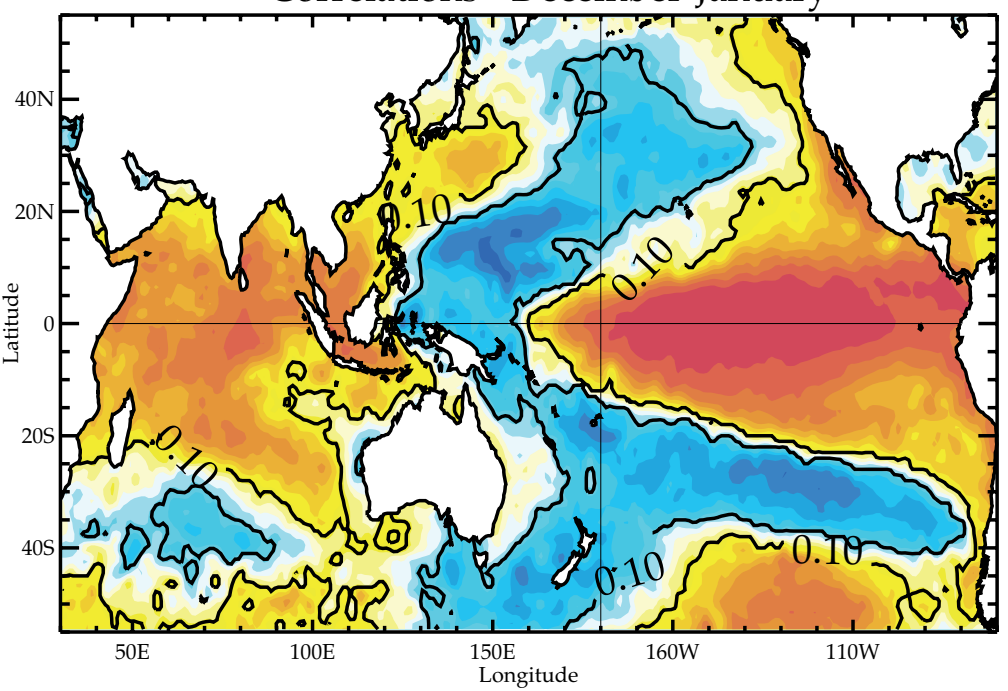

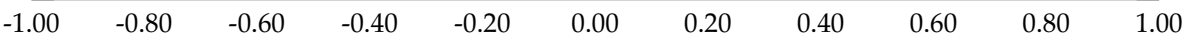


Correlations Nino34 SST (12-1) Indo-Pacific SSTs - SINTEX $2 \mathrm{~h} 31$ - Year 0

Correlations - February-March

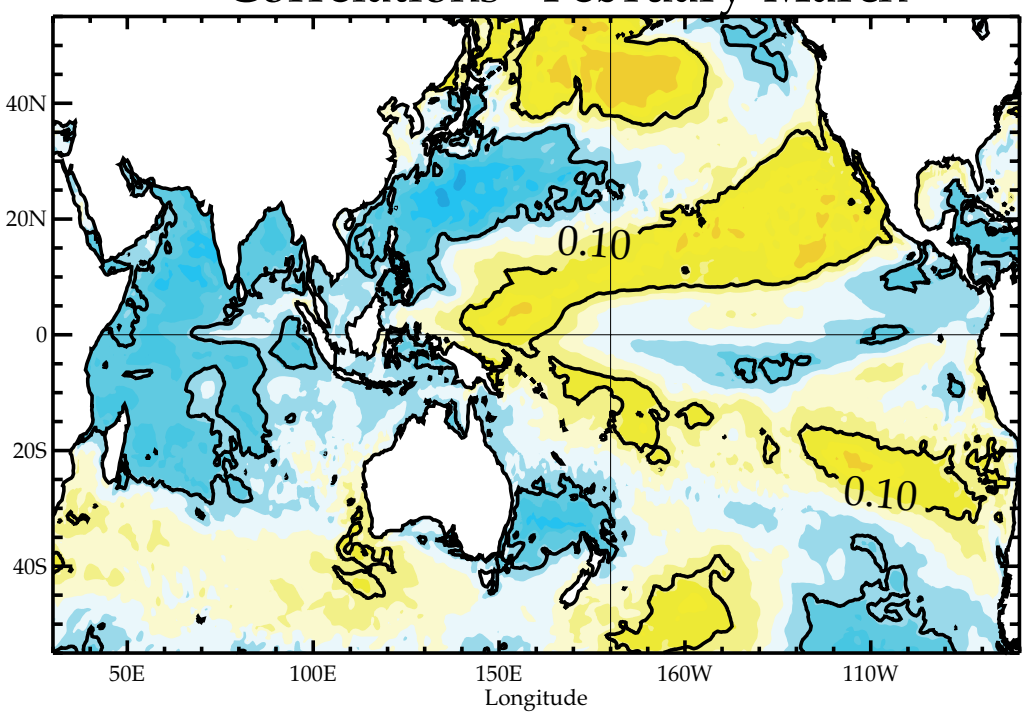

Correlations - June-July

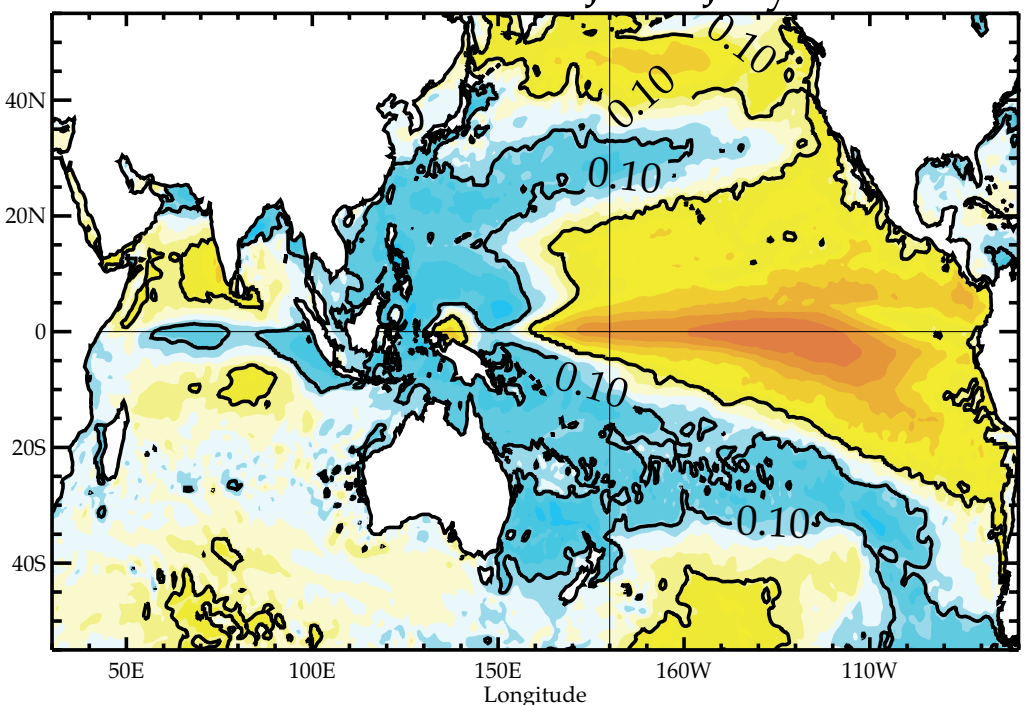

Correlations - October-November

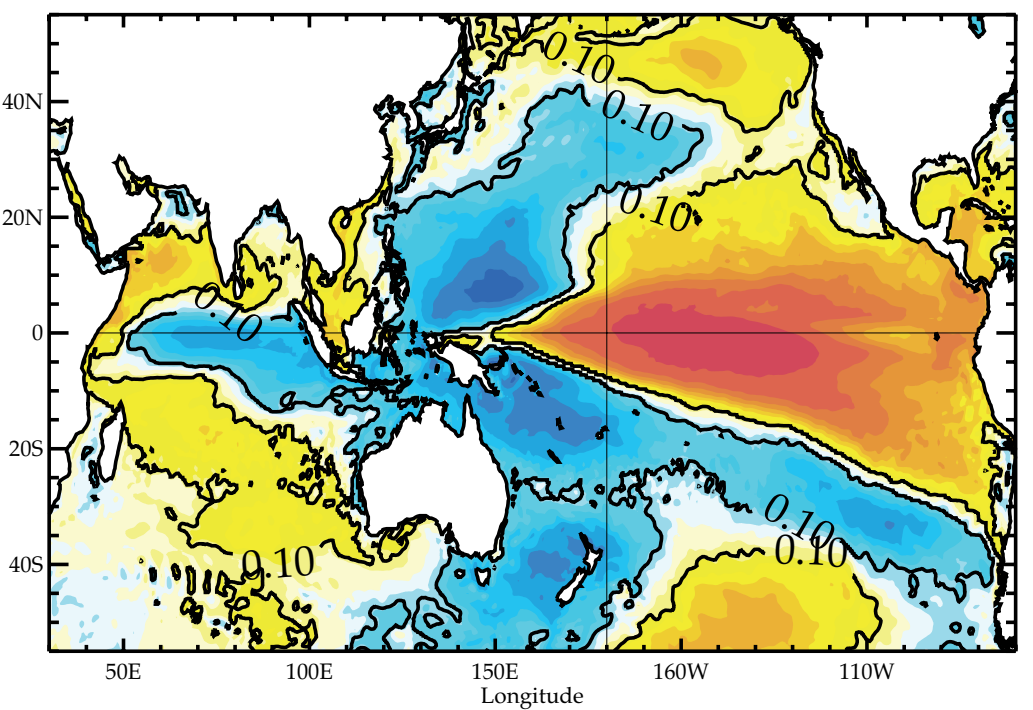

Correlations - April-May

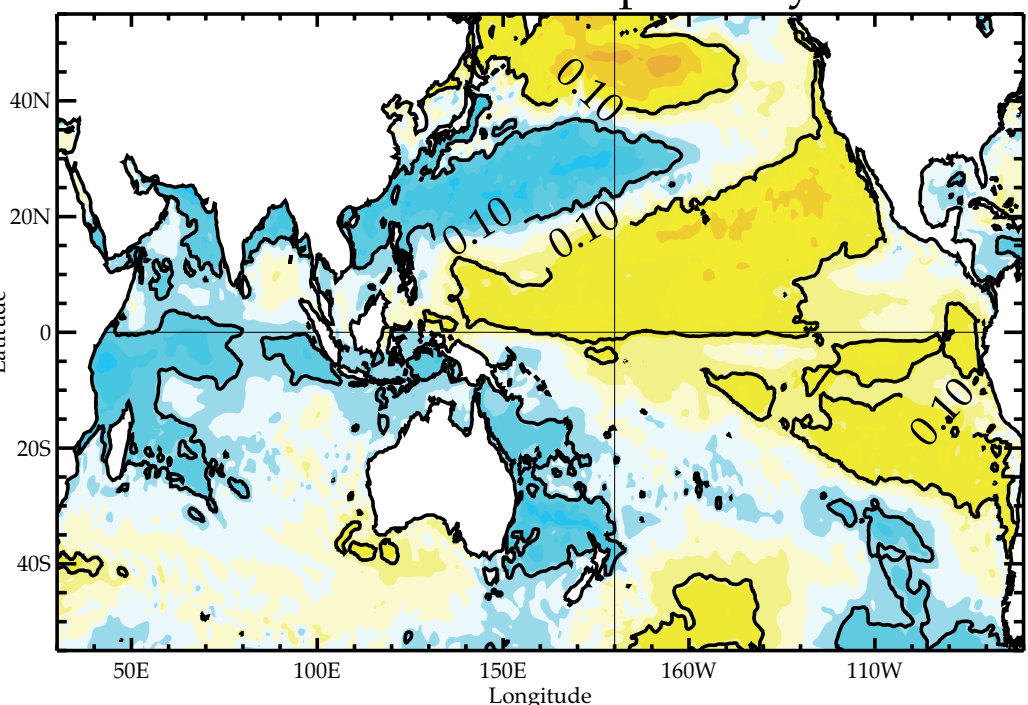

Correlations - August-September

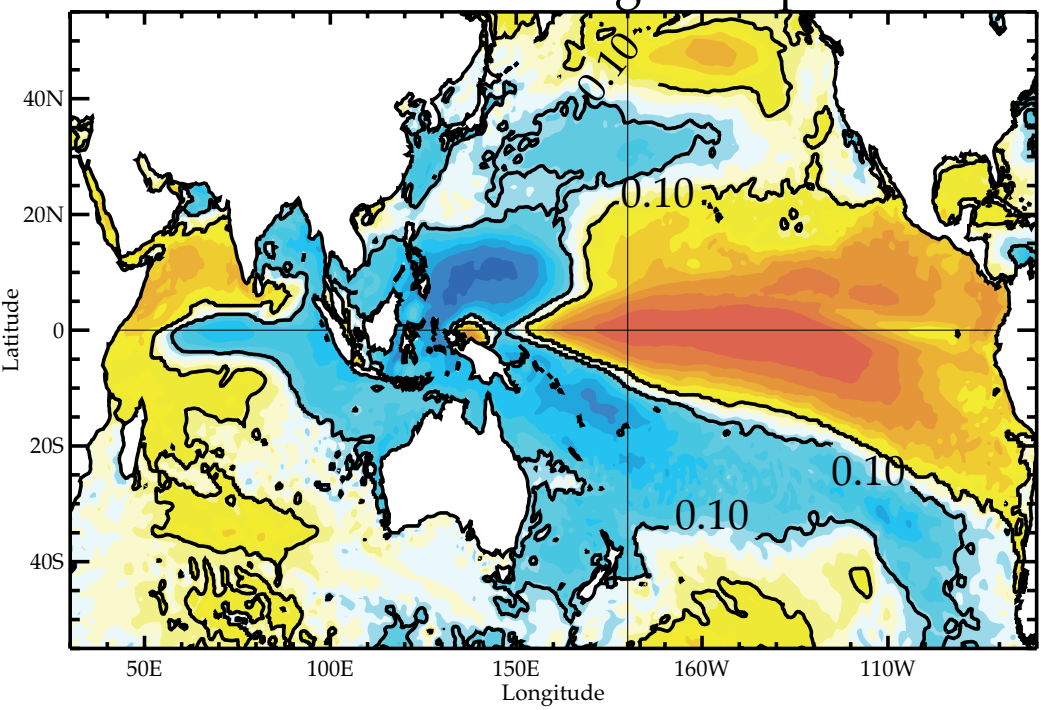

Correlations - December-January

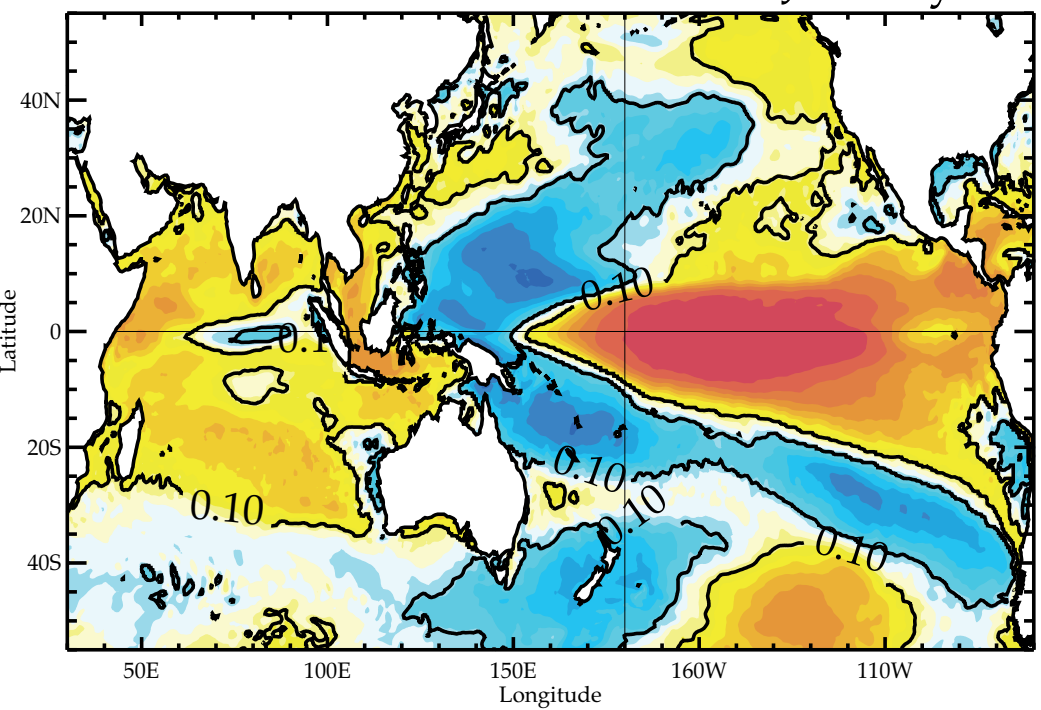


Correlations Nino34 SST (12-1) Indo-Pacific SSTs - SINTEX 24 h31 - Year 0

Correlations - February-March

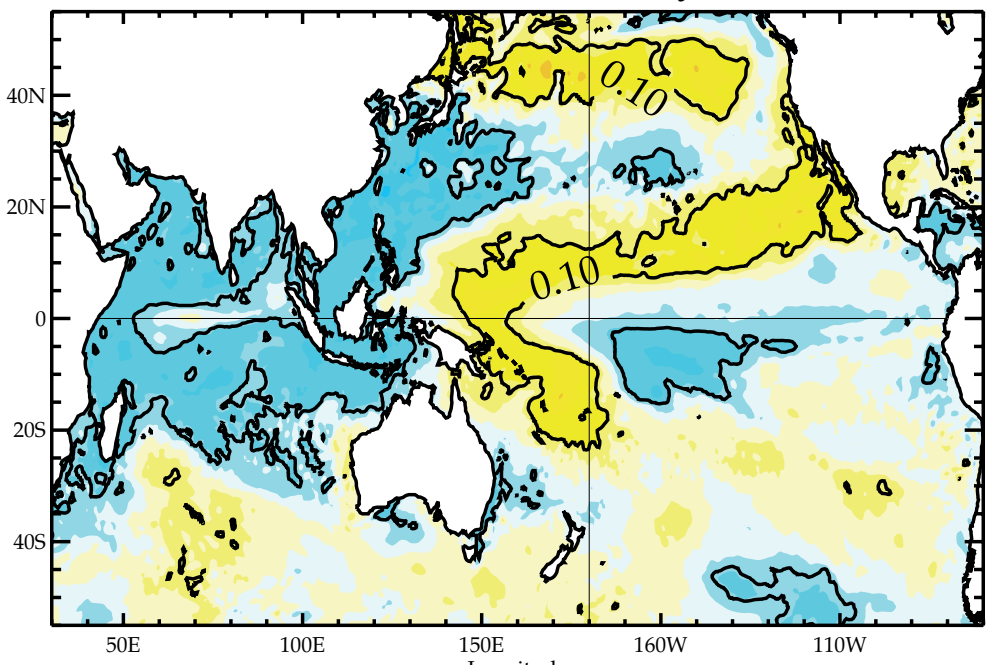

Correlations - June-July

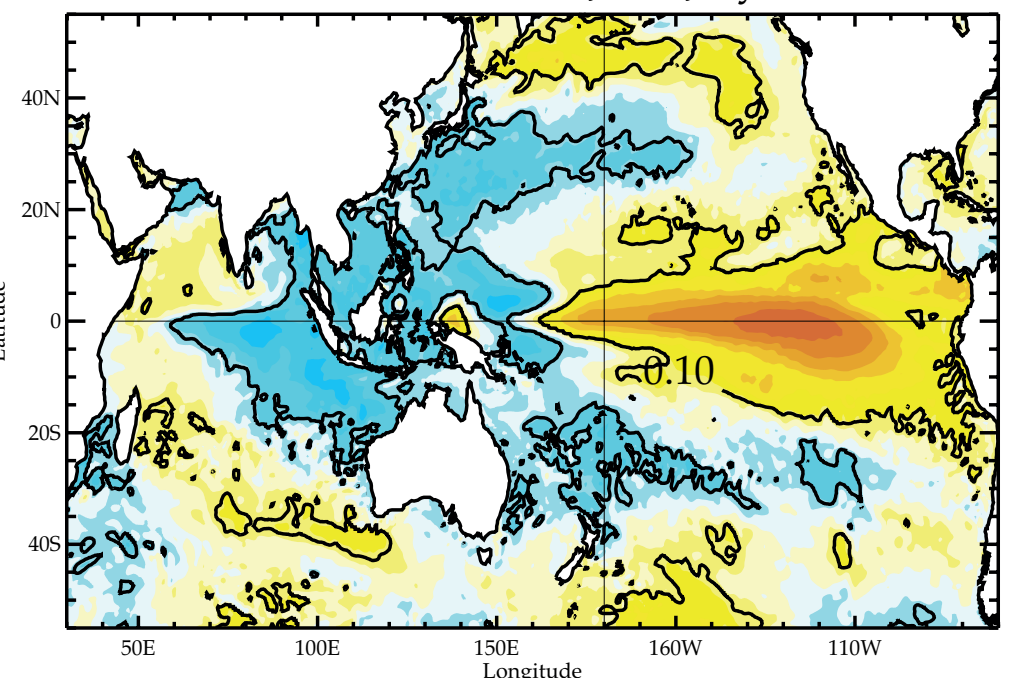

Correlations - October-November

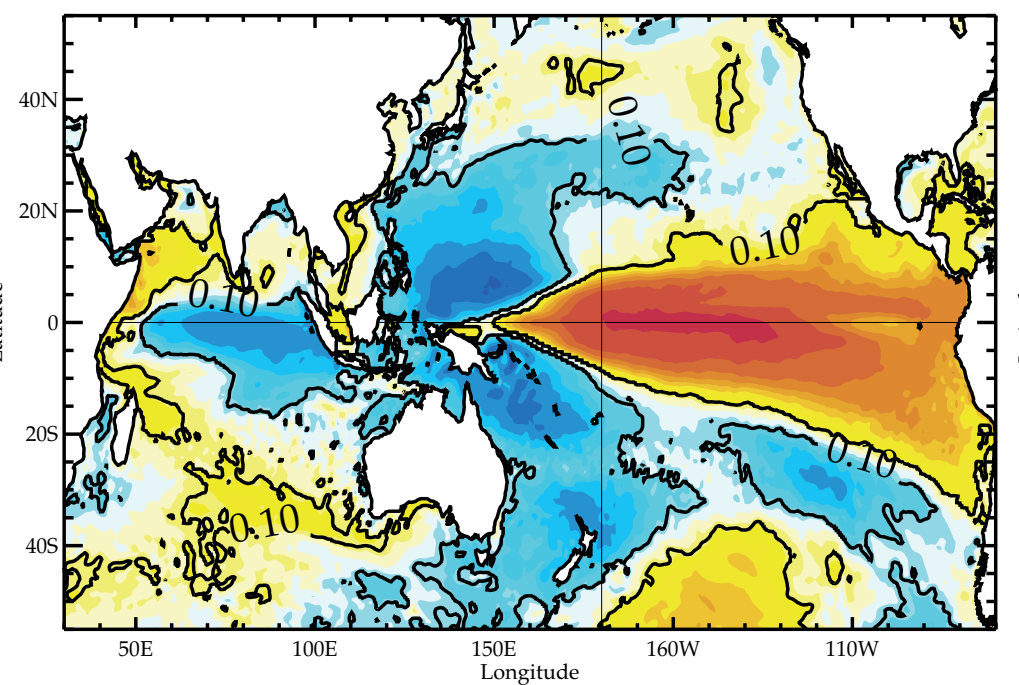

Correlations - April-May

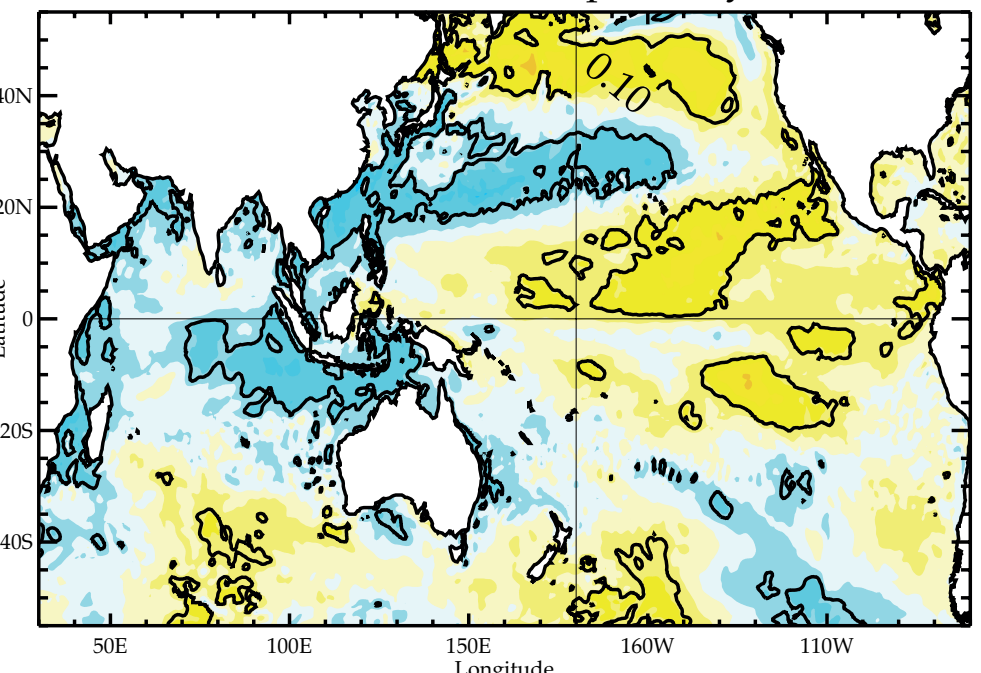

Correlations - August-September

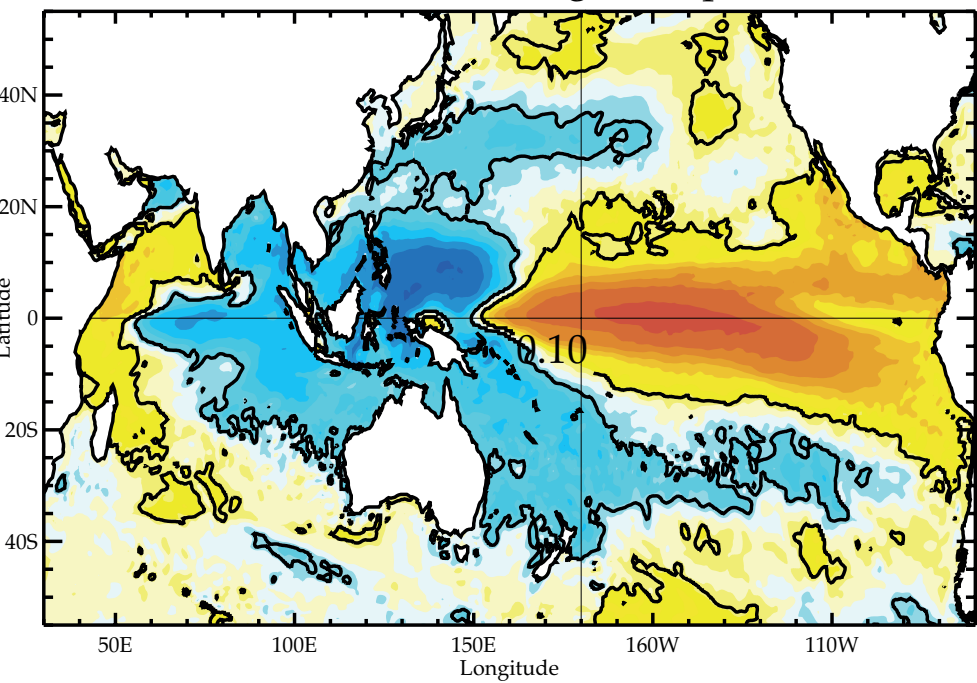

Correlations - December-January

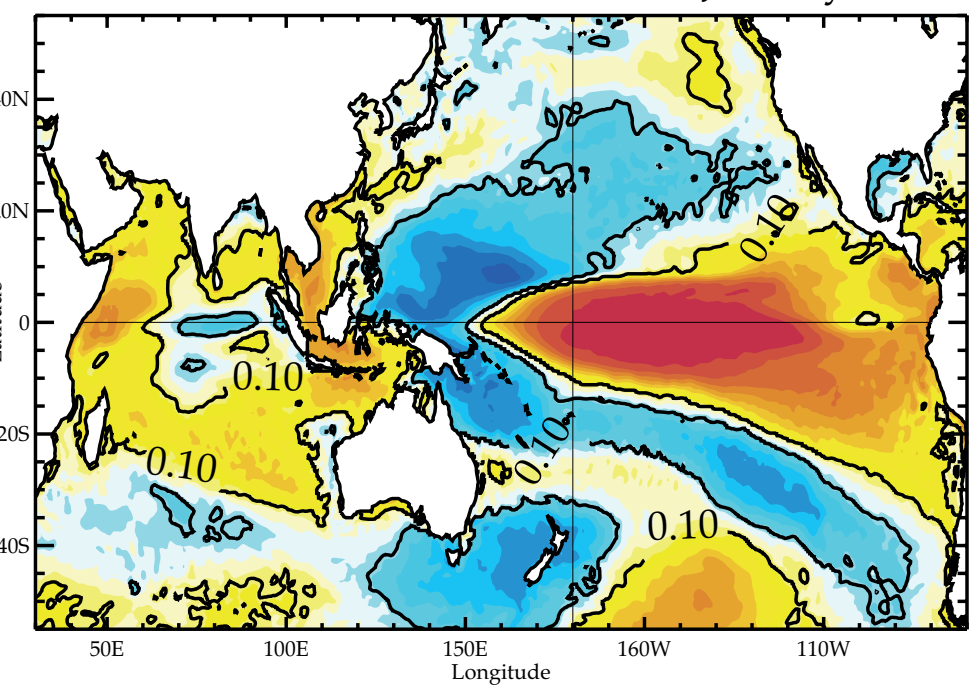

